\title{
Third-Party Reproduction: Assisted Reproductive Technologies, Commodification and Biopolitics
}

\author{
by \\ Bojana Bogeljic
}

A thesis submitted to the Faculty of Graduate and Postdoctoral Affairs in partial fulfillment of the requirements for the degree of

Master of Arts

in

Sociology

Carleton University

Ottawa, Ontario

(C) 2015

Bojana Bogeljic 


\begin{abstract}
The purpose of this study is to investigate the issues that arise in Assisted Reproductive Technology (ART) through cross-border reproductive travel, the global trade in ova and the contracting of surrogates. The concern is around the commercialization and commodification of women and children, as well as the risks associated with the global for-profit ART industry. The project is divided into three case studies. First, the Canadian ART context shows that restrictive federal policy is challenged by transnational ART. The second case study reveals that international online fertility networks are created and located opportunistically in destination countries where surrogates and egg donors can be recruited. The last case study reveals a trend in some destination countries towards more restrictive ART legal frameworks. In conclusion, this thesis argues that the patterns of cross-border ART are shaped by government regulations and the local availability of egg donors and surrogates.
\end{abstract}




\section{Acknowledgements}

I am truly indebted to my supervisor, Dr. Amine Mire, for encouraging me to look further into this topic following a presentation on gestational surrogacy. Gradually, I have been able to develop this research into an MA thesis thanks to your continuous support and guidance. Throughout this whole process, you have taught me the importance of theoretical concepts and pushed me in the right direction in this complex field of ART.

I would also like to thank my committee member, Dr. Neil Gerlach, whose own work on biotechnologies has been an inspiration to me. Your feedback to my draft proposal and the questions you raised at that time have allowed me to more clearly define the scope of this research. Furthermore, I am very grateful to my internal examiner, Dr. Erika Adams, for her careful review and examination. I also want to express gratitude to my partner, friends and family for their invaluable support and encouragement.

Finally, I would like to show appreciation to the Department of Sociology and Anthropology, as well as the Institute of Health: Science, Technology and Policy at Carleton University. Both departments have been important in shaping my research and analysis skills necessary for bringing this thesis to fruition. 


\section{Table of Contents}

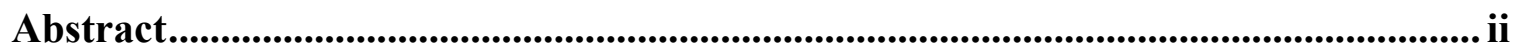

Acknowledgements ........................................................................................................................ iii

Table of Contents ...................................................................................................... iv

List of Figures................................................................................................................................. vii

1 Chapter: Context, Terminology and Introduction ................................................. 8

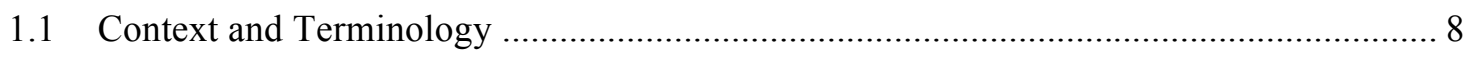

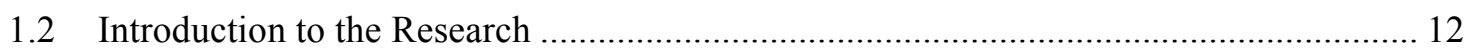

2 Chapter: Literature Overview ................................................................................... 14

2.1 Critical Reflections on Assisted Reproduction: From in vitro fertilization to cross-border

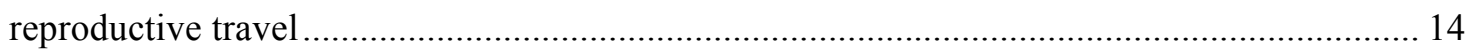

2.2 Understanding the Impact of Medicalization and the Rise of the Patient-Consumer ...... 26

2.3 Applying Biopower and Biopolitics in the Age of Assisted Reproduction ..................... 30

3 Chapter: Theoretical and Methodological Framework ........................................ 39

3.1 Theoretical Framework and Research Questions ........................................................ 39

3.2 Data Collection Strategy for Case Study One ......................................................... 45

3.3 Data Collection Strategy for Case Study Two ........................................................ 48

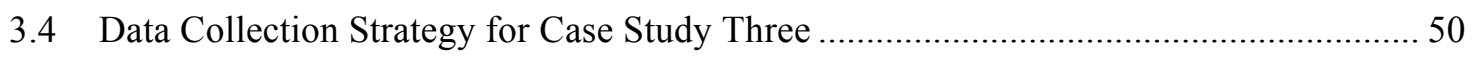

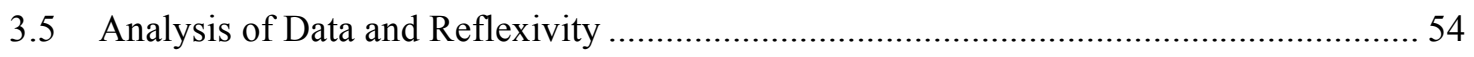

4 Chapter: Case Study One: Canadian ART Law and Controversies ................... 58

4.1 Legal and Regulatory Framework of ART in Canada .............................................. 58

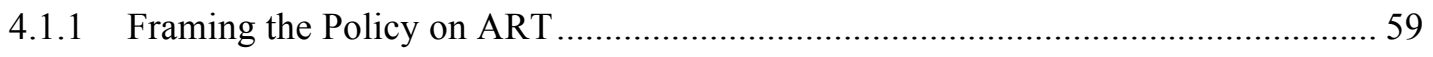

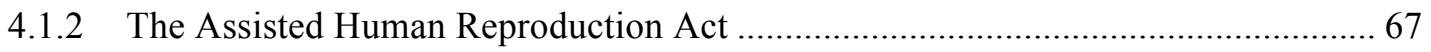

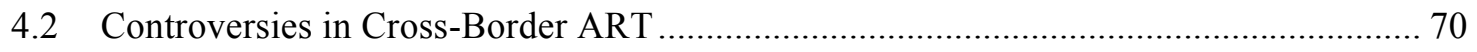




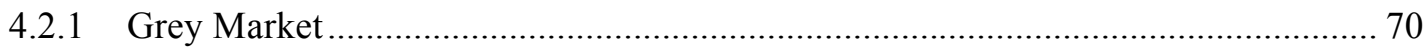

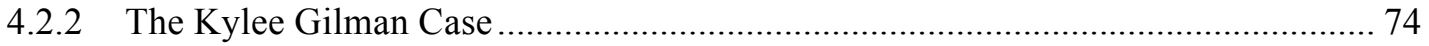

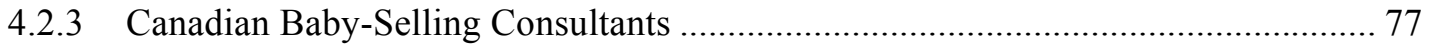

4.3 Conclusion and Theoretical Reflections for Case Study One ...................................... 81

\section{Chapter: Case Study Two: An International Network Group in Third-Party} Assisted Reproduction ................................................................................................... 83

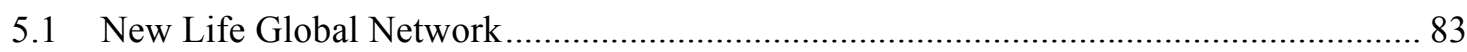

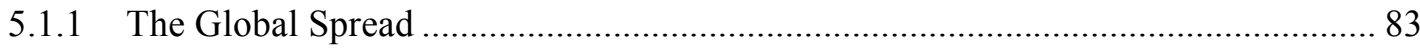

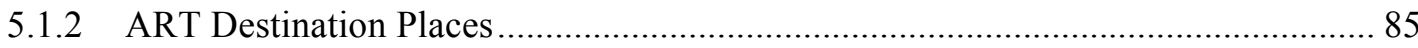

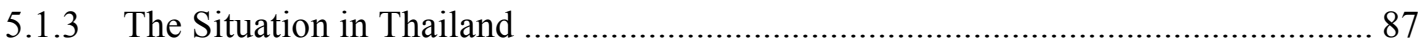

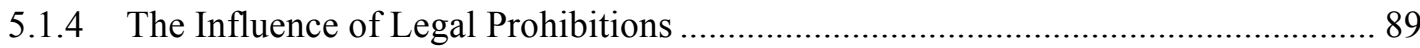

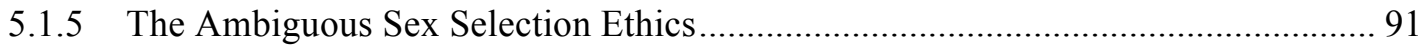

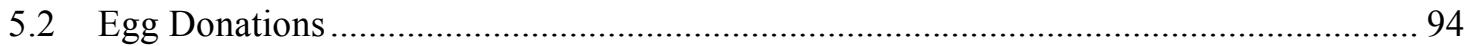

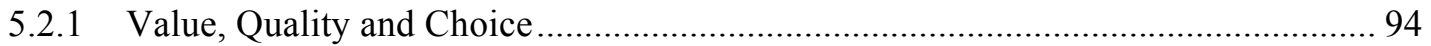

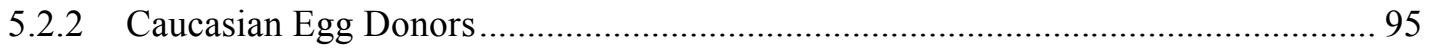

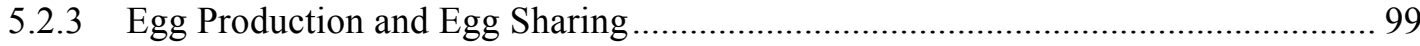

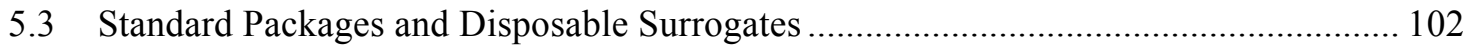

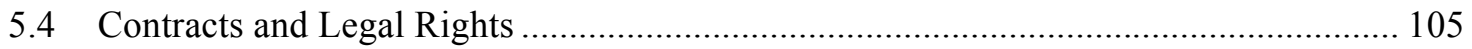

5.5 Conclusion and Theoretical Reflections for Case Study Two ..................................... 108

\section{Chapter: Case Study Three: The Changing Discourse in India, Russia and}

Thailand ...................................................................................................................................... 110

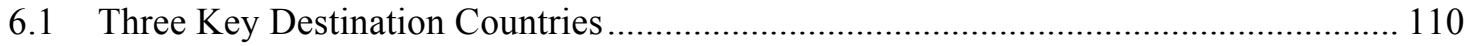

6.2 Stricter Regulations for India's Womb-for-Rent Industry ........................................ 112

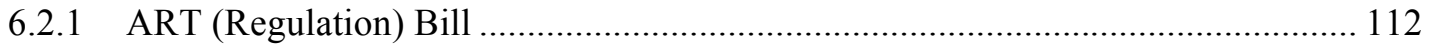

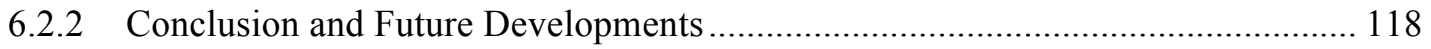

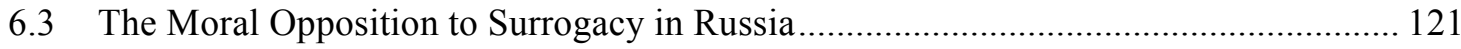


6.3.1 Moral Discourse

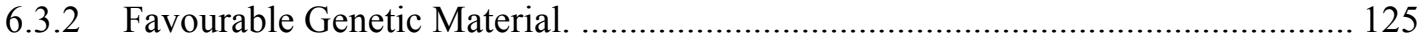

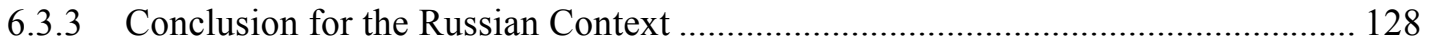

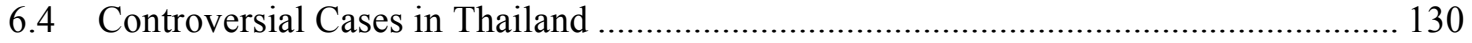

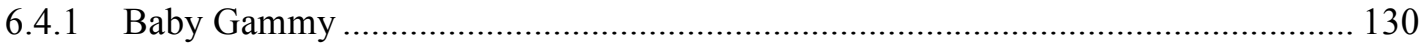

6.4.2 Japanese Man Fathers 16 Surrogate Babies.......................................................... 133

6.4.3 The Impact on International Surrogacy Industry .............................................. 135

6.4.4 The Fast Response of a Strict Military Government …...................................... 136

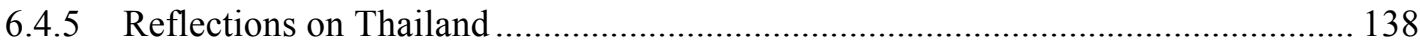

6.5 Conclusion and Theoretical Reflections for Case Study Three ................................... 139

7 Chapter: Conclusion .................................................................................. 141

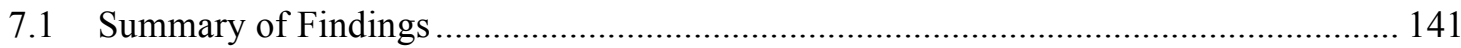

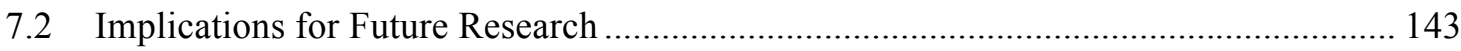

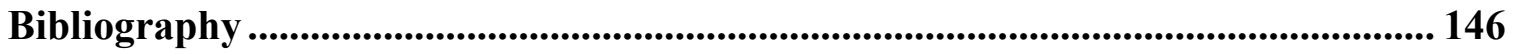




\section{List of Figures}

Figure 1 International Baby-Selling Surrogacy Ring …………………..................... 79

Figure 2 How the New Life Global Network websites are connected through embedded

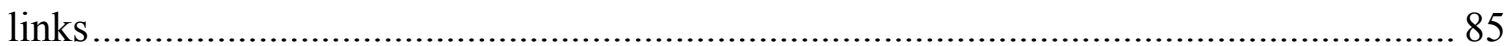




\section{Chapter: Context, Terminology and Introduction}

\subsection{Context and Terminology}

Cross-border ART is flourishing in a world of different national policies on ART and global inequalities. To provide some introduction into the context of global ART, an explanation of the relevance of the topic and the definitions of some key medical terms used throughout this thesis are provided in this section. First it is important to comprehend the increasing value of In Vitro Fertilization (IVF) technologies and the emerging market in ART. A market research report produced in January 2014 by Allied Market Research and titled "In Vitro Fertilization (IVF) Market -Size, Share, Trends, Opportunities, Global Demand, Insights, Analysis, Research, Report, Company Profiles, Segmentation and Forecast 2013-2014" reveals that the IVF global market is expected to

grow by $11.6 \%$ between 2013 and 2020 (“Global In Vitro Fertilization”, 2014). The study evaluates the global IVF market in 2012 to have been $\$ 9.3$ billion and predicts the growth to reach $\$ 21.6$ billion by 2020 . This global IVF overview includes surrogacy services and gamete donors among other services offered. The report claims that rising infertility and increasing maternal age are the main factors driving the growth, while ethical or legal issues and cost function as restraints. Opportunities for growth are reported to be in medical tourism, where developing economies are the preferred destination countries. The report in particular highlights a predicted growth in the highly opportunist AsianPacific market. Allied Market Research confirms that there is indeed a highly profitable and booming global ART industry (“Global In Vitro Fertilization”, 2014). 
While there is considerable market need for fertility treatment all over the world, the cross-border ART industry raises some legal, ethical and social questions. For the legal aspect, there is lack of consistency in the cross-border ART regulation across different nations and there is no specific international law for ART. The governing rule of ART varies across different countries. Some governments have chosen to introduce specific ART laws to ban some aspects, while others have allowed the industry to flourish without much oversight. Many countries around the world completely fail to address cross-border ART legally, leaving the technology unregulated or self-regulated within their borders and consequently, contributing to a cross-border industry. At the international level, there is the self-regulating International Committee for Monitoring Assisted Reproductive Technology (ICMART) and some countries have also national self-regulating bodies comprised of reproductive professionals. Regarding the ethical and social aspects, concerns have been raised around the effect on the child, women's choice, the rights of the embryo, and the health risks associated with IVF-technology (World Health Organization, 2002).

The involvement of a third party in the cross-border ART process presents additional legal and ethical issues. This is because it lays ground for the possibility of having problems with the law over the rights of different parties as well as the potential for exploitation and trafficking of vulnerable women for surrogacy or egg donation (Starrow, 2011; Yaxley, 2014). Cross-border reproduction allows infertile couples and individuals to pay for services in a different part of the world that might not be as accessible, affordable or legal in their home country. This raises concerns around inequalities in resources and power between commissioning infertile couples and the 
women who serve as providers of ova and the women who carry to term the intended parents' children. There is also concern over the health and medical risks that women are exposing themselves to when they function as gestational surrogates or egg/ova donors.

In this thesis, the vocabulary used to describe ART is consistent with the terminology as defined by ICMART and the World Health Organization (ZegersHochschild et al., 2009). Assisted Reproductive Technology (ART) is defined as "all treatments or procedures that include the in vitro handling of both human oocytes and sperm, for the purpose of establishing a pregnancy" (Zegers-Hochschild et al., 2009, p. 2685). ART includes cryopreservation of gametes and embryos, gestational surrogacy, oocyte or embryo donation, Intracytoplasmic Sperm Injection (ICSI) and other associated technologies. In vitro fertilization (IVF) is a procedure to designate extracorporeal fertilization. Cyropreservation refers to the freezing and storing of gametes, embryos and other tissues. Gestational surrogacy involves the use of a gestational carrier or gestational surrogate, which refers to a woman carrying the offspring for the intended parents with the agreement that the offspring will be handed over to them upon birth. The gametes for this offspring can come from the intended parents or from a gamete donor. Two controversial genetic tests, Preimplantation Genetic Diagnosis (PGD) and Preimplantation Genetic Screening (PGS), allow "for the detection of specific genetic, structure and/or chromosomal alternations" for the PGD and "the detection of aneuploidy, mutation and/or DNA rearrangements" (Zegers-Hochschild et al., 2009, p. 2687) for the PGS. Therefore, selection of the sex of the offspring and the detection of genetic abnormalities are possible through these genetic tests. Multiple gestation or birth refers to the pregnancy or delivery with multiple fetuses or neonates. ART has been 
shown to increase the risk of multiple pregnancies (Bergh, Ericson, Hillensiö, Nygren \& Wennerholm, 1999), which has an impact on the health of the infant and the woman carrying the child. Multiple gestation is associated with an increased risk of preterm delivery, low birth weight, congenital malformations and also pregnancy and labour complications (Oliviennes, 2000). This increase in multiple pregnancy and birth due to ART is in part due to IVF, ovarian stimulation and other maternal factors. Another medical risk associated with ART is Ovarian Hyperstimulation Syndrome (OHSS). The WHO defines Ovarian Hyperstimulation Syndrome (OHSS) as the "exaggerated systemic response to ovarian stimulation characterized by wide spectrum of clinical and laboratory manifestations" (Zegers-Hochschild et al., 2009, p. 2686). OHSS can either be mild, moderate or severe, but the severe form of OHSS requires hospitalization. The use of fertility drugs to stimulate ovulation has been reported to increase the risk of OHSS, a potentially life-threatening condition that can lead to heart damage and failure in its most severe form (Ahmad, 2011). In third-party assisted reproduction, it is the intended mother or the egg donor who would be at risk for OHSS in the event of hyperstimulation before egg retrieval. Third-party assisted reproduction is not without medical implications on the health of the gestational carriers and egg donors. As the ART industry continues to expand and new reproductive technologies are introduced into the world, society is forced to consider the complex implications for all parties involved from a variety of perspectives. 


\subsection{Introduction to the Research}

The phenomenon of this study is third-party facilitated reproduction through the use of Assisted Reproductive Technology (ART) across national and international borders. My particular point of interest with this form of reproduction is the commodification of some women's bodies for egg donation and surrogacy, as well as the biopolitical implications of having some countries with restrictive regulation on ART, while other countries take on a more liberal approach to the ART industry. The thesis aims to address the following research question: What does the current pattern in crossborder reproductive travel for purposes of commissioning surrogates or egg donations reveal about the complex and contradictory implications of ART?

In this work I agree that there is a transnational ART industry that benefits and profits from the commodification of a certain class of women for the benefit of a class of consumer-patients that is accommodated and privileged by liberal state policies, the global medical fertility industry, and other international networks of collaborations. First, I will start with a review of the literature where I lay out the different theoretical frameworks that have been used to study biotechnologies and reproductive technologies. Following the literature review, I will present my own theoretical and methodological framework that will help me answer my research questions. This chapter will show that I conduct the research through documentary and discourse analyses of a variety of materials: government documents, websites for online fertility agencies and clinics, and relevant news articles of particular cases. The research takes into account both the global aspect of third-party assisted reproduction, as well as the national context. The qualitative 
research and analysis allows me to study the discourse around third-party assisted reproduction and to conduct in-depth analyses of three different case studies.

In my first case study, I use Canada as an example of a country with restrictive legislation on ART to show that state policies can be a form of ART biogovernance, but that the prohibitions regarding commercial egg donation and surrogacy arrangements are a challenge to the implementation of the ART-specific law given the presence of crossborder ART networks. In case study two, I focus on one unique online fertility network group that connects fertility agencies and clinics across different nations. This case study reveals that the industry opportunistically recruits egg donors and surrogates from certain locations in the world where the women are bioavailable for recruitment and where the laws are favourable for a cross-border industry to flourish. In my third case study, I argue that the risks associated with third-party assisted reproduction are becoming more relevant to the governments in India, Russia and Thailand, as all three destination countries are moving towards stricter ART-specific regulations. 


\section{Chapter: Literature Overview}

\subsection{Critical Reflections on Assisted Reproduction: From in vitro fertilization to cross-border reproductive travel}

The early literature on new reproductive technologies expressed a diversity of concerns with IVF and new reproductive technologies. One of the earlier concerns are possible health risks associated with in vitro fertilization (IVF), as the long-term effects of the technology were largely unknown (Moss, 1988; Schieve et al., 2004). Additionally, feminists were concerned over the threat to women's reproductive rights and options with increasing medicalization and pressures to treat childlessness (Moss, 1988). Others have also pointed out possible discrimination and a lack of equitable access for certain minority groups, such as single women, poor women, people with disability, sexual minorities and racial and ethnic minorities (Armstrong \& Plowden, 2012; Peterson, 2005; Steinberg, 1997). Other issues associated with new reproductive technologies were the high costs and expenses of these procedures that prevent access for some groups (Armstrong \& Plowden, 2012; Moss, 1988), the concomitant ethical concerns with prenatal diagnosis as they relate to gender selection techniques and fetal therapy (Sills \& Palermo, 2002; Strange \& Chadwick, 2010), as well as women's negligible involvement in policy debates (Moss, 1988; Peterson, 2005). While new reproductive technologies expanded some people's reproductive options in particular for heterosexual infertile women and men (Menning, 1981); issues with accessibility, women's rights and options, as well as risks associated with biotechnological intervention on women's bodies remained. 
Franklin's (1997) ethnographic research on women undergoing IVF treatment reveals how new reproductive technologies create new kinship relations with others (through relatedness or assistance), and new complex relationships with contemporary reproductive medicine as women experienced unanticipated failures throughout the progressive stages of the IVF treatment (p. 157). The earlier literature thus explored the complex experiences of women as users and consumers of assisted reproductive technologies, while at the same time analyzing the intense medicalization of reproduction and women's bodies. Some explored the hierarchical and stratified side of the politics of reproduction (Ginsburg \& Rapp, 1991), while others emphasized the intense medical intervention on women's bodies. Raymond (1993) blamed the international medical networks for abusing and trading women's reproductive material and wombs, while Purdy (1996) used a neo-liberal utilitarian philosophy to justify the outsourcing of highrisk pregnancies to surrogates who present a lower risk of pregnancy. Many scholars continued to view reproductive technologies as "medical violence against women" (Klein, 2008, p. 167) that resulted from the normalization of infertility as disease and the commodifying biomedical intervention on women's reproduction.

With increasing globalization of ART over the last two decades, critical reflections on reproductive technologies took on a more complex and transnational perspective. Gupta (2006) considers both women's rights to self-determination through the use of reproductive technologies and the global transactions in body parts for the purpose of assisted conception (p. 32). In the work cited here, Gupta compared egg donors from Netherlands with those from India and established that "women operate on this marketplace both as buyers and sellers" (Gupta, 2006, p. 31) of global ART services. 
Gupta's (2006) analysis reveals that neo-liberal ideologies of consumerism and individualism allow ART services to be traded in the marketplace. The process is greatly facilitated by the Internet. The market driven access of ART supports the right of individuals to consume women's bodies as objects and to produce children as products. Compared to earlier scholarship that focused on women as patients of IVF, Gupta's (2006) perspective takes into account the global transactions in ART in a manner that distinguishes the women who are consumers of infertility treatments from those who are 'sellers' in the trade of ART services (p. 31).

Hawthorne (2008) criticizes what she called 'biotech fundamentalism' which turns women's bodies into raw material through fragmentation, alienation and dissociation ( $\mathrm{p}$. 308). This form of "microcolonialism" (p. 310) of the bodies treats women from a variety of cultures and classes as a natural resource through the patriarchal institutions of science and politics. Hawthorne (2008) uses the terms soma and somata to refer to women's bodies and women's body parts, which are used for the "utilitarian benefit to all of humanity" (Hawthorne, 2008, p. 315). Hawthorne (2008) clarifies that it is "the bodies of the powerless [which] are used for the benefit of the powerful"'(p. 315). The Homeric Greek vocabulary means that the body parts are considered as dead when it is separated from the person and used for reproductive business opportunities. Nevertheless, Hawthorne's analysis of microcolonialism of women's bodies does not clearly demonstrate that some women who contract ART services also function as consumers of donated gametes and gestational surrogacy. Thus, it is difficult to group all women as undergoing the same type of fragmentation through the trade in surrogates and egg donations. A study that focuses more closely on third party reproduction would allow us 
to look at how medicalization of all women leads to the commodification of some women who may more likely function as soma and somata than others in this age of advanced biotechnology.

In an overview of the research on gender and reproductive technologies, Clarke (2008) identifies that there has been a trend to go beyond the Western-focused scholarship towards the East, in particular East Asia. The emerging trend includes localized fertility studies in East Asian countries, but also transnational comparative work and a strong focus on particular forms of medical tourism often identified by the media and researchers as 'reproductive tourism'. Ethnographic research done by medical anthropologist Marcia Inhorn (2011) in the Middle East reveals the diverse reasons for patients to travel for ART services to another country or jurisdiction. Inhorn and Patrizio (2009) argue that the term 'reproductive tourism' does not accurately represent the difficult experiences of infertile patients who engage in ART cross-border travels. Instead, the authors recommend the more patient-centered term 'reproductive exile' as a more accurate description of the infertile couples who feel forced to involuntarily leave their native country in order to "access safe, effective, affordable, and legal infertility care" (Inhorn \& Patrizio, 2009, p. 905).

As an important part of $21^{\text {st }}$ century reproductive technologies, cross-border reproductive care $(\mathrm{CBRC})$ is more of a neutral term and encompasses the variety of travel arrangements for ART purposes. Inhorn and Gürtin (2011) identify that that there is pressing empirical research to be done in CBRC especially on the organization of CBRC (i.e. the business interests and arrangements) and on the identities, demographics and perspectives of the gametes donors and surrogates. Indeed, a lot of research on CBRC has 
been done from the perspective of the patient, where travel is explained in terms of legal and ethical restrictions forcing intended parents to seek treatment in a country with a more liberal approach to ART (Inhorn and Patrizio, 2009). For a research on third party reproduction, it would be important to use language that acknowledges the complexity of movements of persons and reproductive material across national borders. Therefore, referring to cross-border reproductive travel as 'exile' would not always be appropriate vocabulary. The researcher should not be biased towards the subjective experiences of the intended parents who feel that the state regulations are unjust. As a result, researchers must be careful not to identify too closely with the consumers (i.e. the intended parents as the patients). This patient-centered perspective overlooks the commodifying aspects of the global ART network and keeps in the shadow other important actors such as egg donors and surrogates. This is because patient centered approach makes reproductive capacities of donor actors available for consumption in a medical context. The process in turn makes the donors invisible. If one uses medical terms to describe the complex network of the 'ART industry' which includes actors such as medical professionals, scientists, surrogates, egg donors, brokers, sperm banks and pharmaceutical industries (Inhorn \& Birenhaum-Carneki, 2008, p. 187), then the 'patients' are not only the intended parents, but also the egg donors and the surrogates.

With a more critical perspective of the global fertility market, Whittaker and Speier (2010) explored cross-border reproductive travel by taking a closer look at the companies and clinics that function as intermediaries between the patients and the supply of ova donors and surrogates. In this work, Whittaker and Speier (2010) conducted fieldwork on medical facilitation companies in Thailand, U.S. and Czech Republic to 
explore the commodification of bodies and global stratification of reproduction. By contacting facilitation company websites and fertility clinics in destination countries, they were able to interview company representatives and their patients. In Thailand, there is little state intervention and a variety of technologies can be practiced without regulation, including Pre-implantation Genetic Diagnosis (PDG). The cost for an IVF cycle is a third of what U.S. patients would be paying in their native country. The low cost and the variety of services that are available are attracting foreign reproductive travellers to Thai IVF clinics. The authors' results for the Czech Republic reveal that the fertility clinics mostly target foreign patients requiring ova donation, as the availability of young white Eastern European donors functions as a market advantage for the country. Treatment is also less expensive than in the U.S. and the legislation permits anonymous egg donation and generous compensatory payments to the donors. All of these factors make the Czech Republic a country with a flourishing ART travel industry.

According to Cohen (2005), the possibilities of bodily exchanges that have become available through new biomedical advances can potentially be harmful in addition to being able to save lives. The harmful effect of these new biotechnologically led exchanges in organs, blood, and other materials is that the human tissues of some selective populations become more bioavailable for extraction than others (Cohen, 2005). Cohen defines bioavailability as selective disaggregation of one's cells or tissues and their reincorporation into another body (machine)" (Cohen, 2005, p. 83). Whittaker and Speier (2010) apply Cohen's concept of bioavailability in their research to geographically locate some of the bioavailable populations of ova donors and surrogates in countries like India, Thailand and the Czech Republic. Medical facilitation companies and ART clinics 
function as intermediaries between patients and the bioavailable supply of egg donors that is strategically located in countries where medical tourism is intense and there is little state intervention in the industry (Whitaker and Speier's, 2010). Consequently, commercial interests for the benefit of the elite are favoured by the cross-border reproductive travel industry because one would need to have the means to travel and pay for those privately-provided services, while the reproductive labour and emotional involvement by the ova donor or the surrogate is framed in commercial terms and thus their role is reduced to commercial interests. Whitaker and Speier's (2010) methodology focuses on studying the global ART industry at the level of intermediary actors, such as fertility clinics and medical facilitation companies who organize the contracts between the intended parents and the egg donors or surrogates. This is often done through their online-based advertisements in order to attract foreign travellers and make the commercial transactions possible. The role of these intermediary actors (and their collaborators) is critical in an analysis of the globalization and stratification of ART industry.

Sarojini, Marwah and Shenoi (2011) provide particular insights into the operationalization of a profitable and booming ART industry in India. This case study was based on the findings from the research conducted by Sama, an Indian resource group for women and health based in New Delhi. Overall, the research included 43 ART providers and 80 women users across three Indian states. The authors discovered that the ART industry uses aggressive advertising to promote medical tourism packages to foreign customers. For example, package deals are offered to customers and success rates are inflated or misleading. The Indian ART industry collaborates with a variety of actors 
nationally and internationally in order to attract more global clients including surrogacy agents, international hospitals and tourism departments. The authors also discovered a variety of ethical concerns due to a lack of state regulation such as inflating success rates, the lack of standardization of costs across the different Indian clinics, the lack of standard treatment protocols across the clinics, and the oversight or minimization of side effects and health risks to patients. Sarojini, Marwah and Shenoi's (2011) research supports and advocates for closer regulation of the industry in order to avoid exploitation of vulnerable women, especially those involved as gestational carriers in the booming and unregulated Indian surrogacy market. This Indian case study is important for understanding how a lack of regulations can have an impact on the way that ART is practiced within the country.

Nonetheless, laws that regulate assisted reproduction are often framed in terms of restrictions to access. In an article on the legal hazards in cross-border reproductive care (CBRC), Storrow (2011) provides evidence which supports his claim that the laws on ART can induce cross-border reproductive travel when the legal provisions place restrictions on the use of ART and the physicians, lawyers and brokers can be sanctioned in their country for providing illegal ART services. The laws can interfere with CBRC when they specifically criminalize the crossing of borders for ART purposes or when the intended parents are refused recognition as legal parents of children born abroad through ART. Several European and Asian countries including France, Germany, Japan and the U.K. make it difficult for their citizens to bring back their children attained through commercial surrogacy into the native country (Storrow, 2011, p. 539). Storrow (2011) uses the example of Turkey to demonstrate legal extraterritoriality (p.539). Specific 
provisions have been introduced to prohibit Turkish citizens from traveling to another country for services that are illegal in Turkey, such in the procurement of donor gametes (Urman \& Yakin, 2010). It is important to study how the law interacts with ART travel and to consider all the legal dimensions in CBRC; however, there often seems to be a bias towards looking at the regulation of ART as an unfair prohibition of the rights of individuals of access to services. This perspective implies that the default state of legal regimes should be permissive to ART in all countries. This perspective contrasts to Sarojini, Marwah and Shenoi's (2011) study that critiques deliberate state nonintervention. For a balanced analysis of third-party assisted reproduction, it would be beneficial to consider both state intervention through restrictive laws and deliberate nonintervention through a lack of ART-specific regulations as having an equal role in shaping CBRC globally.

To conclude this review of ART literature, allow me to carefully consider what types of different frameworks have been used for understanding cross-border assisted reproduction. To this end, I am assessing Kroløkke, Foss and Pant's (2012) three theoretical frameworks in order to see which framework or which combination of methods could be a good fit for my own research question. In the first perspective mentioned by Kroløkke et al. (2012), global reproduction of ART is conceptualized as an extended network of care and engineering of human reproduction. A variety of individuals thus become involved in mothering and in producing a child. The second framework relies on discussing transnational reproduction in terms of 'reproscapes' and 'reproflows'. The term 'reproscapes' has been developed by Inhorn (2010) to describe the process of globalized reproduction. In this way, reproscapes is an additional 
dimension of the five global scapes theorized by Appadurai (1996) to describe the processes of globalization. Appadurai (1996) has theorized the following five dimensions of the globalization: ethnoscapes, technoscapes, financescapes, mediascapes and ideoscapes. By adding reproscapes as one of the global scapes that cross cultural boundaries across the globe, Inhorn (2010) is able to include the flow of biogenic substances, bodies and technologies that cross national borders into the processes of globalization. Inhorn (2010) has also suggested the term 'reproflows'. Reproflows refers more specifically to the flow of technologies, embryos and gametes across the world in a transnational global market that involves the crossing of national borders. These terms captures the complexities of CBRC and all other types of transnational flows and movements for purposes of assisted reproduction. The third framework covered by Kroløkke et al. (2012) is the gift/commodities framework, which states that biogenic substances are embedded in a discourse of gifts and altruism, while they are simultaneously being turned into commodities by the ART industry. This gifts/commodities framework allows the researcher to consider whose bodies become donor bodies and whose bodies or body parts become recipient bodies. All the frameworks mentioned by Kroløkke et al. (2012) incorporate transnational travel and stratified labour in the global ART network; however, the concept of power and the role of the state in the global ART trade are underexplored. To take into account of all the different aspects of global ART, I will rely on a combination of the different frameworks as outlined by Kroløkke et al. (2012) with a specific focus on the framework of gift/commodities and the reproscapes/reproflows framework. It will allow me to situate 
cross-border ART within a global flow of gametes, donors, surrogates, intended parents and children.

The following study illustrates how reproflows circlute within and across national borders. Kroløkke (2014) interviewed women and couples who travel from Denmark to Spain for fertility treatment using Spanish egg donors. Spain is a hotspot location for trans-European travel for oocyte donation due to its liberal legal regulatory framework on reproductive technologies and a sufficient pool of donors who are compensated for anonymous donations (Kroløkke, 2014, p. 58). Kroløkke (2014) explains the popularity of Spanish oocytes among Danish women by the way the clients imagine similarities and differences between themselves and the donors. The donors are described as better quality oocytes than those from Eastern European clinics. Kroløkke (2014) reveals an important aspect of how racial similarities and differences are constructed by the clients, as Western 'whiteness' is expressed in the narratives of the clients as desirable characteristic. Kroløkke's (2014) study shows that the construction of whiteness can have an important role in cross-border reproductive travel, especially when the clients are middle to upper class white women. This article also reveals that an analysis on race should be included in the methodology and can be studied from the narratives of interviewees, the promotional material and the visual representations on the clinics' websites.

It is also important to consider what type of framework on race and ethnicity one can use in a study on third party assisted reproduction. In Wayward Reproductions: Genealogies of Race and Nation in Transatlantic Modern Thought, Weinbaum (2004) studies how race and reproduction are connected in nationalist, racist and imperialist 
ideologies and deems this concept as the 'race/reproduction bind'. The notion of a 'race/reproduction bind' in the sense that racial identity is biologically reproduced is still relevant in our post-genomic age, even though we are aware that racial differences cannot be traced in the genome. However, it can be seen that in reproductive technologies, race and ethnicity still play a factor in the selection of gamete donors. In gamete donation, the social parents have the option to select for particular genotypes or phenotypes and often they are looking for a racial match to their own genetic background. Weinbaum (2004) states that such technologies can be used to reproduce racial identities and racial hierarchies. With respect to surrogacy, they can even recreate racial division of labour (Weinbaum, 2004, p. 230). Weinbaum's understanding of race with respect to reproduction needs to be considered when reproductive technologies are being investigated. As well, more empirical research is needed to understand the role of race in third party assisted reproduction.

Within my own methodology, I will thus have to take into account that racial preferences might be a factor in cross-border reproductive travel. Overall, the literature that has been reviewed so far reveals the importance of certain concepts such as crossborder reproductive travel (Inhorn \& Grutin, 2011; Whittaker \& Speier, 2010), bioavailability (Cohen, 2005; Whittaker \& Speier, 2010), soma/somata (Hawthorne, 2008) and reproscapes/reproflows (Inhorn, 2010). In the following section, I elaborate on the medicalizing aspects of ART and consider the social construction of the receiver of ART as patient and a consumer. 


\subsection{Understanding the Impact of Medicalization and the Rise of the Patient-}

\section{Consumer}

One important aspect of ART is the reliance on complex technologies and its application on the human body through invasive procedures. Global ART is part of the health care system through its emphasis on the treatment of infertility and a global industry through its profit-based fertility agencies and clinics. By looking further into some key scholarship on important theoretical concepts regarding medicalization, it will be easier to apply the appropriate understanding and perspective to ART and third-party assisted reproduction in particular. In order to develop my theoretical framework on cross-border reproductive travel further, I will reflect on the effects of shifts and intensifications in medicalization and the current field of reproductive and medical consumption.

In the 1970's, various scholars reflected on the medicalization of society. The concept of 'medicalization' explains how medical jurisdiction has expanded into new realms and how medicine was permitted to make judgments, not as a result of gaining political power, but in the name of health. In 1972, Zola expressed concerns regarding medicine becoming a major institution of social control by medicalizing aspects of daily life that previously used to be outside of the medical jurisdiction (Zola, 1972).

In 1973, Foucault's The Birth of the Clinic: An Archeology of Medical Perception (1973) introduced the term 'medical gaze' to describe the objectifying clinical gaze through which the human body is constituted as separate from the subject. According to Foucault (1973), medical knowledge and discourse is a form of social power and control, as it shapes our understanding of what is normal or healthy and what is pathological or 
diseased. The concept of medicalization remains important in the $21^{\text {st }}$ century and is highly relevant for studying biotechnologies such as cross-border ART. Clarke, Shim, Mamo, Fosket and Fishman (2003) have updated Foucault's medical gaze by arguing that since about 1985 Western medicine has been undergoing a transformation from medicalization to 'biomedicalization.' Clarke et al. (2003) claim that this rapid transformation is due to technoscientific developments in contemporary biomedicine. Clarke et al. (2003) defines biomedicalizaiton as "the increasingly complex, multisited, multidirectional process of medicalization"(p. 162). The shifts in medicalization are intensifying in complex ways and allow to transform the human and the nonhuman through innovations such as molecular biology, genomics, biotechnologies, transplant medicine and new medical technologies (Clarke et al., 2003). One of the aspects that characterize this transformation towards medicalization is the increasing commercialization of health through privatized and corporatized biomedicine.

By updating the vocabulary related to medicalization and the medical industrial complex, Clarke et al. (2003) emphasize the role of corporations and related institutions in biomedicalization. The results of the pervasiveness of biomedical technologies has lead to the transformation of bodies, the creation of new identities through biosocialities, as well as the possibilities of self-governance. In Clarke et al.'s (2003) analysis, the state has a decreasing role in driving the processes of medicalization compared to the medicalization process in the $20^{\text {th }}$ century. Clarke et al. (2003) theorize instead that it is the multinational and globalizing corporate forces that are becoming more prevalent in medicalization processes. 
Conrad (2003) argues that doctors have taken on a more subordinate role in medicalization as now commercial and market interests are dominating over professional claim-makers. Conrad (2003) defines corporatized medicine as a buyer-driven system where patients are acting as consumers and are increasingly vocal about demanding services that they consider they have the right to access (p.9). Contrary to Clarke et al. (2003) who do not highlight the role of medical consumers, Conrad (2003) emphasizes the role of consumers in driving medicalization and the function of the Internet in becoming an "important consumer vehicle" (p. 9). The term 'patient-consumers' is used to emphasize the blurring of the line between patients and buyers (Conrad, 2003, p. 5). This term could be very useful in my framework as it takes into account the corporatized medical environment when it comes to cross-border ART. Both Conrad (2003) and Clarke et al. (2003) explain recent shifts in medicalization with the advances in biotechnology and the corporatization of medical research and health services. Contemporary scholarship on medicalization thus places the Internet as an important space and tool for establishing relationships of medical consumption. The literature shows that new biomedical advances, the corporatization of health services, and the availability of ART services on the Internet play a critical role in the consumption of ART services (Clarke et al., 2003; Conrad, 2003).

Regarding the medical consumption through assisted reproductive technologies, Fletcher (2006) has developed a framework for understanding reproductive consumption as an active process where human agents create relationships through consumption and make choices to address their desires and felt needs. With the idea that biological reproduction is a site of consumption of various reproductive goods and services, 
Fletcher (2006) attempts to go beyond an analysis focused on commodification in order to show that reproductive consumption does not only involve exchange and use values, but also adaptive and relational values. This perspective claims that individuals can be "consumers when they use bought services and goods in executing their reproduction" (Fletcher, 2006,p. 43) and they can be "objects of consumption when they sell their gametes and their gestative capacity" (p. 43). Even though Fletcher's (2006) conceptual framework acknowledges that gamete donors and surrogates are to some extent objectified in the consumption of reproductive technology, the framework does not differentiate third-party assisted reproduction from any other type of pregnancy or conception-related consumption. This is my only critique of Fletcher's (2006) framework, as the use of folic acid by pregnant women and abortion services do not involve the commodification of a third-party like surrogacy or egg donation programs do. By framing reproductive technologies as a way for negotiating reproduction in new, creative and active ways and simultaneously neglecting commodification of third parties, Fletcher (2006) does not see the threat that commodification in ART might pose to human relationships and dismisses anti-commodification arguments too easily.

In order to understand global patterns of reproductive consumption and types of human relationships that are created through ART, it might be useful to look at reproductive consumption as happening within the sphere of medical tourism and travelling medical consumers. Turner (2007) shows that some countries, such as India, Malaysia, Indonesia, Philippines, Singapore and Thailand, specifically market themselves as destination countries because the medical tourism industry represents a significant resource for national economic development. In the global medical market place, a global 
network of brokers, private hospital associations, government ministries, travel associations, and medical facilities cooperate in order to promote and advertise medical tourism to international patients. Turner (2007) explains that since the industry is based on servicing international paying customers, medical travel contributes to the commodification and privatization of health services. This analysis of medical tourism is useful to add to my framework, as cross-border ART is both unique in type of the medical services that are delivered, while also being part of this bigger field of medical tourism in destination countries.

The impact of medicalization and biomedicalization cannot be overlooked in a critical sociological study on third-party assisted reproduction, primarily because medicalization has allowed infertility and childlessness to be constructed as a medical problem that can be solved through the intervention of reproductive technologies. As a result, it is critical that my framework includes the concept of medicalization and patientconsumers in order to understand that commodification involves intended parents who function as patient-consumers and are important actors in ART and the establishment of relationships of consumption. However, I will also need to supplement my framework with a discourse of the human body, its fragmentation through biotechnology and the relationships of power. These concepts are further developed in the following section.

\subsection{Applying Biopower and Biopolitics in the Age of Assisted Reproduction}

This section engages with the literature on the application of Michel Foucault's concepts of biopower to biotechnology in order to develop a framework that also includes the role the state plays in shaping third-party reproduction and how power can be 
conceptualized with respect to third-party assisted reproduction. Foucault (2003) coined the term biopower to describe the type of power that is directed at man as a living being. These are technologies of power that effect disciplinary and regulatory mechanisms to manage the population (Foucault, 2003, p. 247) Biopolitics are the regulatory mechanisms that deal with the living man as part of a population in order to optimize life (Foucault, 2003, p. 243). These technologies are concerned with birth rates, mortality, longevity, and illness. The bioregulations are found at both the state and the sub-state level through various institutions (Foucault, 2003, p. 250). Therefore, Foucault (2003) clarifies that the 'power-knowledge' of the institution of medicine can have both disciplinary and regulatory effects that are applied to both the individual body and the population (Foucault, 2003, p. 252). Since Foucault's first introduction of the concept, many developments in biotechnology have taken place and various scholars have taken up Foucault's concept of biopower and his use of the term biopolitics to theorize and explain the advances in biotechnology in the twenty-first century.

Rabinow and Rose (2006) define contemporary biopower as containing truth discourses around human vitality, various strategies to intervene in order to optimize vitality, and modes of subjectification through which individuals construct new ideas about their identities and subjectivities. Moreover, contemporary biopolitics encompass "all the specific strategies and contestations over problematizations of collective human vitality, morbidity, and mortality; over forms of knowledge, regimes of authority and practices of intervention that are desirable, legitimate and efficacious" (Rabinow \& Rose, 2006, p. 197). In modern neo-liberal societies, individuals are responsibilized to manage their own health and to maximize their vitality through self-governance and recourse to 
biotechnology. From this perspective, contemporary biopolitics are framed around vitality, the duty of self-responsibility and self-governance, but not necessarily around mortality. Rabinow and Rose (2006) contrast their use of biopower to the neo-Marxist readings of Foucault's work by Agamben (1998) and Hardt and Negri (2000). This is because Rabinow and Rose (2006) claim that the neo-Marxist understanding of biopower is about global domination over social life and the bodies of the population by the power of the state to enforce death. In contrast, Rabinow and Rose (2006) do not see eugenics in contemporary biopolitics, but rather, new forms of subjectivization and biosocialities.

The concept of 'biosocialities' refers to the formation of new social identities and relationships based on biological conditions or genetic diagnoses (Rabinow, 1996). For Rabinow and Rose (2006), reproductive technologies generate new choices, new forms of responsibilizations and obligations. Rose (2007) in particular establishes that the biopolitics in the twenty-first century are about self-optimization through the biomedical techniques such as reproductive technologies, genetic screening, psychiatric drugs and genetic modification. In Rose's analysis (2007), the state is nothing more than an enabler or facilitator (p. 63), while it is the individual, and not the nation or the population, who exercises freedom and choices in the contemporary neo-liberal biopolitical arena.

In Giorgio Agamben's Homo Sacer: Sovereign Power and Bare Life (1998), biopower of the state is conceptualized as concrete power that takes the biological life of its citizens, more specifically the bare life (zoe) of the homo sacer, the one who "may be killed and yet not sacrificed" (p. 12). Agamben (1998) uses the eugenic camps in the twentieth century totalitarian states as exemplary places of biopolitics (p. 10). This paradigm of modern biopolitics involves death of those who do not deserve to live though 
the means of reducing the qualified life (bios) of a subject to bare life (zoe). While Agamben (1998) allocates the biological life of the subject as primarily belonging to the state, he claims that Nazism, being the first biopolitical state in its radical form, presents a point in time where the decisions regarding biological life began to not be dependent on purely political motivations. In fact, Agamben claims that "the integration of medicine and politics" (Agamben, 1998, p. 83) became an essential characteristic of biopolitics in the twentieth century Nationalist Socialist Reich. Although it might seem that using extreme examples of radical biopolitical states might not be appropriate for studying modern neo-liberal societies as Rose (2007) would claim, Agamben's (1998) emphasis on the objectification of the body could be useful in studying biomedical technologies that rely on a supply of bodily human material. Agamben's (1998) use of the concepts bios and zoe to describe two forms of state of living can be applied to modern biomedical technologies, such as transplant medicine, that treat some bodies or tissues as devoid of subject.

In her anthropological research on organs trafficking, Nancy Scheper-Hughes (2002) reasserts Agamben's use of the Aristotlean terms bios and zoe to explain how these concepts can be applied to study the trade in commercial transplant. ScheperHughes' (2002) research reveals that global capitalism and the availability of advanced biomedical technologies have lead to the demand for bodily material (i.e. organs, blood, or the genetic or reproductive material) of others for the benefit of those who are deemed patients. For instance, it is the demand for organs in one area of the world that drives certain disadvantaged individuals to have their organs extracted, transported and then to be transplanted into an organ receiver of privileged class in another part of the world. In 
the new global economy, organ donors make bodily sacrifices that are easily replaceable and disposable within the continuous circulation and mobilization of body parts. Brokers get their supply of spare body parts from certain disadvantaged individuals, populations or nations. In Scheper-Hughes' (2002) study on the fetishization of organs, the sacrifices of the donors are masked by discourses of altruism and the pragmatic utilitarianism of medical bioethics.

Scheper-Hughes refers to the global commercial transplant trade as operating in the arena of "post-modern biopolitics" (Scheper-Hughes, 2003,p. 198). In her critique of the military medical industrial complex and the discipline of bioethics, Scheper-Hughes (2003) states that in the new global free market medicine, it is the privileged postmodern consumer who's right to buy is protected (p. 206). In the postmodern biopolitics, modernist values are abandoned for new values of free circulation of goods and services, individuality and disposability (p. 213). Scheper-Hughes (2003) reveals in her research how some doctors participate in unethical and illegal organ trade that exploits the poor and the desperate (p. 198). While the example of trafficking in transplant tourism and organ trade may seem to be more of an extreme case of the dark side of postmodern medical ethics, this particular application of biopolitics focuses on the mobilization of body parts across the world. Similar understanding of supply and demand can be applied to third party reproduction and cross-border reproductive travel. Scheper-Hughes (2003) situates medical tourism and the global medical consumption of divisible bodies within the spheres of economic liberalism and the new postmodern values that are based on the neo-liberal episteme. Indeed, the economic doctrine of neoliberalism promotes free circulation of goods and labour across national borders (Appadurai, 2001). For a 
profitable exploitation of raw material in the global economy, the state must take on a minimal role to allow for free circulation of commodities (Appadurai, 2001, p. 51). Neoliberalism is a useful concept in understanding the global circulation of goods within the reproductive flows of cross-border ART, as neo-liberal policies can reinforce the rise of cross-border ART. The neo-liberal regulatory framework involves shifting public services and publically funded systems to more privatized systems (Magnusson, 2005). Neoliberalism is in part characterized by deregulation, privatization and market rule (as cited in Magnusson, 2005). In terms of ART, the cross-border market requires national governments to have neo-liberal legal regimes, as strong government intervention through regulation and public oversight could hinder industry development. My framework on cross-border ART would include the insight that neo-liberal medical ethics and governing rule of ART have an impact on the type of health care that is delivered in fertility clinics.

Among the previously covered literature on biopower and biopolitics, there was little consideration given to the role of the state in terms of governance and regulations. Agamben's (1998) neo-Marxist application of biopower involved the power over death by the state. However, this concept of biopower is different from contemporary understandings of biopower which revolve around individual choices (Rose, 2007) or the exploitative practices of global neo-liberal capitalism (see Scheper-Hughes, 2002). In Becoming Biosubjects: Bodies, Systems, Technologies, Gerlach, Hamilton, Sullivan and Walton (2011) combine the theory of biopower more closely with governmentality, while at the same time taking into account how biotechnologies have led to the fragmentation of the body and subjectivities. A closer look at the concept of the biosubject, as well as 
Gerlach et al.'s (2011) application of biopower could be useful for developing a framework that includes the state as a regulator of ART.

Gerlach et al. (2011) state that one of the social impacts of biotechnologies is the fragmentation of our biosubjectivies, where "the subject is both alienated from and dependent upon a fragmented body" (Gerlach et al., 2011, p. 6). By putting into question the apparent ontological integrity of the body, biotechnology renders it fragmented, volatile, temporary and violable. These resulting contingent bodies and their associated subjects are more challenging for modern states to govern than the bounded body of an individual subject. In Gerlach's (2004) model of Canadian biogovernance, five processes are involved in addressing biotechnological risks: privatization, politicization, objectification and normalization. These four processes at last lead to responsibilization, which is the final condition for biogovernance. The ultimate result is that risk and governance is being assigned to the citizens for self-management. For Gerlach et al. (2011), biopower is synonymous with governmental power and it involves obligations of self-care and self-governance by the citizens (p. 10). In the Canadian case of the debate regarding assisted human reproduction, Gerlach et al. (2011) reveal key governmental events that have shifted Canadian focus in reproductive technologies from the regulation of conception to the regulation of fertility. One of those key events was the establishment of the Royal Commission on New Reproductive Technologies (RCNRT) in 1989 to address issues around new reproductive technologies and make recommendations for governance of assisted human reproduction. The RCNRT's recommendations reflected the shift in biogovernmental framework from women's rights over their bodies in abortion debates towards the management of reproduction and the fertility of the nation. 
The embryo was framed as the biosubject of interest. The final legislation on reproductive technologies, Bill C-6, the Assisted Human Reproduction Act (AHRA) that was adopted in 2004 and the establishment of the federal agency Assisted Human Reproduction Canada (AHRC) in 2006 represented the final event that closed the debate on reproductive technologies in Canada. Gerlach et al. (2011) highlighted some controversies in the media regarding the prohibiting of commercial surrogacy and the trade in reproductive material. Reproductive technologies were often framed in politicaleconomic arguments and focused on the promises of genetic research and the possibilities for the creation of healthy children. The Canadian context of ART governance shows that in general reproductive technologies were framed in terms of fertility assistance (Gerlach et al., 2011; Sullivan, 2005). The intervention of the government in the ART industry and medical practices through the AHRA was justified on the account that infertility was framed as an issue of public health (Sullivan, 2005).

The debate in Canada around reproductive technologies and the resulting legislations are interesting for a variety of reasons. As Gerlach et al. (2011) pointed out there was an opportunity for the government to appoint a new object of biogovernance and replace the controversial sexual politics around abortion and women's rights with the concerns around addressing infertility issues in heterosexual couples who struggle to conceive. Compared to other frameworks around biopower and biopolitics, Gerlach et al. (2011) look more closely at the interests of the state in governing and addressing the risks associated with biotechnologies. Canada in particular seems to be an illustrative case of a state that regulates ART through a legislation that bans certain aspects of ART and regulates the activities that are permitted. Jones and Salter (2010) have emphasized a 
cautionary approach towards ART and a feminist-based anti-commercialization argument used in the Canadian legal framework on ART. It would be useful to further look into Canadian ART biogovernance with a particular focus on egg donation and surrogacy in order to understand how third-party assisted reproduction was framed and which implications have been considered in the development of the policy. Additionally, it would be beneficial to provide an update on the public controversies around ART in Canada with the purpose to assess how cross-border reproductive travel can intersect with the implementation of a federal law. 


\section{Chapter: Theoretical and Methodological Framework}

\subsection{Theoretical Framework and Research Questions}

The theoretical framework that is applied in the current thesis is heavily influenced by the various theories covered in the literature review that present themselves as particularly useful and relevant for studying third-party assisted reproduction with a critical sociological perspective. Three main conclusions can be drawn from previous research on ART and biotechnologies. First, ART-specific literature reveals that current concerns over the commodification of women's bodies as a result of ART should be studied both globally and by taking into account the specific locations that are destinations for reproductive tourism. These strategies are critically important because knowledge and transactions are facilitated by national and international networks of actors who benefit from the trade. Previous research has shown that fertility agencies and clinics function as intermediary actors between the intended parents receiving the services and the women who are recruited as egg donors or surrogates. In order to advance the dialogue around the commodifying aspects of third-party assisted reproduction, the concepts of soma/somata (Hawthorne, 2008) and bioavailability (Cohen, 2005; Whittaker \& Speier, 2010) will be explored. Soma and somata will thus be used to think of women egg donors and women surrogates as resources for reproductive bodies and reproductive material, respectively. Additionally, the concept of bioavailability as identified by Cohen (2005), and later on used by Whittaker and Speier (2010) to define bioavailable supply, provides supplementary vocabulary that allow a researcher to critically examine the geographical locations, and the cultural and social 
characteristics of the women that are usually considered available for purposes of egg donations and gestational surrogacy. More in-depth research into commodification is possible through a study on the ART industry in those places where surrogates and egg donors are recruited for international clients.

Second, theorists reveal that one of the outcomes of biomedicalization has been increased medical consumption. Reproductive consumption within the medical tourism industry is facilitated by the Internet, which functions as a place where cross-border relationships of medical consumptions are established. Because women function as both consumers and providers of reproductive material and gestational labour, the framework of commodification must take into account the biomedical context of the ART industry. With the concept of 'patient-consumers' as revealed in the literature on medicalization by Conrad (2003), I am able to critically situate ART as a form of medical consumption in the global medical tourism industry. Intended parents can thus be considered as both the patients and as the consumers in commercial third-party assisted reproduction arrangements. This allows the researcher to adopt a different perspective of the type of relationship that is established in surrogacy and egg donation agreements. Accordingly, the discourse on commodification of women in the ART industry can be developed through a critique of the assumption that the intended parents have the unquestionable right to have their needs and desires for reproductive consumption met through the use of third parties.

Third, research on ART can benefit from a theoretical framework that addresses the inequalities of the different parties involved as well as the issues of power and governance at the national and international levels. One way to understand that is by 
using Foucault concept of biopower (Foucault, 2003). There are certainly different contemporary understandings of Foucault's concept of biopower. The theory hasn't been applied specifically to transnational third-party assisted reproduction. However, the theory benefits the research on ART by pointing towards the role of the state in the regulation of the technology, the bodies that are being invaded, fragmented and used by the invasive medical procedures, and the context of inequalities across nation states and the people that are involved. Notably, the field can be advanced by studying how nation states try to control the risks associated with ART through the introduction of laws to regulate or restrict some commercial activities. By using third-party assisted reproduction as an example of biopower, one can gain further insight in the complexities of ART. For example, regulations of ART are established by individual states and become a matter of governance through the introduction of laws permitting the government to regulate the industry within a state or a country. Therefore, it is beneficial to study the legal framework as a form of biogovernance and the object of governance as an established biosubject, such as Gerlach et al. (2011) have done for Canadian law on new reproductive technologies. Nevertheless, cross-border ART is not only a matter of governance by individual states, but also a matter of global post-modern biopolitics. Scheper-Hughes' (2003) perspective takes into account the global free market medicine and the neo-liberal values of free circulation of goods across borders. It is important to note that the global flow and circulation of people and reproductive goods shape the pattern of the crossborder ART.

The commodification framework, the medical consumption framework and the biopower/biopolitics concepts will be used to forge a working framework which will be 
applied pragmatically in order to address the main research questions of this project. The goal of the thesis is to get in-depth information on the way that ART is practiced by the different social actors involved within the context that characterizes third-party assisted reproduction. The analysis is separated into three sections based on the following research questions:

a. What form of biogovernmental discourse is used to justify a restrictive legal and regulatory framework with respect to ART and how does it impact the practice of ART within the country and transnationally?

b. Which countries are considered favourable destinations for ART travel by the ART agencies that advertise to an international clientele and how does the industry handle the legal, social and ethical implications of the services they offer?

c. How do destination countries respond to the intensification of crossborder reproductive travel and the controversies surrounding it?

The case study methodology is used to address each of the three questions in order to get an in-depth and contextual understanding of the phenomenon of third-party assisted reproduction. I have chosen the qualitative method to collect data from a variety of legal, public and online sources to capture different types of discourses. Selection for cases that are atypical or extreme can lead to more rich discoveries and stronger engagement of different social actors than choosing random typical cases (Flyvbjerg, 2001). For this reason, I have paid attention to controversial ART cases or to those that show a possible but not typical outcome resulting from an ART arrangement. All three 
case studies in this research include documentary analysis, discourse analysis, and even visual analysis when available. The first case is based on the Canadian ART legal framework and cross-border controversies in Canada. Canada regulates assisted human reproduction through a federal law that prohibits commercial forms of surrogacy and egg donations. While Canada is not the only country with such restrictive regulations, the Canadian context is atypical in the sense that it shares a geographical proximity with the United States, a country whose laws on ART are regulated by individual states. In the second case study, the objective is to investigate the online field of fertility agencies through its networks and the content that the websites provide. The best example is an interconnected network of fertility agencies that crosses national borders and is easily accessible to international customers. The online network can used to discover which countries the ART companies are relying on for the international supply of surrogates and egg donors. Whereas the first case study is based on a Western nation with seemingly little reproductive tourism, the second case study is primarily situated in the cyberfield of ART where individuals from anywhere in the world can engage in surrogacy or egg donor contracts. Finally, the last case study focuses on some key destination countries. Recently, some surrogacy cases have received considerable media attention. Similarily, the lack of regulations in some destination countries has been publically questioned and debated in the media. In response to the booming ART industry and its associated risks, countries such as India, Russia and Thailand, are moving towards more restrictive framework to third-party assisted reproduction. This phenomenon is interesting because the international ART trade is being publically criticized as a result of scandals involving global ART. 
All three research questions focus on three main intermediary actors that shape, facilitate or restrict the global ART industry: state regulations, fertility clinics/agencies and news media. As a result, the body of materials to be analyzed is comprised largely of policy documents, websites for fertility agencies and clinics, and news articles. Unobtrusive measures are taken to conduct the research on the case studies. All the information to answer the research questions can be obtained through documents that are publically accessible and have been prepared for public viewing. Policy documents can be used for studying the content of the material and its function as an actor of a network (Prior, 2008). Based on actor-network-theory (ANT), one can assume that nonhuman actors, a category that includes material objects such as documents, function as actors within a network (Callon, 1986). As a consequence, my perspective is that state regulations are intermediary actors between the consumers and the egg donors and surrogates because they impact the way that ART is practiced. In the analysis, how the Canadian policy on ART was developed, the impact of the policy instrument and the arguments that support this policy decision will be analyzed. Similarly, webpages of fertility agencies and clinics are also documents that are studied for the information they provide and their connections to other websites through outlinks, i.e. an embedded link that points to other website (Prioir, 2008). Tracing the links between websites generates a network that can be visualized and analyzed. As for news articles, they represent a different type of documents as they report on particular controversial cases and issues in third-party assisted reproduction. They will be studied mainly for their content; however, the media's ability to expose controversial cases might have an impact on the development of the story and the response from the ART industry and the governments. 
Thus, the news articles will be mainly studied chronologically as they are published in order to capture the development of the narrative over time.

\subsection{Data Collection Strategy for Case Study One}

My first case study focuses on the Canadian context to answer the first research question on the Canadian ART biogovernance and the effects of a restrictive legislation on cross-border ART. I selected Canada for practical and illustrative reasons. As a Canadian citizen and resident, my familiarity with the existence of the law, the controversies in the media, and my ability to easily access archives and legal documents of interest allows me to conduct this case study effectively. Another good reason for selecting Canada as one of my case studies is to examine issues around prohibitions of the commercial form of gamete donation and surrogacy. Additionally, Canada's geographical proximity to the United States is unique among other liberal democratic Western countries with similar legislation. The U.S. with its many states varies in terms of laws regarding ART from state to state, and does not have a federal law addressing ART. While Canada is not the only country with restrictive regulations on ART, the availability of some existing research on the Canadian biotechnology and governance will allow me to update the field by specifically focusing on third-party assisted reproduction. To summarize, ART in Canada represents an interesting case form which I can gather rich information. Most of the material is publically available online, but some archival documents available in print will also be used. The selection of materials is based on validity, the results shown through the Google search engine, and relevance to the research question. For the online material, I am interested in only studying the 
websites that are accessible to a Canadian Internet user. Overall, the material of interest for the first case study includes legal government documents, including the law that regulates ART, commissioned government reports on ART, news articles which center around controversies on egg donation or surrogacy in Canada, and some selected online websites of fertility agencies and clinics.

My data collection strategy starts by looking for publically available relevant government documents through online search engines. The first material discovered is the publically available and electronically accessible Assisted Human Reproduction Act (S.C. 2004, c.2) having been last amended on September $30^{\text {th }}, 2012$, on the Government of Canada's Justice Laws Website. On that same website, under "Regulations made under this Act", there is a link to the Assisted Human Reproduction (Section 8 consent) Regulations (SOR/2007-137), having last been amended on December $1^{\text {st }}, 2007$. Both documents are bilingual; however, only the English text will be used for the analysis. Google search engine also revealed a section on the Health Canada website titled “Assisted Human Reproduction" that contains relevant information on the AHRA (Health Canada, 2014). Given that Health Canada is currently responsible for the administration and enforcement of the act, Health Canada's website contains additional information on the AHRA, fact sheets on prohibitions, and a glossary that might be useful for analysis. In order to capture any other government report on new reproductive technologies, I searched the archives through an online search on the Library and Archives Canada website using the keyword "reproductive technologies". The searched showed the 1993 two-volume final report by the Royal Commission on New Reproductive Technologies (Royal Commission on New Reproductive Technologies [RCNRT], 1993). Created in 
1989 by the federal government, the RCNRT had been mandated to study the implications of new reproductive technologies in Canada and their impact on Canadian society. The final report is an important document to include in the analysis as it reveals the issues that the RCNRT has identified with new reproductive technologies and the arguments used to support their recommendations to the government. As supplementary material, using the Google search engine for the Royal Commission on New Reproductive Technologies, I found an archived CBC news video report in which the chair of the commission Dr. Patricia Baird was being interviewed on November 30, 1993, by CBC News (“The Royal Commission”, 1993).

To find out if there are any other documents published by the RCNRT, I performed a search on the Carleton University Library website (http://www.library.carleton.ca/) which revealed a variety of stored government documents published by the RCNRT available for library use only. In addition to the final recommendation by the RCNRT 'Proceed with care' volume 1 and volume 2, the library contained 13 volumes of research studies by the RCNRT covering various topics all published in 1993. The rich amount of government material is available for consultation in case the final report does not address in detail the topic of interest.

To address recent controversies around third-party assisted reproduction in Canada, a couple of news articles have been selected in the study for their relevance to the topic at hand to provide the context for studying of the AHRA and its impact ten years after the bill was passed and 25 years after the creation of the RCNRT. Using search term "assisted reproductive technology" in Google news search, six news articles that represented issues around egg donation and/or surrogacy have been selected. All of 
them have been published within the last few years, from March 2012 to December 2013. The news articles selected are covering three different topics: the grey egg donor market in Canada, a cross-border egg donor case involving an American egg donor, and the case of an international baby-selling ring that resulted in a federal prosecution of a Canadian fertility consultant company. All the news articles selected for analysis reveal some of the illegal elements that happen behind the curtain and highlight the ethical complications of the third-party assisted reproduction.

\subsection{Data Collection Strategy for Case Study Two}

The second case study in this thesis is based on one online network of fertility agencies and clinics that operates in many countries. The reasoning behind this method is to study the cross-border industry involved in egg donation and surrogacy from the perspective of the broker. It allows the researcher to unobtrusively study the context of commercialization and commodification directly from the discourse of the for-profit fertility companies that advertise on the Internet. Because the location of a researcher might influence the results in a search engine, I have taken the role of a potential Canadian customer who is interested in surrogacy and/or egg donation. I assumed that a Canadian is likely to have been exposed to news articles highlighting India as an international commercial surrogacy hub. My first step was to search for websites using the keyword 'India surrogacy' on Google search engine. On the second search engine results page, I found the New Life India website (www.newlifeindia.com). On the home page of New Life India, the visitor is told that New Life India is a part of a global network group named the "New Life Global Network Group" with successful operations 
in different Eastern European countries, Israel and India. Seeing the potential to make interesting network connections, I decided to include New Life India in my research material and base my second case study around the New Life Global Network group. The second website discovered is accessed directly though an embedded link titled 'Caucasian egg donors' which leads to the New Life Egg Donors website (www.newlifeeggdonors.com). Also directly form the New Life India website, under the banner 'branches', I accessed New Life Georgia (www.newlifegeorgia.com), New Life Ukraine (www.newlifeukraine.com), New Life Thailand (www.newlifethailand.com), New Life South Africa (www.newlifesouthafrica.com), New Life Israel (www.newlifeisrael.com) and New Life Poland (http://www.newlifepoland.net/). In order to verify if there are other websites related to the New Life Network Group, I made an online search for the New Life Global Network and discovered that there is a website for the New Life Global Network (www.newlifeglobalnetwork.com) and also New Life Mexico (www.newlifemexico.net). New Life Mexico was however not directly linked from the other websites, but is clearly part of the same network group. In total, ten different websites have been found to belong to the network group, as researched on September $14^{\text {th }} 2014$.

New Life Global Network and all of its associated sites within the network group have been selected for this case study for a number of reasons. First, the network covers at least eight countries. Countries like India and Thailand are known as destination countries for international reproductive tourism, but others such as South Africa are not recognized as popular cross-border ART locations. The inclusion of many Eastern European countries is also interesting, especially with respect to the advertised 
'Caucasian' egg donation programs, which allows the aspect of race and ethnicity to be included in the analysis. It is important to include all the different branches of the network within my analysis, as it would allow me to compare amongst the branches and to potentially uncover a pattern behind the selection of these particular countries for the establishment of their fertility clinics. Each country in which the network operates has its own locally registered website, which allows for an extensive amount of content to be analyzed and comparisons to be made across different locations within the network. Finally, this network is interesting because other websites that resulted from researching surrogacy or egg donation in the search engine were not openly presenting themselves as an international network group. This network group contains a lot of information on prices, program packages, and offers both surrogacy and egg donation services. This allows me to analyze a large amount of content across different locations. In order to corroborate some of the results from this network, additional websites of local fertility agencies or clinics will be used if supplementary information is necessary. This would only be used as supplementary material because the case study is primarily focused on the websites belonging to the New Life Global Network.

\subsection{Data Collection Strategy for Case Study Three}

The goal of the last part of my thesis is to compare and contrast three destination countries for cross-border ART that were involved in recent controversies on third-party assisted reproduction. My selection is based on countries that have had ART controversial cases in the news media in 2013 and 2014, during the time of my research, involving either surrogacy or egg donation cases. News media is a good source to get a 
different perspective on third-party assisted reproduction because it brings to light situations that go wrong and often involve a variety of actors within the scandal. As a source of research material, it provides a more sensationalized account of the events, but there are many benefits of using news articles as research material. For instance, many different actors can be identified and the development of the discourse on a particular topic can be followed chronologically over time. Online news articles are easily available in English through a simple search by using relevant keywords in search engines. The benefit of using online news articles rather than printed media is that I can get access to newspaper journals published in many countries across the world.

Throughout my research, I selected India, Russia and Thailand as the destination countries of interest. All of the countries have a similar approach to ART governance in the sense that there has been historically little government oversight or regulations of the ART industry. As well, there have been no legal prohibitions with respect to third-party assisted reproduction in those countries until these discussions around regulations began. Surrogacy in India has been a hot topic in the media for while; however, within the last few years, there has been an increase in concerns raised about the lack of regulations by the Indian government. Overall, I discovered 14 relevant news articles to chronologically follow the development of the public discourse in the media from March 2013 until October 2014, with a majority of the articles having been published by Indian sources such as the Hindu, First Post and Bangalore Mirror. The analysis for India is starting with an article published in March $19^{\text {th }}, 2013$, which announces the proposal of the Indian government to introduce a bill on ART ("Govt proposes to bring Bill”, 2013). Over the course of the year, six additional articles were found to be relevant to the topic. The 
Hindu provides direct links to related articles through its website, which has facilitated the search for articles on surrogacy in India. For 2014, seven articles have been found to be relevant to the Indian ART context.

The extent of the New Life Global Network reveals that Eastern Europe and South Asia are favourable locations for operating fertility clinics and recruiting surrogate mothers and egg donors. This particular network does not have fertility clinics in Russia. However, surrogacy in Russia is attracting a good amount of foreigners, as it has been reported by the media (Ivankiva, 2012). Russia is a good choice to include into the analysis. Russia's Family Code permits the parents to be registered as legal parents on the birth certificate with the consent of the surrogate. Russia also has no legal restrictions on commercial egg donations. Compared to other countries in Eastern Europe, English Russian news source are more readily available online. Russia has had an open public engagement on the topic of surrogacy by Russian religious leaders and government officials. Compared to India, the discourse on surrogacy in Russia relies on other types of arguments to advance the cause for increased regulations for surrogacy arrangements. The first article that caught my attention was published in October $6^{\text {th }}$, 2013, in Russia Today. The article reports that the Russian Orthodox Church seeks legal ban of surrogacy (Lisitsyn, 2013). Following this Lisitsyn's article (2013), I have found four other news articles on the development of the discourse on surrogacy in Russia. To provide supplementary context, a few news articles on the ban on foreign adoptions will be included in the analysis. The Russian ART context is unique in the sense that it more openly involves religious leaders and government officials and it overlaps with discussions on foreign adoptions and abortion. 
Therefore, this is an important destination country to study because the legal framework on ART might become more restrictive with time. Because the Russian ART field is first introduced at this point of the research and Russian online field has not been studied, I have chosen to include a couple of online fertility website as additional sources. Based on a Google search for surrogacy in Russia, the following websites have been selected: Surrogacy in Russia and Abroad (http://www.surrogacy.ru/eng/) and Mom Service Surrogacy and Donation (http://www.surrogate-donation.com/).

Thailand is a major destination country for reproductive tourism that has had tremendous exposure in the media in 2014. The recent controversies on surrogacy in Thailand are based on two different cases that seem to converge and lead to an interesting and fast response by the military government in Thailand. On August $1^{\text {st }}$, the Telegraph publishes an article on a Thai surrogacy where a newborn with Down's syndrome is abandoned by their Australian intended parents (Pearlman, 2014). The other significant surrogacy case is on a Japanese man who fathered many children in a short period of time through Thai surrogate mothers (“Thai police raid", 2014). My research on the Thai surrogacy cases ends in November 2014 with the last report on the approval of a ban on surrogacy ("Thailand's parliament approves", 2014). The developments since the first news report and the approval of the new bill is analyzed through a total of 15 news reports and two fertility websites from Thailand. Given that Thailand has gotten the most media coverage in 2014 with its controversial surrogacy cases, the development of the surrogacy controversies in Thailand is significant and might have an interesting impact on the surrogacy industry and the way that other countries respond to the risks associated with being a surrogacy destination country. 


\subsection{Analysis of Data and Reflexivity}

The material that I have collected from the government documents, online websites and news articles will be analyzed in a Foucauldian approach. I have decided to use Foucault's (1980) power/knowledge framework because it allows me look at the discourse to understand what type of discourse permeates the ART field and how the different sources of material address the ethical issues and legal and social implications of ART. Foucault's concept of knowledge/power shows that "power" can be exercised through the production of regimes of "truth" (Foucault, 1980, p. 93). Thus, power/knowledge regimes can be understood as discourses that constitute subjects and the social world. Foucault sees this form of power as a productive force that can create particular truth regimes. This can be pragmatically used in a research that approaches the study of a phenomenon from both a critical and constructivist manner. There are a variety of doctrines and ideologies that can influence the way that ART is conceptualized and problematized. Looking at patterns in the language and themes will reveal what types of regimes of truth are created as a result. I aim to use Foucault's analytic approach in order to understand how third-party assisted reproduction is framed by different actors.

Discourse analysis is useful for my first case study as I rely heavily on government documents. Foucauldian approaches can be used to do policy analysis with a focus on language and especially the ways that the policy problem is framed (Prior, Hughes \& Peckham, 2012). The goal is to find out how the policy problem was defined, which type of vocabulary is dominant, which instrument have been chosen to address the policy problem, and how the risks of ART have been framed. However, the government documents which includes the AHRA and the publications released by the RCNRT 
represent official government perspective. Multiple perspectives are beneficial to ensure reliability. For case study two, the analysis I am conducting is focused on the various subjects that are created through the discourse that circulates within the field of thirdparty assisted reproduction from the industry perspective. It is important to analyze the discourse form the fertility agencies and clinics because the truths that circulate within this field reflect the way that surrogates, egg donors, children and intended parents are handled in this cross-border ART industry. ART has already its own language to designate the different parties involved and to describe the services. This language tends to be based on the medical terms used in IVF technology. It can be assumed that the discourse is largely consistent across all sources. For this reason, I will collect the data from the different sources by looking at which truths and meanings are created, how the subjects are constituted, what type of vocabulary is used, and whether or not particular themes around key concepts such as commodification, exploitation, or risks are being highlighted. The discourse can reveal the relative perceived value of the different parties and the nature of their relationships. My primary intention is to focus on the way that egg donors and surrogates are commodified or in what manner they are assigned perceived value. My strategy is to look for patterns and themes within the text and the visual representation where appropriate. Content-wise, the information of interest is related to surrogacy and egg donation, the prices, the mention of health risks, any mention of the laws on ART, and copies of contracts if available. Network analysis is also an important component of this research, as it allows to track connections and the pattern of the circulation of power/knowledge. The visual content of websites and the wording on the main page will be studied to find out who the website considers its target audience. 
Additionally, any mention of risks associated to commercialization and commodification will be of interest. For the case study on the online network, discourse, content and network analysis are performed. Any similarities and differences on the different websites will be compared. Of particular interest is the network analysis that can be performed by tracking the links between the websites. Networks can be visually represented in sociogramms revealing actors or locations.

A different type of discourse, often revealing more problematic and controversial aspects of the ART field, can be found in the news media. For case study three, my analysis will be based on the discourse in the news media in three destination countries. To confirm the content of the news article, the perspective of the industry players is included in the analysis by supplementing the material through fertility websites. For India and Thailand, the issues and cases revealed within the content of the news articles are important to study chronologically as the story is developing to track the change in discourse and the response of the government. For all three countries, particular attention will be paid to which actors are revealed through these stories and what can be found about them. For Russia, in addition to the news articles on surrogacy, new reports on adoption and some fertility websites will be included in the analysis. This will allow me to compare Russia to the other countries that have already been studied through their website content and to contextualize how the law in Russia impacts the commercial activities. Comparative analysis can be conducted for these three countries for similarities and differences in issues covered, the type of discourse that dominates and the responses or lack thereof of the government to the media attention. 
Critical social science research relies on theory to guide the research design and to interpret the evidence (Neuman, 2011, p. 108). It is a self-reflective form of research with the assumption that there is an objective world underneath the surface. One of the complexities of studying ART is the apparent voluntary involvement of all the parties. For example, contracts ensure consent of all parties and are an important part of surrogacy arrangements. However, consent is not enough to ensure that there is no exploitation or prevention of risks to the women used as egg donors or surrogate and the children born out of these arrangements. An oversimplified perspective on ART that only focuses on consent and choice could easily overlook the cultural and material boundaries that are restricting the options of the women who function as egg donors or gestational carriers. To address the connection between agency and structure, critical social science views human agency through bounded autonomy (Neuman, 2011, p. 111). Bounded autonomy assumes that choices are restricted by a lack of options, or by social structures that are both material and cultural. In a world with unequal control over resources and power, technologies that facilitate the commodification of a class of women for the benefit of an increase in the fertility of more privileged class must question the interests of all the actors and thoroughly explore the ART industry in a critical manner. As a researcher, I am motivated to highlight the global commodification of women and risks associated it. The overall goal is to get a contextual understanding of third-party ART, by looking at the way that the industry represents itself, by outlining the networks and relationships between different actors, and by putting national legislation into context through the use of real life cases involving risky, illegal or controversial ART practices. 


\section{Chapter: Case Study One: Canadian ART Law and Controversies}

\subsection{Legal and Regulatory Framework of ART in Canada}

Some countries have ART-specific laws, while others completely leave the issues surrounding ART unaddressed and unregulated. Among the countries that regulate ART through legislation, Canada, United Kingdom and Australia have similar laws on ART, forbidding commercial transactions in egg donation and surrogacy arrangements through a nation-wide regulatory approach (Nelson, 2013). Given the wide spread of the booming ART industry and the potential of such technologies to address infertility, it is reasonable to question the reasoning behind legal restrictions and regulations on ART. What type of framework does the government rely on to support this approach and how does it impact the way that ART is practiced within the country and transnationally? To study the role of the government in shaping of third-party assisted ART, the Canadian context is used as an illustrative example of a country with a restrictive regulatory framework. The Canadian legislation on assisted human reproduction was drafted to address the concerns raised by society and government on new reproductive technologies. Since 2004, the Assisted Human Reproduction Act (AHRA) prohibits with criminal sanctions several aspects related to new reproductive technologies, including the commercial forms of gamete donations and surrogacy services, allowing only altruistic third-party assisted reproduction to be practiced in Canada. To understand why the Canadian government has chosen this regulatory approach, background information on the development of the policy can be found in the final report by the Royal Commission on New Reproductive Technologies (RCNRT), which gives insight into how the policy problem was defined 
and why the instrument of federal legislation was chosen to address the issue. This information will be used to understand the type of biogovernance involved in ART.

\subsubsection{Framing the Policy on ART}

The legal framework for regulating ART in Canada started with the appointment of the Royal Commission on New Reproductive Technologies (RCNRT) by the federal government in 1989. The commission's mandate was to “inquire into and report on current and potential medical and scientific developments related to new reproductive technologies, considering in particular their social, ethical, health, research, legal and economic implications and the public interest" (Royal Commission on New Reproductive Technologies [RCNRT], 1993, p. 2) and to make recommendations for handling new reproductive technologies. The term 'new reproductive technologies' within this context refers to a broad array of new complex technologies as well as some already existing practices such as assisted reproduction through in vitro fertilization, artificial insemination, gene therapy, genetic alteration, prenatal diagnosis, the use of fetal tissues and embryos, and infertility prevention (RCNRT, 1993, p. 4). The commission engaged in consultations with Canadian organizations and individuals across Canada. About 300 academics and researchers were also involved. The RCNRT claims to have generated 15 volumes of research that accompanies the final report; however, only 13 of these volumes were found in the library. Relying on the feedback from the Canadian public and the results from their inquiries, the RCNRT's final report summarized their recommendations in two volumes titled "Proceed with Care: The Final Report of the Royal Commission on New Reproductive Technologies" in November 1993. In a total of 31 chapters, the final 
report reveals the guiding principles that make up their final recommendations.

Throughout the report, certain themes are recurrent in the discourse, namely collective principles and values, non-commercialization, commodification, social harm, and establishing boundaries. To the RCNRT, the issues around new reproductive technologies are medical and social with both a current and future impact on individuals, groups and Canadian society at large. The RCNRT takes the position that new reproductive technologies have the potential to be beneficial and harmful. In an interview with $\mathrm{CBC}$ News following the release of the final report, the director of the commission Dr. Patricia Braid confirms that the push behind the report is to get the benefits of these technologies, while at the same time "contain the harms and limit and prohibit those things that are in fact going to be harmful to people and to our community" ("The Royal Commission on New Reproductive Technology Reports", 1993). Thus, their cautionary approach balances the benefits of infertility treatment to infertile people and the harms that these new possibilities pose to collective principles and Canadian values. Among these values, non-commercialization, equitable access to services, equality and diversity, responsible use of resources, prevention of harm and the protection of the health and safety of users are listed in the report (RCNRT, 1993, p. 11). In fact, these values are framed as the collective values and attitudes of Canadians, which is also reflected in the feedback from the public that was consulted.

The principle of non-commercialization is based on the idea that the exchange of money and goods in assisted human reproduction commodifies, instrumentalizes, and dehumanizes women and children. Consequently, commercialization in the discourse of the RCNRT is strongly tied to commodification, which is defined as the treatment of 
humans or their bodily tissues as commodities, i.e. when humans or their tissues are seen "as means to an end, not as ends in themselves" (RCNRT, 1993, p. 55). Indeed, commercialization's harmful consequence is commodification. Their ethical framework is embedded in the idea that commodification of human beings threatens human dignity. The RCNRT references the principle of no charge, which applies to blood donation and organ donation in Canada, to make the argument that for the same reasons reproductive material and services should also not become objects of commerce. Throughout the report, market forces and profit motives have negative connotations, as they are tied to the potential to exploit women and children, limit access to health services, and expose women to additional medical risks. The concept of exploitation, while never clearly defined, is linked to the idea that there are individuals and groups in Canada that are more vulnerable and would thus be more at risk to be commercially exploited for corporate interests. Nevertheless, the principle of protecting the vulnerable does not only apply to specific groups, such as people of low socioeconomic status, but also to women in general, children, and patients. The context of health care and medical services is taken into account when profit motives are framed to be in opposition to accessibility, i.e. low cost and equitable non-discriminatory access to health services. Additionally, the RCNRT considers the vulnerability of the patient with respect to the medical establishment. The reasoning is that profit interests would favour the development of fertility drugs and new technology over the prevention of infertility (RCNRT, 1993, p. 389). In sum, for-profit interests would overly medicalize reproduction and consequently, expose women to increased medical risks.

In addition to the new reproductive technologies, the RCNRT was mandated to 
study the prevalence of infertility, possible risks factors, and infertility prevention (RCNRT, 1993, p. 144). The commission conducted three national surveys to discover the prevalence of infertility in Canada, i.e. the percentage of heterosexual couples who are infertile at a specific point in time. Their results showed that the prevalence is $8.5 \%$ for married or cohabitating couples who had not used contraception but had failed to have a pregnancy for at least one year, and $7 \%$ if there was no resulting pregnancy for at least two years. The RCNRT defined infertility as the inability to conceive over a period of time. This data is a reliable estimate of all three national surveys (RCNRT, 1993, p. 180), but it does not include the prevalence of same-sex couples that desire to conceive children through ART. Sexually transmitted infections, smoking, and age are some of the risk factors analyzed in the final report. A whole chapter is also dedicated to adoption; however, the commission acknowledges that adoption is not an easy and accessible option for many infertile Canadians and that the demand for adoption is higher than the number of children available to be adopted in Canada (RCNRT, 1993, p. 359). Overall, the final report advocates strongly for infertility prevention as a more cost-effective and favourable approach than the development of new reproductive technologies. It is clear that the commission took a comprehensive approach to infertility by not only focusing on treatment through technology, but also on the prevention of infertility and alternative methods, which do not contain as many risks to individuals and society.

The topic of egg donation is covered in a chapter on the handling of gametes and embryos. The RCNRT describes egg donation as an invasive surgical procedure that is accompanied by pain, medical risk, and long-term health effects that are largely unknown (RCNRT, 1993, p. 592). Consistent with the anti-commodification argument, payment 
for gamete donation is considered completely inappropriate and unethical. However, there is a strong emphasis on the medical risk that women are subjected through egg retrieval, namely multiple egg induction (i.e., hyperstimulation of ovaries). They consider it unacceptable that a healthy woman would subject herself to medical risks that she otherwise would not be exposed to for the benefit of someone else. For these reasons, the final report states that "egg retrieval exclusively for purposes of donation should not be permissible" (RCNRT, 1993, p. 503). This statement also prohibits altruistic egg donation as it has the potential to be coercive and exploitative. Therefore, only women who are already undergoing invasive procedures either for their own treatment or for unrelated surgery can be in a position to consent to egg donation (RCNRT, 1993, p. 594). The recommendations on the regulation of egg donation in the final report are more restrictive than the prohibitions in the final draft of the law.

In the final report, a whole chapter is dedicated to preconception arrangements, a term used to refer to surrogacy. Compared to egg donation, preconception arrangements seem to be have an even higher potential for exploitation. The discourse is less focused on medical risks and more on the exploitative nature of such arrangements. The RCNRT's own research into surrogacy arrangements showed that there are social and economic disparities between the surrogate mother and the intended parents. Surrogate mothers were found to be younger with less education and of lower income than the intended parents (RCNRT, 1993, p. 593). Based on the RCNRT's research, the standard contract is highly problematic because it puts restrictions on the surrogate's lifestyle and requires her to submit herself to all the tests and treatments requested by the commissioning couple. Additionally, she is only guaranteed the full payment of services 
upon the delivery of the child and must certify in advance that she will not develop a maternal bond and keep the child. The RCNRT believes that contracts are problematic as it limits the rights of the gestational surrogate. Making these contracts legally enforceable in Canada would make the gestational women even more vulnerable in such arrangements. As well, it is highly problematic that some men would be able to make legal claims to women's bodies. The existence of brokers in such arrangements only reinforces the inequality between the surrogate and the commissioning couple. They do not screen the parents and this lack of screening places the child at risk as well. The commercial brokers are defined as intermediaries between the parties (NCRT, 1993, p. 672), but their service-oriented approach favours the interests of their paying clients over the gestational woman. Overall, preconception arrangements are described as “dehumanizing and degrading to women" (RCNRT, 1993, p. 674) with potentially profound effects on children born out of these arrangements. The social harms of surrogacy are the impacts it has on sexual inequality and the perception of women as being reduced to their sexual and reproductive functions. Nevertheless, in an effort to avoid driving surrogacy underground, RCNRT concludes that non-commercial arrangements may be made acceptable (RCNRT, 1993, p. 680). The best option that Canada has is thus to reduce the potential for exploitation, social harm, and abuse of vulnerable individuals, as well as to uphold the best interest of the child. The commission justifies placing limits on the exercise of free choice because it is "fundamentally incompatible with values such as respect for human dignity and the inalienability of the person" (RCNRT, 1993, p. 686).

The majority of the anti-commercialization arguments are focused on the effects 
commodification would have on Canadian society. For instance, market forces and corporate goals are a described as a potential threat to an equitable Canadian health care system. At certain points throughout the final report, there are also some references to the global implications of new reproductive technologies. For example, the commission states that that "the profit motive, taken to its extreme, would lead to a global market in reproductive materials and services" (RCNRT, 1993, p. 718). In an interview on November $30^{\text {th }} 2004$, following the release of the final report, Dr. Patricia Braid acknowledged that infertile Canadian couples could be traveling to the U.S. for reproductive services and pointed out that given the "long leaky border" between the U.S. and Canada, there will be need for Canada to also work in an international forum and to establish international agreements ("The Royal Commission", 1993). The RCNRT thus saw the necessity for the federal government to place limits around commercial interests in the fertility industry on the basis of the protection of the vulnerable as the "guardian of the public interest" (RCNRT, 1993, p. 718). However, the final report provided no recommendations or solutions for the government on how to prevent reproductive tourism beyond the recommendation to prohibit the commercialization within Canadian borders.

Throughout the whole report, the RCNRT places great emphasis on the idea of establishing boundaries around new reproductive technologies in Canada. The RCNRT recommends the policy instrument of federal legislation in order to ensure that some practices and technologies are prohibited under the Criminal Code (RCNRT, 1993, p. 108). They judge that it is the duty of the federal government as the guardian of the public interest to protect individuals and society against the harm caused by inappropriate 
use of reproductive technologies, which would commodify human beings and offend human dignity (RCNRT, 1993, p. 1020). Their first recommendation makes illegal some aspects of ART, including the prohibitions on commercial surrogacy, on the sale of eggs and other research-related prohibitions regarding the use and handling of human embryos and fetal tissues. The second recommendation is to establish a national regulatory and licensing body with the function to manage new technological development and ensure appropriate use of what has been made permissible (RCNRT, 1993, p. 22). The RCNRT provides detailed recommendations on how to establish the independent federal body. For successful implementation of all the recommendations in the final report, consultation and cooperation between the federal and provincial/territorial governments has to be established (RCNRT, 1993, p. 1240). Other federal departments and health care professionals are also considered important partners in the implementation of the recommendations. As a result of these recommendations, the Assisted Human Reproduction Act (AHRA) also called "An Act respecting assisted human reproduction and related research" (Bill C-6, 2004), was drafted and passed in 2004 and a federal regulatory agency Assisted Human Reproduction Canada was created in 2006 to administer and enforce the law. However, a 2010 Supreme Court of Canada ruling reduced the scope of the regulatory framework of the federal agency due to some sections that were deemed as unconstitutional. As a result, Assisted Human Reproduction Canada was wound down in 2012 with the remaining responsibility transferred to Health Canada, which is the current Canadian federal authority for enforcing the AHRA (Health Canada, 2014). 


\subsubsection{The Assisted Human Reproduction Act}

The current version of the AHRA, last amended on September $30^{\text {th }} 2012$, is based on the same principles as the recommendations in the final report by the RCNRT. Among the principles outlined in section 1, priority is given to the health and well being of children and there in an acknowledgement that women are significantly more affected by these technologies than men. In section 1(f), the law explains that prohibitions on the trade of reproductive capabilities of women and exploitation of women, children and men for commercial ends is justified on the grounds of health and ethical concerns it raises. The act uses the similar language and concepts as the final report, reflecting the concerns around commercial use of new reproductive technologies. Surrogates are described as surrogate mothers and the involvement of brokers is referenced indirectly through the term "intermediary" and "person acting on behalf of a donor". The mention of "advertisement" is common in reference to surrogacy services and gamete donation. Early in the act, prohibited activities are listed from section 5 to section 12, starting with the prohibited procedures on human cloning, prohibited use of embryos, sex selection procedures, and the creation of chimeras and hybrids. Consistent with the recommendations by the RCNRT on preconception arrangement, section 6 makes illegal the payment or the advertisement of payment for surrogacy, acting as an intermediary for arranging the services of a surrogate mother and the payment to intermediaries to arrange for such services. This section also clearly specifies that the minimum age for surrogate mothers is 21 years. Section 8 (1) and (2) covers the purchase of gametes and embryos and prohibits purchasing, offering and advertising for the purchase of ova. With respect to reproductive material, there is no mention of intermediaries that arrange services, but 
the expression "a person acting on behalf of a donor" is used instead. Section 8 states the requirement of written consent before the use of reproductive material of that person. The act sets the minimum age for ova donors at 18 years, with the exception when the person wants to preserve their gametes for their own reproductive treatment in the future.

Out of the whole draft, about a fifth of the sections are shaded and thus not in force. Section 12 covers the reimbursement of expenditures, requiring that receipts be provided for reimbursement; however, according to the previous versions of the draft on the Justice Laws website, these provisions in original enactments have not been brought into force yet. The rest of the provisions that are not in effect are on administration and enforcement of the law covered in section 45 to 58 . More specifically, these sections are on licensing and the investigation and prosecution of offences. Over half of the provisions in the draft have been repealed since the first version in 2004. The content has been repealed is largely on the role and responsibilities on the Assisted Human Reproduction Agency in Canada. These sections included information on licensing, sharing of health information and keeping health registries and the ability to be involved in the investigation and prosecution of offences. Nevertheless, the sections on offence and punishment are in force. Section 60 makes it clear that any person that violates the prohibitions, which includes those surrogacy and egg donations, is liable for a fine up to $\$ 500,000 \$$ and $/$ or imprisonment for up to ten years for indictable offences, and up to $\$ 250,000$ or imprisonment for up to four years for summary conviction offences. At the same time while section 8 of the AHRA came into force in 2007, the Assisted Human Reproduction (Section 8 Consent) Regulations (2007) have been introduced as annexed regulations to the AHRA. Divided into three sections, the annexed regulations on the consent that is 
given for the use of reproductive material for creating an embryo, consent regarding the posthumous removal of material, and consent for the use of in vitro embryos for any purposes. There is a strong emphasis on having written consent of the gamete or embryo donor before any use of reproductive material. Regarding gamete donation for example, paragraph 4(1)(c) on written consent states that a person needs to have written consent of the donor before the material can be used for the reproductive use of a third party. In this case, this refers to gamete donation for someone else's fertility treatment.

This research into the reports by the RCNRT and the AHRA shows that the Canadian government relied strongly on an anti-commercialization and anticommodification position to make commercial third-party assisted reproduction illegal in Canada. Their framework relies on the idea of collective principles and societal values, which as we have seen, are sometimes even referred to as Canadian values, to limit free choice if it is an affront to human dignity and the integrity of the person. There is also a negative perception of market forces playing a role in negatively impacting Canadian women and children, as well as a reference to this situation turning into a global industry and that it needs to be prevented through a national policy. The policy problem has thus been framed as a way to manage technology by getting the benefits of infertility treatment but by avoiding significant negative future impact on Canadians. Infertility in Canada is thus seen as a problem that can be managed through prevention and the desire for children can thus be satisfied through altruistic forms of assisted reproduction. The following section aims to look at a more recent and different perspective of the practices in assisted reproduction in Canada. My aim is to discover, decades after the introduction of the law, what type of issues in assisted reproduction are present in Canada, which 
actors are involved, and what types of practice are taking place, given the clear prohibitions in the AHRA.

\subsection{Controversies in Cross-Border ART}

\subsubsection{Grey Market}

Considering the legal prohibition of commercial transactions in third-party assisted reproduction since 2004, it is important to look at the current ART practices in Canada and how it interacts with the law. On one hand, the Canadian government has drafted and passed a law on assisted human reproduction that is overall clear in its prohibition of payment, advertisement for, and acting as an intermediary for egg donation and surrogacy. On the other hand, the media have highlighted some concerns with the lack of enforcement of the law, the existence of cross-border grey markets, and international networks that are in clear violation of the law. The Canadian media reporting on ART within the recent years can be divided into three cases: the grey egg donor market, the Kylee Gilman case, and the case of a Canadian fertility consultant fined for being involved in a baby-selling ring.

The first four news reports reveal that egg donation is still continuing to be practiced in Canada, both within its borders involving Canadian donors and outside of national borders with American egg donors. In 2012, a news article titled "Canadian women flout laws to donate eggs" (2012) revealed that young Canadian women are still selling their eggs in 2012, even though it has been made illegal for many years with the passing of the AHRA in 2004. The university student that has been interviewed by CTV News reveals that her egg retrieval has been conducted in a Toronto fertility clinic for a fee of 5,000\$. 
While the young woman does not regret having undergone the procedure that left her with 24 fewer eggs, the issue raised in the news article is the lack of enforcement of the law that forbids the selling of eggs. It is apparent that there are agencies matching Canadian egg donors with couples and there are Canadian medical clinics and doctors who perform the egg retrieval necessary for the transaction. CTV News identifies that in the federal law, the reimbursement of the expenses is legal but not clearly defined and that the lack of enforcement of the law seems to stem from the 2010 Supreme Court of Canada rule that left the regulation and licensing of fertility clinics under provincial jurisdiction. At the time of this article, Assisted Human Reproduction Canada was still in charge of enforcing the AHRA, yet at this point; no one is known to have been charged for breaking any provisions. Some critics expressed worry about the lack of regulation in the trade of human reproductive material, while others blamed the prohibitions in the federal act for driving the industry underground. According to the media in 2012, there is indeed a grey market in egg donation in Canada despite the legal prohibitions in the law (“Canadian women flout”, 2012).

Less than a month after the first article is published, CBC News reports that American frozen eggs are traveling across the border to be used in Canadian fertility clinics. These American eggs are then thawed in Canadian clinics and implanted into Canadian recipients (“Frozen human egg”, 2012). The cross-border trade is facilitated with the new possibility of cryopreservation, which allows egg banking and transportation across borders without anyone ensuring that there has been written consent. Within the discourse of the article, the 'no watchdog' theme summarizes the critique that is established against the Canadian regulators. In fact, no federal department 
or agency or provincial governments are stepping in to address the cross-border selling of frozen eggs. Similarly to the sale of eggs within Canadian borders ("Canadian women flout", 2012), the frozen transnational egg trade leaves legal "wiggle room”("Buying eggs", 2012) for the industry, due to the lack of provisions on reimbursement of out-ofpocket expenses to gamete donors and surrogates. Egg donation in this article is clearly framed as a business of selling and buying that is completely unregulated and leaves women at risk. CBC News states that it is not clear whether Canadians can face criminal charges when they buy eggs online from American providers. One of the companies that provide frozen eggs to Canadians, World Egg Bank, claims that doctors are not scared of the legislation ("Frozen human egg", 2012).

On the World Egg Bank website (http://www.theworldeggbank.com/), the company claims that that donors can be compensated from $\$ 2,500$ to $\$ 5,000$ US. According to CBC News ("Frozen human egg”, 2012) clients however pay up to \$12,000. Egg banking companies, just like any other agency providing fresh egg donors, are thus intermediary actors between the women who donates eggs and the intended parents. The clients have the option of selecting for physical traits, blood types, education level, medical history, ethnicity and talents, among other characteristics. World Egg Bank provides an electronic catalogue of egg donors that contains adult pictures of some of the women from whom the eggs are retrieved for sale. About two decades after the final report by the RCNRT that intended to prevent commercialization and commodification of women's reproductive material, the media reveal that Canadians are involved in the commodification of women's gametes ("Frozen human egg", 2012), when they engage in the commercial transactions through these types of online companies whose business also 
caters to a Canadian clientele.

In an embedded video interview to the CBC article (“Frozen human egg", 2012), a reproductive lawyer emphasizes the confusion around the legality of buying eggs in the way that the law was initially drafted ("Buying eggs", 2013). While Canadians are not allowed to pay a surrogacy agency to arrange for services, fertility lawyer Sherry Levitan states that there are no prohibitions on paying an egg donor agency in the law. To confirm Levitan's statement, I reviewed the AHRA sections on egg donation. In the AHRA, section 6 contains prohibitions on "acting as intermediary" and "payment to intermediaries" for surrogacy services. For gamete donation, section 7 paragraph 1 states that no person shall purchase "from a donor or a person acting on behalf of a donor" (Bill C-6, 2004). The lack of mention of 'intermediary' actors seems to cause confusion, even though agencies can be said to be acting on behalf of the egg donor. It is unclear why the law does not repeat the same specific prohibitions regarding intermediaries for egg donation, as it does for surrogacy arrangements. It could be that the risk of exploitation of surrogates through brokers has been estimated to be higher than that for egg donors by the RCNRT back in 1993 in their final report. The RCNRT's lack of clear foresight of the role of brokers in egg donation seems to be a mistake on their part as the grey egg donor market is attracting public attention.

The controversy on the grey egg donor market in Canada revisits the media in March 2014 in an article titled "Canadians pay egg donors on the grey market" (2014). According to $\mathrm{CBC}$ News, an investigation revealed that some fertility clinics are circumventing the law by referring infertile people to agencies in the U.S. who then send their donors to Canadian clinics for retrieval. The example of a Missouri woman is used 
to show that she was sent to Canada to donate eggs for $\$ 6,500$ in a confidential commercial transaction that left no paper trail. The article confirms that there is a growing demand for egg donors in Canada and that this demand is filled by the crossborder trade. Depending on whether the transaction was made abroad or in Canada, they may necessarily not be violation of the law. As confirmed by this news report, not only are frozen eggs traveling from U.S. to Canada, but women are also flown into Canada to meet the demand in the Canadian market. Overall, these news reports reveal that the egg donation transactions involving Canadian donors are confidential and that cross-border egg trade is happening between American and Canadian agencies and clinics. This trade involves either the travel of American women or the transport of frozen eggs into Canada from American egg donor banks.

\subsubsection{The Kylee Gilman Case}

In 2013, one egg donation case involving an American egg donor and a Canadian fertility clinic received media coverage. This particular case highlighted some of the health risks associated with cross-border ART. Kylee Gilman is a young egg donor from Florida who donated her eggs in a Toronto fertility clinic and suffered serious health consequences as a result of the egg donation (Motluk, 2013). She filed a lawsuit for alleged negligence against both the doctor who performed the procedure and the U.S. egg donor agency who referred her to the Canadian clinic. The donor claims that Dr. Ryan from the Toronto West Fertility Centre prescribed too much medication, which caused her to feel ill right after the egg retrieval. When she returned to Florida within the same day as her procedure, she continued to feel ill but alleges that she did not receive 
adequate advice from the doctor. Eventually, she was taken to a hospital where she suffered a stroke and was diagnosed with severe OHSS. During the 10 days of her stay in the hospital, she had fluid drained from her abdomen, she was treated for acute kidney injury and she received blood transfusions. She claims that she has lost complete feeling on the right side of her body. The details in Motluk (2013) reveal that she was paid $\$ 5,500$ by her agency, Giving Hope, for her anonymous egg donation to a Canadian couple.

Motluk's (2013) report framed this case as a form of medical negligence. However, an American news report by Schindler (2013) provides a different perspective and better context to the Kylee Gilman case. This report from First Coast News focuses on the danger to the U.S. egg donors as a result of the "cross-border black market" (Schindler, 2013, para. 1) between the U.S. and Canada. Fertility experts reveal that her excessive response to the stimulation should have lead the doctor to cancel the procedure. Even though he was aware the production of eggs was above normal levels, he did not stop the egg donation procedure. This raises question about why the doctor did not cancel the cycle, as it would have been best medical practice. The article hints that the problem is due to the travel requirements. The egg donors are stimulated and sent back home on the same day, without proper follow up medical care. The medical environment for the egg donor that travels to Canada is suboptimal.

The Kylee Gilman case raises several concerns with cross-border egg donation. First, an unusually high amount of eggs were retrieved from the donor, which lead to OHSS. According to medical experts, the optimal number is 15 eggs, but Kylee responded strongly to the drugs and produced 45 as a result. The high production of eggs in her 
ovaries put her at significant health risk. Given these points, there seems to be negligence by the doctor in proceeding with the retrieval despite the health risks to the donor. Second, the conditions around this cross-border arrangement between the CReATe, the Toronto fertility clinic, and Giving Hope, the egg donor agency whose headquarters are in Dallas lead to the negligence of the woman's health. The agency functioned as a broker to assure her payment, while the clinic functioned as an egg retriever to assure that the intended parents received their egg donation. None of these intermediary parties between the donor and the intended parents put the donor's health as a priority. She was allowed to leave the clinic right after her donation and to fly back home within the same day. The egg donor indeed was not treated as a proper patient in this case, as her primary role was to produce enough eggs for the doctor's patients, i.e., the intended parents. Finally, it can be concluded that the medical ethics in cross-border ART are not adequate to ensure the protection of the egg donor. The egg donor is not the focus and the recipient of care. The primary goal by the fertility clinics is to provide infertility treatment to someone else. There have been no subsequent news reports on the Kylee Gilman case. Jennifer Lahl (2014) from the Center for Bioethics and Culture (CBC) Network explains that the civil case against the doctor and the agency has been settled. It was a confidential settlement, which prevents the egg donor from sharing any information about the settlement and leaves the public uninformed about the dangers to women's health in egg donation. The Toronto West Fertility Center clinic website (http://www.torontofertility.com/index.html) shows that the doctor is still practicing. Under fertility services, the website lists both anonymous egg donation and surrogacy as options that they offer to the clients. Since no prices for those services are included, it can 
easily be assumed that those are altruistic surrogacy and egg donation arrangements as permitted by the AHRA. However, the Kylee Gilman case showed that the "Anonymous Dedicated Egg Donor", as listed on their website, is more likely be an American egg donor that is paid for her services than altruistic anonymous egg donor. Giving Hope Inc still advertises its 900 egg donor database on its website (http://www.givinghopeinc.com/) and recruits more donors through their egg donor application form. The AHRA's only role in this case was to prevent Dr. Ryan from receiving insurance coverage due to breaking the law (Lahl, 2014).

In summary, the cross-border egg trade is facilitated by Canadian clinics and American agencies. While the American egg donation agencies are not breaking their state laws when they engage in this cross-border trade, the Canadian doctors and medical staff that is involved in this business is in contravention of the AHRA. This obviously raises many issues about the lack of enforcement of the law. The clinics do not openly advertise on their websites that egg donation and surrogacy programs are offered for pay, as advertisement for such services is forbidden. However, some clinics are clearly establishing cross-border connections with American agencies to offer commercial egg donation services. Even under an anti-commercialization law, some Canadian fertility clinics are operating as part of the international ART industry network without any charges being raised against them.

\subsubsection{Canadian Baby-Selling Consultants}

In December 2013, Canadians saw the first prosecution under the AHRA (Blackwell, 2013). Leia Picard and her company, Canadian Fertility Consultants (CFC) received a 
$\$ 60,000$ fine for federal offences. Picard pleaded guilty for paying five women to donate eggs and three women to be gestational carriers. She is said to have recruited the surrogates through online classifieds such as Craigslist or Kijiji for a flat fee of $\$ 24,000$ and added bonuses for carrying twins or undergoing a Caesarian section. She also pleaded guilty for her involvement in an international baby-selling surrogacy ring. For a fee, she referred Canadian intended parents to Hilary Neiman, a Maryland reproductive lawyer, who was arranging Ukrainian surrogates to be impregnated before a preconception agreement was made with any potential parents. Neiman was running a baby-selling business that involves many egg donors and surrogates at a time. There was no preconception arrangement between the intended parents and the surrogate. The unborn children were sold to potential parents when the surrogate was at her second trimester. The parents were told that the original intended parents backed out of the agreement with the surrogate and that they had the option of getting the child for a fee around $\$ 130,000$ to $\$ 150,000$. Even though it is called a baby-selling ring, the connections between the different parties involved is linear with the gestational surrogates on one end in Ukraine and the intended parents on the other end of the commercial transaction in Canada. Figure 1 represents how the different actors involved in this ring were connected in the baby-selling network. Note the placement of intermediary actors between the intended parents and the surrogates and egg donors, and the geographical distances between these two. 


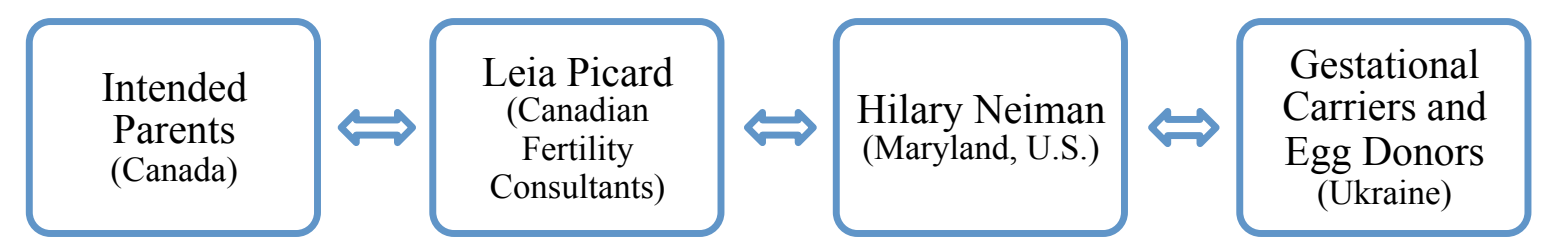

Figure 1 International Baby-Selling Surrogacy Ring

There was no agreement between the surrogates who carried the babies and the parents who got custody when they were born. The only factor that mattered and that travelled through the network was money. The network in Figure1 emphasizes that the brokers are placed in the middle between the intended parents and the surrogates. This cross-border case did not only involve Canada and U.S., but also a surrogacy business in Ukraine. One aspect of international ART industry is the ability to divide the labour across different countries in order to get the maximum profit and to find the best conditions where such unethical businesses can take place without oversight. It has been concluded that Picard was not aware of the true nature of Neiman's business when she referred Canadian couples to the American lawyer (Blackwell, 2013). The risks of international networks such as these is that one party cannot be fully aware of how the surrogacy arrangements are made and whether or not there are illegal or unethical 
practices happening at the other end of network. In Blackwell's (2013) article, a connection is made between this case and Canada's lack of regulation with respect to ART, the lack of clear rules and the lack of comprehensive regulation by Canadian authorities. Again, Health Canada is called out for needed to pass clear regulations on reimbursement of expenses.

On the Health Canada website (Health Canada, 2013a), it is clearly stated that under section 7 of the AHRA, egg donations cannot be bought. Similarly, Health Canada clarifies that paying for surrogacy is illegal either directly to the surrogate mother or through another person (Health Canada, 2013b). Health Canada also makes reference to third parties like fertility clinics that are involved in matching intended parents with surrogate mothers. These third parties are prohibited from hiring the surrogates for a fee and making indirect and disguised payments. As the review of the news articles has revealed, the provisions related to commercial surrogacy and egg donation are not enough to prevent the commercial trade of women and children. Stricter enforcement must be conducted and clear regulations must be enacted to uphold the principles of the Canadian law.

My review of the news articles revealed that Canadian doctors and fertility clinics are circumventing the law that prohibits commercial forms of egg donation and surrogacy. It is particularly egg donation that seems to pose a challenge to Canadian egg donors as there are travelling egg donors from America and frozen egg banks that provide the supply that is missing in Canada. The media has identified the lack of enforcement by the Canadian government as a major factor in the grey egg donor market. Additionally, I was also able to identify some of the risks associated with egg donation through this review. 
For instance, there is a risk that travelling egg donors do not receive proper patient care by Canadian doctors. It is not only the circumstances around the travel and the underground nature of the egg donation procedures that lead to this lack of patient care. It is also the way that the commercial aspect of the ART industry favours the paying customer, i.e. intended parents. For example, there is tendency to extract a high number of eggs in order to ensure success rate for the intended parents. Egg donors are thus being put under health risks as a result of the consumer-oriented ART environment. Lastly, the review of the articles showed that cross-border networks with the U.S. are easily established across the world and involve reproductive lawyers and consultants. These actors have not been fully researched in the literature on ART. In fact, their role in crossborder ART is not well understood. My review has shown that these actors are functioning as brokers at different levels, some more directly connected to the egg donors and surrogates than others. Therefore, reproductive consultants and lawyers can be involved in this type of international networks of exploitation of women. Another high risk identified in this review is the possibility, through ART, of creating children before there is even a guarantee that they will have parents upon birth. The use of ART for such purposes is highly problematic as the children are sold to the highest bidders and undergo the risk of being trafficked or abandoned.

\subsection{Conclusion and Theoretical Reflections for Case Study One}

The research conducted in case study one shows that the biogovernmental framework in Canada is supported by anti-commercialization and anti-commodification arguments. The legal prohibitions in the Canadian law specifically ban commercial forms of egg 
donation and surrogacy due to the risks of letting the private ART industry flourish in Canada that the RCNRT has identified in their final reports. The law has not been strongly enforced, but the existence of the law still prevents Canadian agencies and clinics from advertising themselves as international destination places for ART. Nonetheless, given the lack of enforcement of the law and the challenges posed by the cross-border ART networks, the ART industry is still operating in Canadian fertility clinics.

It is interesting to note that Canadian policy makers have identified the risks associated with neo-liberal ART policies to values of equity and accessibility of the Canadian health care system. Collective principles were put above the neo-liberal values of choice and the right to have ART services at all cost. The prohibitions on commercial third-party assisted reproduction have been justified on accounts of the protection of children and women from exploitation and harm. This has been a good step in preventing Canada form becoming an international destination country for reproductive tourism. However, the global ART industry is still able to cross borders either from the U.S. side or other locations in the world. International networks are able to infiltrate countries like Canada as long as there are other locations where women can be recruited as surrogates and egg donors and where the industry networks can function due to a lack of regulations or enforcement of such regulations. 


\section{Chapter: Case Study Two: An International Network Group in Third-Party Assisted Reproduction}

\subsection{New Life Global Network}

\subsubsection{The Global Spread}

The second case study takes a closer look at one important intermediary actor between the intended parents and the egg donors or surrogates: the fertility agencies and clinics. The ART industry is an important actor in shaping the global patterns of reproductive tourism and the availability of services that are offered to infertile couples. I am interested in an international network that is not limited or constrained by national borders or geographical distances and whose services are easily accessible through the Internet to interested infertile couples from a Western country like Canada. The case study is thus based on the New Life Global Network, a network composed of a group of fertility centers operating in many countries but whose head office is in Georgia. The goal is to use all the New Life Global Network websites to discover the pattern of crossborder ART by tracking the connections between the websites, by looking at the content of prices and services offered, and by looking at the discourse that is used to describe the services, the surrogates, and the egg donors. The analysis will answer the following research question: What can be learned about the ART industry from the international ART agencies about the way that the legal, social and ethical implications are handled? More precisely, this case study will help me to gain an understanding of how ART industry influences the global pattern in ART travel and how their operations are influenced by the local laws. It will provide insight into the egg donation programs and 
surrogacy programs to discover what determines the availability of certain women as egg donors and surrogates.

The New Life Global Network was founded by Dr. Mariam Kukanashvili, a member of the European Society of Human Reproduction and Embryology, in 2008 in Georgia. The network has been extended since then and operates currently in eight different countries, each of which have their own New Life branch and website. My research path is reflected in Figure 2. It shows the different branches and websites in the network and how they are linked to each other. From my own research, the most accessible of their websites was the Indian branch and the New Life Egg Donors websites. This network provides a wide variety of services including surrogacy, egg donation programs, cryopreservation, and other standard fertility treatment like in vitro fertilization (IVF) and intra-cytoplasmic sperm injection (ICSI). Depending on the branch, they might also offer sex selection services through preimplantation genetic diagnosis (PGD). The network even caters to same-sex couples, LGBT, single and HIVpositive parents in some of the branches. They advertise that their clientele comes from Australia, UK, India, Europe, Canada, U.S. and Japan, but they also cater to local customers. The network group operates fertility clinics in some destination countries in Eastern Europe, South Asian and other key destinations. However, for those countries where they have not set up their own branches, they might also partner up with some local clinics and doctors and only function as facilitators between the intended parents and the partner clinic. The variety of options of where the intended parents can have their fertility treatment is advertised as an advantage of this network. This reflects their international clientele. The availability of a large database of European and Asian egg 
donors and of the surrogates that are available worldwide seems to be a selling point that is consistently emphasized throughout all their websites.

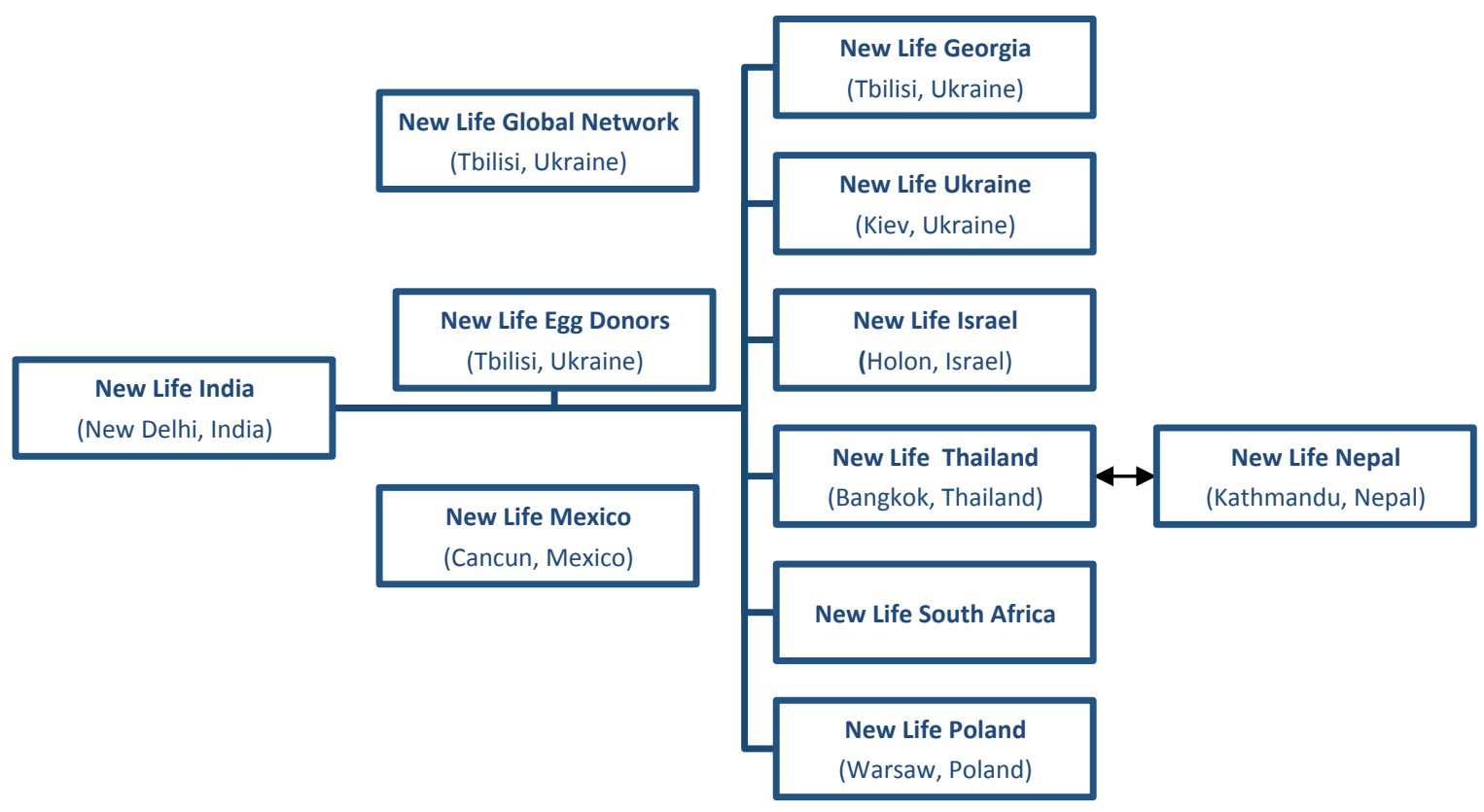

Figure 2 How the New Life Global Network websites are connected through embedded links

\subsubsection{ART Destination Places}

The first website that I discovered from the New Life Global Network is New

Life India (www.newlifeindia.com), which has connected me directly through an embedded link titled "Caucasian Egg Donors" to a website called New Life Egg Donors (www.newlifeeggdonors.com) and a couple of other New Life branches in Georgia (www.newlifegeorgia.com), Ukraine (www.newlifeukraine.com), Israel (www.newlifeisrael.com), Thailand, South Africa (www.newlifesouthafrica.com) and Poland (http://www.newlifepoland.net/). The branch in Mexico 
(www.newlifemexico.net) was not directly linked from any of the other New Life websites, but was discovered when it was mentioned on New Life South Africa (www.newlifesouthafrica.com). New Life Thailand was available and advertised as the newest branch of the network when I first accessed it in February 2014, but it is currently renamed to New Life Nepal, as last accessed in November 2014. All links to Thailand now lead to New Life Nepal (www.newlifenepal.com). In a blog post on New Life Nepal, the opening of the new branch was announced on October 24, 2014, making Nepal the newest addition to the network according to this announcement. New Life Global Network, the parent organization of all the branches, also has its own website (www.newlifglobalnetwork.com) that was not directly linked from any of the other branches. The New Life Global Network website lists their branches in Georgia, Ukraine, India, Mexico, South Africa, Poland, Israel, Thailand and Nepal. They even announce that some upcoming branches might soon be opening in China, South Korea, Japan, Brazil, Argentina, Egypt and various locations in Europe that are not specified. The branch in Georgia is referred to as the "global headquarters of the illustrious international surrogacy provider" (New Life Global Network, n.d.); however, they clarify that only legally married couples are allowed ART services in Georgia. Since 1997, gestational surrogacy has been legal in Georgia for heterosexual couples. Georgian law makes the country a perfect location for surrogacy services because the surrogate mother is not registered as a parent nor is her consent required to register the commissioning couple as parents. This means that the gestational surrogate has no legal basis to make any claims to the baby after delivery. In addition to the favourable regulations, Georgia is an advantageous location because the services are cheaper than in the U.S. and the rest of 
Europe, and young and healthy women are available as egg donors and surrogates.

Georgia is hailed as the most favourable destination for married potential parents with a convenient location, European standards of care and modern infrastructure. New Life Ukraine is also described as a cost-effective place for international surrogacy. New Life India is described as the only European-owned clinic in the country. It offers surrogacy services and egg donations from Indian or Caucasian donors. For the branch in Poland, emphasis is put on the comprehensive database of young and healthy Polish egg donors that are ready to travel to the destination of the intended parents.

The branches in Thailand, Mexico and Nepal are offering a larger range of services to local and international clients, including programs for single, LGBT and HIVpositive intended parents. Additionally, New Life Thailand offers sex selection through PGD. New Life Israel is also LGBT and single parent friendly branch. New Life South Africa is the only branch that does not cater to international customers, as it is prohibited by law for foreign nationals to get infertility treatment in the country. Nonetheless, South African intended parents are invited to get surrogacy services from outside of the country. New Life South Africa offers them traveling surrogate mothers, from Georgia, Thailand or Ukraine, who only need to come to South Africa once for embryo transfer. The surrogates will then spend the gestational period and will birth the baby in their native country.

\subsubsection{The Situation in Thailand}

On New Life Global Network, a section titled "The Thailand Fracas” informs the reader that the closing of the in vitro fertilization clinics in Thailand and questioning by 
the government of ongoing surrogacy cases were caused by the change in the regime following the military coup (New Life Global Network, n.d.). New Life Global Network claims that this has had a devastating effect on the intended parents with surrogate-born children in Thailand, forcing them to be stuck on the borders. Nevertheless, Thailand is still mentioned as part of their network, in addition to Nepal, even though the New Life Thailand website has been taken down. It is not clear whether the Nepal branch has opened as a direct result of the Thailand branch being forced to close or whether Nepal is simply a new addition and the Thailand branch is waiting to see how the situation in Thailand will develop. The other branches mention Thailand on many occasions as a location where the customers can get unique and special services. For example, New Life India refers its single and LGBT customers to their Thailand branch for egg donation and surrogacy services. In India, the requirement for intended parents to get medical surrogacy visas instead of tourist visas limits the services that are offered to only heterosexual couples who have been married for at least two years. This requirement is clearly explained to the visitor under their 'Legislation' section on the New Life India website (New Life India, 2007a). Yet, New Life India still advertises on its website that it is "LGBT Friendly", even containing a picture of a gay couple with a baby, and has a "Gender Selection" section that contains nothing but the statement that it is illegal and not available in India. Based on my research, this advertisement is there because it assures the customer that they can get those services offered under the New Life Global Network in another branch where the laws are more lenient. The customers can be referred to a branch where these services are offered, while at the same time the network is abiding by the local laws on ART. This network allows flexibility and easy virtual 
cross-border movement between the different locations. New Life Georgia as well refers single parents and HIV positive men to Thailand. Gay couples are referred to both their Thailand and Mexico branch. Similar to New Life Thailand, New Life Nepal offers programs for HIV-positive patients. It is unclear whether PDG for sex selection is permitted in Nepal. The process is described but it does not explicitly state that it is a legal procedure in Nepal and that the gender selection service is offered to clients.

The network itself highlights Thailand as a unique branch. It appears that Thailand's uniqueness is due there being a lack of laws governing surrogacy arrangements. It is on the New Life South Africa website that customers can learn that in Thailand "surrogacy is widely practiced and tolerated by the local government" (New Life South Africa, 2012a). However, the site clarifies that there is a draft bill on surrogacy that has emerged in 2007 but has not yet been approved by Thai authorities. This situation with New Life Thailand shows that fertility networks such as these take advantage of a country's lack of laws on ART. If there are no explicit legal prohibitions, then it is assumed that the business can operate in the country at least temporarily until a bill is approved and enforced. If the situation changes in that location, the network can opportunistically move to another country where there is a lack of state oversight and a lack of legal prohibitions.

\subsubsection{The Influence of Legal Prohibitions}

Almost all of the branches provide information on the country's legislation and how it affects the services that are offered. There are ways that the agency gets around some of the limitations set by the local laws. One interesting example is New Life 
Mexico. The corporate location of the branch is in Cancun, Mexico, which is also the place where IVF is performed. However, on the legislation section of New Life Mexico's website, the state of Tabasco's civil code is quoted even though the city of Cancun is in the state of Quintana Roo. Tabasco law makes the contracting parents the legal parents on the birth certificates in surrogacy cases, even when an egg donor is involved. Additionally, the civil code does not discriminate based on sexual orientation or marital status of the contracting parents. For these reasons, New Life Mexico refers to the state of Tabasco as "one of the safest global destinations for gestational surrogacy" (New Life Mexico, 2013). It is understandable then why New Life Mexico makes its surrogates give birth in a different state, as it benefits the contracting parents to have their names instantly on the birth certificate. This example illustrates how the fertility service providers can work around the state laws to best accommodate the intended parents. It also highlights the importance of the birth certificate, as it is more convenient for the intended parents.

Another example is legislation regarding surrogacy in South Africa. New Life South Africa explains that since 2010, South Africa's Children's Act “protects the rights of the children as well as highlights the responsibilities of the intended parents and the surrogate mother" (New Life South Africa, 2012b). Following this statement, all the requirements for surrogacy arrangement are listed. The following are some of the interesting requirements: the surrogate mother needs to be a South African resident; she cannot be involved in commercial surrogacy arrangements; intended parents need to have medical proof of need for surrogacy services; the parental rights must be relinquished from the surrogate to the intended parents through a court order before the embryo is 
transferred to the surrogate mother. One would think that these specific requirements would make South Africa a bad location for a fertility for-profit agency that offers surrogacy services. Yet, New Life South Africa gets around the law by offering to South Africans their surrogate mothers from countries such as Ukraine, Georgia and supposedly Thailand, although that last option is likely to not be available in the future. It remains to be seen whether the references to Thailand will be updated on their websites. As a result of the country's legislation, the South African branch is not advertising to international clients nor is it recruiting surrogates from South Africa. Their focus is on encouraging egg donor candidates to apply and join their egg donor database. Overall, New Life South Africa can offer the same surrogacy and egg donors services just like any other of their locations despite the restrictive legal requirements and the specific prohibition of commercial surrogacy arrangements.

\subsubsection{The Ambiguous Sex Selection Ethics}

Nevertheless, there are instances when it is not clear whether a service is being offered in that particular branch or not. This is especially true for sex selection services. Sex selection is explained often under the banner of 'gender selection' on most of the New Life websites. For India, the only statement available in this section is the ban on sex selection by Indian law and thus the fact that such services are not offered in the Indian clinic. On New Life Georgia, sex selection is listed under the services menu and a lot of content is provided in this section. It covers the risks, the different techniques for sex selection, historical practices of sex selection and the ethical considerations. It is not their own position on the ethics of sex selection that they cover; rather it is a summary of 
some of the ethical issues with sex selection raised generally by others. In this section, they reference the bias towards the male sex, the risks associated with PGD for selecting against specific traits in general, and the lack of a $100 \%$ guarantee that the procedure will select for the desirable sex. They claim that this could cause psychological harm to the children and the parents if the resultant child is not of the right biological sex.

Nevertheless, their position and policy with respect to this ethically controversial practice is ambiguous. They do not explicitly state whether this service is offered in the clinic, but they acknowledge that "some families want to use this technique to obtain a gender balance among the kids" (New Life Georgia, 2008a) and then they list their criteria for the procedure. For example, the couple should already have a child of a gender opposite to the one they are requesting.

We can learn by reading carefully that prenatal selection through the termination of pregnancy is not offered in the Georgian clinic. According to New Life Georgia, PGDbased sex selection is legal in most developed countries. Contrary to the confusing information that is offered on New Life Georgia, New Life Ukraine provides a clear statement in bold that sex selection is legal in the country. New Life Mexico contains the generic information on sex selection without specifying whether the services are offered in the Mexican clinic or not. New Life South Africa and New Life Poland completely leave out any references to sex selection on their websites. New Life Israel has the clearest information on their sex selection services. From the New Life Israel website, it states that sex selection is only available in Ukraine for family balancing, while Georgia only allows sex selection for medical reasons. New Life Thailand used to advertise sex selection on the website when it was functional, yet on the current New Life Nepal 
website, no clear statement is made. Regardless of where these ethically controversial services can be offered, the network group certainly aims to offer this option to its customers when it is available on the basis that it helps the intended parents to balance the sexes in their families. It is reasonable to conclude that their ethical position on sex selection is one that is based on providing the services that their clients desire, as long as it is for the purpose of balancing the family or for medical reasons. If the law does not permit it in one location, then the customer can be referred to a sister clinic in another country.

From the locations of the branches, it can be seen that New Life Global Network operates opportunistically in places where the laws are favourable for third-party assisted reproduction and where there are women who are available to enter their pools of egg donors and surrogates. The location of the intended parents is not a defining factor for the locations of the branches, since both egg donors and surrogates can travel to any location as required and the intended parents can get all their arrangements done online and their contracts signed electronically. There is currently a higher presence of the network in Eastern Europe and South Asia than in any other places of the world. However, there is no reason for them to limit themselves to those parts of the world, as long as the laws on surrogacy and egg donation are favourable to their operations. Destination countries for surrogacy and egg donation are made through government policy and the opportunistic ambitions of ART industry players who can easily move from one nation to another or circumvent the legal restrictions through cross-border arrangements. 


\subsection{Egg Donations}

\subsubsection{Value, Quality and Choice}

New Life Global Network recruits its own egg donors and surrogates. Their clinics do not work through a third-party agency. They have a variety of egg donors of various ethnicities whose profiles are stored in an egg donor database. They specifically mention Ukrainian, Georgian, Asian, Estonian, Mexican, Indian and American egg donors. They recruit egg donors even from countries where they do not have a branch. They provide travelling donors that can be sent to any country for egg donation as requested by the intended parent and frozen eggs that can be shipped anywhere, which are a cheaper option. Potential egg donors are recruited through some of these websites. There are some program qualifications for the candidates listed on the New Life Egg Donors website such as an age range of 18 to 30 years old, being a healthy non-smoker with no sexually transmitted infections, having no psychological disorders and being within a normal range of height or weight. The candidates can apply through New Life Egg Donors by filling out the online application form and submitting five photos. The next stage of the screening process is an interview. The egg donor candidate will also have to undergo medical and psychological pre-screening tests before she can be registered in the database. The medical procedures and the risks are explained to the potential candidates. The agency recruits its candidates by appealing to the possibility for these women to be compensated to travel all over the world. It is surprising that the travelling requirement is an advantage and a selling point. All their travel logistics and visa requirements are taken care of by the agency. She will be accompanied by a staff member referred as 'chaperone' throughout her stay in the foreign country. More than 
any other branch, New Life South Africa aggressively emphasizes the opportunity to travel. The first sentence that can be read through the "Become an Egg Donor" link that is available on the main page is: "Become Egg Donor at New life South Africa and Travel to Various Interesting Countries!" (New Life South Africa, 2012c). During the week of the visit, the egg donors have the opportunity to get new pleasant experiences and enjoy the sightseeing that the agency has scheduled for them. The blog section of New Life South Africa shows travelling donors in different countries and having a good time.

Nevertheless, it is not all about the travelling. The candidates are informed about the egg donation process and the importance of the contract. After the screening, the normal cycle of the egg donors will be stopped through the use of birth control pills to get it synchronized with the recipient, which can either be intended mother or the gestational surrogate. Then, three different classes of hormonal drugs will be used to stimulate egg production. And finally, a surgical procedure is performed to retrieve the eggs. On New Life Egg Donors, the egg donor compensation is estimated to be around 1500 to 2000 USD depending on their location and history of previous donation.

\subsubsection{Caucasian Egg Donors}

Throughout all the websites, the visual analysis reveals a predominance of white families and white babies in the images on the websites. Even on New Life India, the images show happy white families and children, mostly blond. These images are only for advertising purposes and are not their real clients. This could reflect the agency's attempt to appeal to a primarily Western or white clientele. However, the blog shows pictures of 
their clients (intended parents) of a variety of ethnicities. To understand why whiteness is advertised visually, I analyzed the textual discourse for any reference to race or ethnicity. The analysis reveals some racialist terms. On New Life India, "Caucasian donors" are listed as one of the advantages that distinguish the clinic from others. An assumption can be made that this refers to their unique advantage in offering Caucasian donors compared to other local Indian clinics that offer only Indian egg donors. Being an international network, the "patients/parents have the unique opportunity to choose egg donors not only from Indian origin, but also from Caucasian egg donors who are able to travel from our Georgia and Ukraine clinics” (New Life India, 2007b).

Given that the headquarters are in Georgia, the term Caucasian is used accurately when it refers to the egg donors from Georgia. They even explain in a travel section that Georgia is located in the Caucasus region. However, the term is also used in a general sense to refer to white-skinned European donors, enclosing all the other Eastern European donors within the same term. In this sense, the Slavic Ukrainians and Poles also become 'Caucasian' when advertised on New Life Global Network websites as egg donors. In addition to the Caucasian category in egg donation, there are also the Asian egg donors and egg donors banks. The Asian donor group includes egg donors from India and Thailand. Geographically, the egg donors are located as coming from primarily two regions: the Caucasus and Asia. These two locations are thus important geographical areas of egg donors availability and even desirability. If one looks at the availability of all the websites in English and the visual representations of white families and babies, the global network seems to be targeting a Western white clientele. Their egg donors are able to travel worldwide to accommodate its clientele, but the egg donor pools are localized in 
Eastern Europe/Caucasus and Asia. Surrogates are also localized in the same area, but their ethnicity is not advertised to such an extent. What matters for surrogacy services is the legal framework on surrogacy in that particular country. The value of the so-called Caucasian egg donor is extolled by the agency itself. On New Life India, the price for an egg donation program increases by 10,000 USD if the customers desire to use Caucasian instead of Indian eggs. No explanation is provided for the difference in cost besides the following statement which shows that it is based on the desires of the clients: "New Life network understands that you may need a Caucasian egg donor to meet your requirements, so we have a joint program with our New Life Ukraine and Georgia agencies" (New Life India, 2007c). This is a steep increase in cost for the intended parents just to get a different type of genetic material. The cost is not only based on perceived genetic material, but also the ability to choose. On New Life Georgia, we learn that "since choosing which donated eggs to use is possibly the most important part of assisted reproduction, many couples wish to receive as much information as possible about their prospective egg donor" (New Life Georgia, 2008b). The availability of a 300egg donor pool is appealing to the intended parents, as they can make this important decision by sifting through the catalogue of what will make half of the genetic material of their baby. The intended parents are thus paying to be able to choose the right egg donor. An interesting case of a child born through third-party assisted reproduction is found in one of the blog posts from New Life India, posted on October 17, 2014, titled "Miracle in Australian Family". New Life India posts:

Nine months ago, Caucasian Egg donor traveled in India for egg donation, and now we got the amazing result of our joint efforts. On this week Australian prince was 
born in New Delhi. This baby has brought an unimaginable joy into their family life and they said many thanks to our staff. (New Life India, 2007d)

In this case, the birth of an Australian baby was the outcome of a Caucasian egg donor and an Indian surrogate. The boy is already given its national identity from its Australian parents, whose faces are blurred in the pictures to protect their identity. The mixture of nationalities is illustrative of cross-border reproductive tourism with its division of reproductive labour. Eastern European eggs and at least one Indian womb have worked for the outcome of a child that will return to Australia with its intended parents. This is an example that illustrates how third-party assisted reproduction at the global level is often manifested in locations such as New Delhi where the local women can be commissioned by Western clients for gestational labour and Caucasian women can be flown in from Eastern Europe for their unique and valuable ova. This example also shows the convenience of the traveling donors. It allows the intended parent to have a preference for a Caucasian egg donor, over a local Indian donor. The egg donor is labeled a 'Caucasian egg donor' without any specific reference to where she is from or whether she really is Georgian or not. Her identity mattered when she was being selected for, but after the donation was accomplished, her contribution to the resultant child's life and identity is fully reduced to the fact that she had Caucasian eggs. Regardless of the donor's native country, the intended parents had to pay extra to get donated eggs from the non-Asian category of egg donors. 


\subsubsection{Egg Production and Egg Sharing}

The egg donor's value is directly connected to the eggs that she can donate. Her education level, physical appearance, accomplishments, healthy, genetics and any other characteristics that parents might want to select for do not matter unless she is able to produce good quality eggs for donation. Any reference to egg donors is associated with youth, production and quality. The success rate of an egg donation program depends on the youth of the egg donor and her capacity to produce good quality eggs. Even though the donors seem to be taken care by the agencies and the chaperones, this whole process exists to make sure that it leads to the ultimate goal - retrieval of quality eggs. This is also visually represented by pictures of babies hatching out of eggshells. There is a close link between the egg as a product and the baby as the outcome. The language of production is reflected in the reference to the harvesting of the eggs during the egg retrieval procedure. The ability to produce in abundance is valued by the agency. For example, New Life Georgia informs their potential clients that $80 \%$ of their egg donors are "experienced donors whose cycles have resulted in pregnancy, and have produced 1525 high quality eggs" (New Life Georgia, 2008c). It is not clear whether this production of 15-25 eggs refers to the amount of eggs retrieved at a time or the amount of eggs that was considered quality enough to be used for egg donation programs from one egg donor. Nonetheless, it shows that their donors donate more than once and that their previous success at high quality production is advantageous. New Life Georgia clarifies that egg quantity cannot be guaranteed; it is possible that one egg donor produces no eggs. Because the donor is carefully selected by each "patient", the Georgian clinic does not 
offer any guarantees on egg quantity or egg sharing programs. This is a realistic and honest approach to egg donation.

In contrast, New Life India advertises a guaranteed program with the headline of "We guarantee baby or you will get your money back!" (New Life India, 2008e). There is a new line of egg donation and surrogacy program at the Indian branch that ensures a higher level of security and guarantee for the intended parents. Albeit, this program requires the intended parents to chose among a group of seven or eight egg donors that are provided by the agency and to share the donors' eggs with other intended parents. An additional eligibility requirement states that they must agree to the transfer into two surrogate mothers. If both surrogates get pregnant, the parents are responsible for both surrogates. However, they have the option to hand over the right to the agency to give the additional child for adoption, if they are not ready to care for more than one child. Embryo reduction is only an option if one surrogate is pregnant with more than two babies. The program costs 60,000 USD if one surrogate mother gets pregnant and 70,000 USD in the case of two pregnancies. We are told that this is a cost-effective program. The guarantees can be made because the customers get to have three attempts at the program and the chances of success are maximized because they have more eggs and surrogates at their disposal. This information is a quite shocking example of commodification of egg donors, surrogates and children. The primary goal of the clinic is to offer the best services available for their customers, but it is done to the detriment of the children that will be given up for adoption. With this program, the risk of having a surrogate-born child that goes straight to the orphanage is increased. The egg sharing aspect takes away the choice that the intended parents have in selecting their unique egg 
donor, but this is a trade-off for the cost-effectiveness of the program. It is unknown how the donors are compensated for their donation if for one cycle they produce many eggs and those eggs lead to many pregnancies. It is also unknown how these egg donors are selected to be part of the egg-sharing program and whether they have less perceived value than other donors in terms of compensation or desirability to the customer.

Ultimately, the egg donors are highly objectified and commodified in this process. Under the circumstances of commercial cross-border egg donation, the agencies and clinics tailor their programs to the benefit of their customers. The impact on the children is not a priority. The extra value for the Caucasian donor over the Indian one and the way that racial terms are used throughout the websites show the close relationships between race and reproduction. Intended parents are the patients, while the egg donor is considered in her capacity of egg production. She stands in for the eggs until the eggs are retrieved. She is not seen as a patient even though she undergoes medical tests, takes a high amount of hormonal drugs and undergoes invasive procedures. Instead, it is the infertile parents, often the infertile mother herself that is considered the patient in this form of commercialized infertility treatment. The bioavailability of the egg donors is dependent on having enough women in a location that can function as egg donors for the creation of an egg donor pool and having a selection of women that are in demand by the intended parents. For example, New Life Ukraine advertises that one of the advantages of Ukraine is the "availability of young, healthy egg donors and surrogate mothers" which means that there is "no waiting time" for their clients. (New Life Ukraine, 2007). 


\subsection{Standard Packages and Disposable Surrogates}

All the different branches in the New Life Network provide seven to 12 program packages. Normally, there is a surrogacy package, a surrogate and an egg donation package, an IVF and egg donation package, and a surrogacy with frozen embryo. Additionally, there are more expensive packages that include two surrogates with or without egg donations included in the price. In the case of the packages with two surrogates, both receive embryo implantation, but depending on how many of them have successful pregnancies, the price will change. For those standard big packages, the payments are requested in four transfers. The prices among the branches are comparable and even the compensations that go directly to the egg donor and surrogate are comparable across all the branches, with the exception of the Indian branch that is much less expensive and pays its surrogates less. For example, a standard New Life surrogacy package costs 21,500 USD in India and 29,00 USD in Georgia. For surrogacy and egg donation, the cost is 26,500 USD in India and 34,000 USD in Georgia. The compensation going to surrogates varies also between the branches. The surrogates get 5,000 USD in India and 12,300 USD in Georgia out of the total package fee. The egg donor is paid 1000 USD in India and Georgia. As one of the most expensive surrogacy packages, the two surrogates with egg donation that result in two pregnancies package costs 42,500 USD in India and 58,300 USD in Georgia. All the other branches have similar prices to Georgia, but Mexico seems to be the highest. These amounts to not include incidental fees. If one compares the New Life prices to a local Georgian clinic T. Khachapuridze Centre for Reproductive Health (www.surrogacy.ge/en) and the local Ukrainian Successful Parents agency (http://www.successful-parents.com/), the prices for a 
surrogacy and egg donation package are very comparable. Even the amount that is taken out of the total cost to compensate the surrogates and egg donors are almost the same. It can be concluded that the fees for programs are competitive with the local market and that even compensations to their donors and surrogates follow this rule. The surrogate receives monthly compensations during her pregnancy and the resulting compensation that is due for them after the birth of the baby. The egg donors only receive one compensation fee for undergoing an egg retrieval cycle.

The standard packages provide a standard compensation fee that appears to be the same among all the surrogates and egg donors within each branch. It is the agency, as the broker between the intended parents and the donor and surrogates, that decides the amount that each woman is getting in any arrangement. This reflects the replaceability of the surrogate mothers. While egg donors seem to be appreciated for their individual accomplishments and characteristics in the selection and matching process, surrogates are more easily interchangeable throughout the whole process of gestational surrogacy. On New Life Georgia, the FAQ section explains how surrogates are selected for a program (New Life Georgia, 2008d). The doctor selects potential surrogate mothers for the intended parents who will then make the final decision. This allows the doctors to examine the woman's health beforehand. Based on the Georgian branch, it seems that the health and functionality of the woman takes prominence over the idea of having a selection of surrogates for the intended parents to choose from at their liking. New Life South Africa offers a surrogate mother database for its South African clients (New Life South Africa, 2008d); however, this does not mean that the intended parents can chose any surrogate. Based on the South African branch, several surrogates are selected by the 
doctor for the preparation of each program and depending on the response to medical stimulation, a surrogate will be chosen by the doctor. Both the Georgian and South African branch demonstrate that many women are being prepared for the pregnancy, even when just one is required. This puts additional women at medical risk in order to increase the agency's success rate. The value of the surrogate is based on her ability to lead to a desirable outcome, i.e. a successful pregnancy.

The program packages with two surrogates show how easily the number of surrogates can be multiplied to increase or as New Life Georgia says, to "significantly maximize the chance of success" (New Life Georgia, 2008d). Potential customers are made aware that there is a small risk of having two or four babies as a result of this type of arrangement. Embryo reduction can only be performed on one surrogate that is carrying more than two babies. Depending on the outcome, the final cost will reflect whether there were two pregnancies or one. Consequently, the amount that is due to surrogate compensation is halved when only one pregnancy is achieved. In the case of one pregnancy, both surrogates are given hormonal medications to prepare their uterus for the embryo transfer, but both are not paid the full surrogacy fee. In short, the additional surrogate is only there to increase the chances of success for the intended parents in case one of them does not respond well to the drugs or does not have a successful pregnancy. Even in regular surrogacy program where only one surrogate is being paid for, back up surrogates are available. Potential problems can arise throughout the preparation period that would require the surrogate mother to be replaced. For example, there is the possibility of endometrium thickness, of sudden bleeding or not being properly synchronized with the women whose egg is retrieved. 


\subsection{Contracts and Legal Rights}

The agency's customer-service oriented approach facilitates the intended parents' travel to a foreign country. In general, surrogacy arrangement or the egg donation process is well explained on their websites. When intended parents pay for program packages, legal services are included in the price. These include birth certificate fees and legal consultation fees. Program coordinators are available for helping them through the whole process and travel logistics. However, once the parents receive the baby and the final transfer has been made, no longer is the agency required to give assistance to the intended parents. The intended parents are assured that travel logistics and visa requirements for the travelling egg donors and their chaperons are taken care of by the agency. Another way that the network helps the customer to have the best experience in cross-border ART services is through electronic contracts. Contracts between the agency and the intended parents are very important. In India, the intended parents must send a copy of their contract in their application for the medical visa in order get into the country.

Contracts are available on most of New Life websites for intended parents to download with the exception of New Life Israel and New Life Nepal. There are four different types of contract forms: the contract between the agency and the egg donor; the intended parents for egg donation program contract; the intended parents for surrogacy program contract; a contract between the agency and the surrogate mother. For the intended parents, there is also an agreement to medical services that includes consent forms for the in vitro fertilization and embryo transfer program. This form is for the intended parents only and refers to contracting parties as "patient-customer". 
I compared the available contracts for similarities and differences across the different countries where New Life has branches. The egg donation contracts contain similar content between the different branches. The only issue in these contracts is that Indian egg donors get paid considerably less in the event that ovaries do not react to stimulation. This means that when Indian egg donors use the same fertility drugs for the stimulation of ovaries and undergo the same risks as donors from other countries, the Indian egg donors are only compensated 100 USD as compared to the 500 USD or more for other donors, if the stimulation fails. In the Indian contracts, there is also the inconsistency between the egg donor compensation stated in the contract between the agency and the egg donor compared to the compensation in the contract for intended parents. The former states that the donor is entitled to a compensation of 40,000 to 50,000 Indian Rupees (i.e., approximately 646 to 808 USD), while the latter sets egg donor compensation at 800 to 1000 USD. Regardless of which exact amount goes to the egg donors, it is fair to conclude that Indian donors get paid less for egg donation than other branches. According to the contracts, South African donors get the highest amount of 2000 USD, compared to the average of 1000 USD for Polish, the 1000 EU (i.e., approximately 1246 USD) for Georgian, or the 1500 USD for Mexican donors. The disparity in compensation is even higher for surrogate mothers if one compares the contracts available for New Life India, New Life South Africa, New Life Georgia and New Life Mexico. The maximum amount paid to Georgian, South African and Mexican surrogates is 13000 USD, whereas Indian surrogates get 7000 USD at most. The obligations of the intended parents towards the surrogate mother also vary across the branches. The Georgian contract lists the compensation requirements to the surrogate in 
case of loss of uterus, ectopic pregnancy and compensation for abortion costs in lifethreatening situations. All these statements are missing in the Indian contract. The Indian surrogate can be compensated 2000 USD in the event of miscarriage at six, seven or eight months of pregnancy. In comparison, the Georgian surrogate can get paid 6000 USD in the event of pregnancy complication or termination at five or six months of pregnancy. It is interesting to note that that the obligations to the surrogate by the intended parents are not equivalent towards all surrogates in the New Life Network. Clearly, they all perform the same reproductive labour and are exposed to the same risks related to the four types of different drugs they have to use to stimulate the ovaries and general pregnancy-related risks during the gestational period. It is possible that the local market and a large pool of available surrogates in India permit the agency to pay their Indian surrogates less and offer the services at a more competitive price to the intendant donors.

With respect to all the different branches, the standard contract limits the rights of the surrogate mother. Intended parents have the right to ask for a replacement surrogate mother, at no additional cost, if the health status of the surrogate is found to be unsatisfactory. In the contract, the surrogate agrees to hand over the child to the potential parent, who will be the legal parents according to local law. Even throughout the pregnancy, the only type of entitlement she has is to receive compensation throughout the process and a final payment after birth. Her right to terminate the pregnancy is not her own. In the Georgian contract, if the physician advises the intended parents that there is a high risk of physical or mental disability, the intended parents can chose abortion and must bear the costs. The surrogate mother is not involved in this decision. The network 
refers to the gestational carriers as surrogate mothers, yet their role as mothers is only temporary and functional in order to carry the child to birth.

\subsection{Conclusion and Theoretical Reflections for Case Study Two}

This case study reveals that what makes one country a good destination for crossborder ART tourism from the perspective of the fertility agencies and clinics are favourable laws towards ART and an availability of egg donors and surrogates for recruitment by the agencies. It is worth noticing that local regulations shape the pattern of cross-border reproductive travel. This pattern is constantly changing, as restrictive ART laws are not suitable for operating for-profit fertility business. This case study relates to a variety of theoretical concepts. If one defines the term 'bioavailabilty' (Cohen, 2005; Whittaker \& Speier, 2010) to surrogates and egg donors, based on my research two main requirements must be met in order to have a country with bioavailable surrogates and egg donors. First, the laws in that country must allow women to be recruited to be paid as egg donors or surrogates and second, there must be enough healthy and young volunteers in that location for the creation of a pool or a database. For egg donors in particular, a racial match between the donor and the intended parents also contributes to bioavailability. The racialist terms used to describe egg donors and to classify them into different categories of donors reflects Weinbaum's (2004) race/reproduction bind theory. In egg donation programs, reproduction is done through the selection of a donated oocyte from the egg donor that contains its own genetic material. Therefore, being able to select the right egg donor is an advantage for the customers who intend to reproduce through ART. 
This case study also supports Inhorn's (2010) concept of reproflows. There is a lot of variety in the movement and circulation of goods and services and people involved. For instance, the European-owned company, New Life Global Network, is opening branches and sending their European-trained doctors and medical staff to different parts of the world. There are travelling egg donors and frozen eggs that can easily be shipped anywhere where the intended parents require them. Similarly, surrogates as well are travelling back and forth out of their native country. The movement also involves clinics moving from one country to another in case there is a crackdown on IVF clinics. As I have demonstrated with gender selection services, the choice to offer these services is only based on the local laws.

The bioethics of the ART industry reflect the neo-liberal values of global medical bioethics, as outlined by Scheper-Hughes (2003). For instance, New Life Global Network aims to offer as many services as possible to as many types of clients as they can. Sex selection procedures are offered to their clients based on the idea that intended parents have the desire for a balance of the sexes in their family. As has been noted, the bioethics of the ART industry are mainly about meeting the desires of their 'patient-customers'. The corporate aspect of the fertility industry prioritizes those who are paying for their services. Consequently, the patient-consumer of the market-driven health care system (Conrad, 2003) becomes the paying patient-customer in the global ART industry. The strong emphasis on customer-service and cost-effective service delivery that can be observed on their websites reflects the commercialization of fertility treatment services and the accompanying commodification of egg donors and surrogates. 


\section{Chapter: Case Study Three: The Changing Discourse in India, Russia and Thailand}

\subsection{Three Key Destination Countries}

Cross-border reproductive travel is a profitable and booming industry ("Global In Vitro Fertilization", 2014). Intended parents can come from anywhere in the world if they can afford the services, but not all locations make good destination countries for gestational surrogacy and egg donation programs. Some countries have seen their ART industry grow to the point that it attracted media attention. News media are very effective in capturing the controversies involved in international cases of ART that result in a scandal. By following the developments in the media chronologically following one key news report, I have chosen to analyze the way that the discourse around surrogacy develops in three key destination countries. Surrogacy in India, Russia and Thailand has received considerable amount of exposure in the media over recent years. It is often surrogacy, rather than egg donation, that attracts more opposition and controversy in the media. This case study indeed centers around controversies involving surrogates for the sole reason that such similar opposition has not been observed, at least not with respect to international ART, towards commercial egg donation. It is fair to assume that a certain number of the surrogacy arrangements involve commercial egg donation, as many clinics offer both programs at the same time in one package.

The countries I have chosen all seem to be in a state where the local government is expressing concern over commercial surrogacy arrangements. For these reasons, it is interesting to follow the development discourse around ART regulation and whether 
these discussions lead towards a new law. India is one of the destination countries with the most exposure in the Western media over the last couple of years. The Indian surrogacy industry has been referred as a 'womb-for-rent' business that services wealthy Western couples ("Indian women carrying”, 2007). Ethical concerns around the exploitation of poor Indian women through international surrogacy arrangements have been raised (Williams, 2013). India has been called the global capital of international surrogacy due to a lack of government regulations. The discourse analysis for India starts with a news article published in March 2013 on the announcement by the Indian government of a proposed bill to regulate the industry ("Govt proposes to bring Bill", 2013). This announcement signifies the beginning of a public discussion on the need for a regulatory framework. Russia is also a country that attracts many foreigners for commercial surrogacy arrangements (Ivankova, 2012). Commercial surrogacy is legal in Russia, but not without strong opposition from Russian public figures. Russia Today reported in October 2013 that a representative of Orthodox Church in Russia referred to surrogacy as "mutiny against God" (Lisitsyn, 2013). Given the influence of the church in Russia and this public opposition to surrogacy, it is important to study the development of this type of discourse in Russia following the publication of this news report. As we have seen in the previous chapter, Eastern Europe and South Asia are profitable and desirable destination locations for egg donations and surrogacy programs. As a former Soviet Union country, the Russian ART field could present a different form of discourse around the regulation of surrogacy compared to the discourse in India. The last destination country to be included in this case study is Thailand. Thailand had a surrogacy industry without any government intervention until two critical events in 2014 
lead to legislative changes in Thai surrogacy. The Thailand military coup in May 2014 forced a change in government ("Thailand military seizes", 2014) and a surrogacy case in August 2014 revealed the story of a baby with Down Syndrome that was abandoned by his intended parents (Pearlman, 2014). The response by the Thai authorities is analyzed through news reports published after the case of the abandoned surrogate-born child was exposed (Pearlman, 2014). These three countries will be used to answer the following research question: How do destination countries respond to an intensification of crossborder reproductive travel and the controversies surrounding third-party assisted reproduction?

\subsection{Stricter Regulations for India's Womb-for-Rent Industry 6.2.1 ART (Regulation) Bill}

The study on the development of the discourse on surrogacy in India starts with the announcement in March 2013 of a proposed draft Assisted Reproduction Technology (Regulation) Bill to effectively regulate the industry ("Govt proposes to bring Bill”, 2013). The Hindu reports that the goal of the bill is to introduce monitoring of ART clinics and banks in India and to help implement the guidelines on accreditation, supervision and regulation, as prepared by the Indian Council of Medical Research (ICRM). According to the Minister of Health and Family Welfare Ghulam Nabi Azad, this law will ensure that the rights and duties of all parties are proscribed and protected. This news report suggests that the lack of regulation is associated with unethical medical practices in the Indian surrogacy industry, which would be addressed by the upcoming bill through the introduction of elements such a national advisory board, a national 
registry for ART clinics and procedures for registering complaints ("Govt proposes to bring Bill”, 2013). In June 2013, the dire need to regulate surrogacy in India is highlighted by a Firstpost article on an Israeli sex offender who was able to adopt a girl born from an Indian surrogate (Pal, 2013). The problem with this particular surrogacy case is that the man who adopted the girl is a recognized sex offender in Israel but neither the Israeli nor the Indian authorities are able to intervene to protect the welfare of the child. This case raises important questions about the possibility of a pedophile getting legal custody of a child, the lack of screening of potential parents by surrogacy agencies in India, the child's nationality and legal status, and the lack of provisions in the ART (Regulation) Bill of 2008 on ensuring the welfare of children born from surrogate mothers (Pal, 2013). This report draws attention to the vulnerability of children born through Indian surrogacy arrangements due to a lack of clear and specific regulations in the current bill. Since they estimate that $50 \%$ of children born to Indian surrogates are claimed by foreigners, if the child's legal status is not clearly defined, it raises the possibility that it is left unclaimed and ends up being handed over to an Indian orphanage by the surrogacy agency. In 2013, the local media is calling for better regulations to protect the rights of children (Nath, 2013). Concern for the wellbeing of children born out of surrogacy arrangements also extends to the child's health. In response to a study that showed an association between breastfeeding and increased brain development in infants, concern was raised around the lack of breastfeeding in children born out of commercial surrogacy (Nath, 2013). After the surrogate gives birth, the child is often handed over to the intended parents who then will feed the child with formula milk. The article frames this issue as a direct problem resulting from a lack of specific directions on breastfeeding 
in the Health Ministry guidelines. The conclusion is that the current National Guidelines for Accreditation, Supervision and Regulation of ART clinics 2005 does not work for the best interest of the child's health. According to Nath (2013), authorities claim that the new bill will address this issue.

The discourse around surrogacy in India shifts from the concerns for the children to a need for comprehensive safeguards for both women and children. In July 2013, the media draw attention to a study on surrogacy in Delhi and Mumbai, conducted by the Centre for Social Research and supported by the Women and Child Development Ministry ("Not enough safeguards", 2013). This report reveals specific problems with the surrogacy industry in India. The report showed a lack of legal safeguards and the exploitation of poor women ("Not enough safeguards", 2013). For instance, the results showed a problem with informed consent, as the surrogates are often illiterate, do not get a copy of the contract they sign and are uninformed about the clauses in the consent form. There were some severe violations of medical guidelines. ICRM guidelines about the maximum number of IVF sessions that can be conducted on one surrogate for one intended parent were found to be violated. The director of the Centre for Social Research made a direct connection of this exploitation to the commercialization of surrogacy ("Not enough safeguards", 2013). Among the industry players, the "middlemen" are mostly blamed for ignoring the ongoing exploitation of surrogates (Dhawan, 2013). 'Middlemen' is a term that is used frequently by Indian critics to refer to the surrogacy agencies that keep the surrogates in shelter homes and function as providers of surrogates to the doctors and fertility clinics. 
The women who are recruited as surrogates mostly work as domestic helps and housemaids. The doctors are also called out on various violations of medical guidelines. To increase the success rate for intended parents, the study showed that the doctors would impregnate some of the women without their knowledge (Dhawan, 2013). In the event that the pregnancy was discovered to be unhealthy, abortion pills would be given to the surrogate without her consent or knowledge of an existing pregnancy. Another technique relied on by the doctors to increase chances of success is the use of more than one surrogate at a time for one commissioning couple (Dhawan, 2013). Because the women are often in a situation of desperation for money and are not knowledgeable about the medical procedures they are undergoing, they are in a vulnerable position to the medical staff. Therefore, they are not well informed about the procedures that they are subjected to. The articles on this study identified in more detail the way that exploitation of surrogates is manifesting and the different actors that are directly involved in the unethical practices surrounding surrogacy (Dhawan, 2013). There is also some reference to commercial surrogacy having a harmful impact on the adoption system. This study suggests that the surrogacy agencies and clinics put the interest of their customers above the well being of their surrogates and the unborn children. Nevertheless, the main argument is that commercialization in combination with a lack of legal framework puts the surrogates at risk of exploitation by agencies, wealthy intended parents, and medical practitioners.

Over the second half of 2013 and the year 2014, the media in India continue reporting on the need for regulations but the discourse changes slightly. It becomes evident that India is not on a path of challenging commercialization or completely 
banning surrogacy. Rather, the framing of the policy problem is on the need to find specific solutions to address the unethical practices and to introduce the best regulations possible for the benefit of all parties involved. Thus, the expectation is that the new ART bill will be the solution to these problems. In July 27, 2013, the Hindu reports that the Planning Commission called for wider consultations with stakeholders in order to avoid pushing the bill too prematurely (Dhar, 2013). In a meeting with the Commission, the stakeholders raised many issues. The lack of protection for the health of the women and the children, lack of rights of women and children, sex selection, and women's lack of opportunities are issues that needed to be addressed by the new draft (Dhar, 2013). In October 2013, the Health Ministry requested the ICRM to make sure that comprehensive safeguards and punitive action for breaking provisions are included in the revised bill to prevent exploitation of surrogate mothers (“Prevent exploitation”, 2013).

In 2014, an article titled "No foreign babies for surrogate moms from six months" (Kamath, 2014) introduces the idea of banning commercial surrogacy for international patients. The article reports that foreign patients are being kept on hold until the new ART bill is passed by Parliament. Fertility specialists claim that there is confusion around the surrogacy laws in the country and as the new surrogacy hub in the world, Thailand might replace India if the ban on foreign patients is held (Kamath, 2014). In April 2014, alleged violations by three different Mumbai surrogacy clinics were exposed in the Hindu and Mumbai Mirror ("Probe into alleged", 2014; Shelar, 2014). The Foreigners Regional Registration Office has discovered abuse of visa norms by three of Mumbai's top surrogacy clinics. The allegations are that the clinics had some clients who travelled on a tourist visa. Since December 2012, the medical visa was made mandatory for all foreign 
nationals visiting India for surrogacy services. Shelar's article (2014) shows that these visa norms were introduced following the death of an underage surrogate mother who had donated her eggs. These reports reveal a concern about India's reputation as international clients are violating the few restrictions that have been introduced by the Indian government. These violations are related to the need to regulate third-party agencies in particular, given that it is their duty to ensure that the intended parents follow the rules. An additional news article related the problem of exploitation of surrogates to the existence of "middlemen" who leave the women after the delivery of the children often with psychological problems ("Law needed to regulate", 2014). This news report also reveals that Bangalore is emerging as one of the biggest hubs for surrogates in the world due to the affordability of surrogacy services and the fact that many surrogates come from slums. The urgency of a need for regulations is reflected in an article published in August 2014 (Perappadan, 2014). This article shows that India is a lucrative surrogacy centre due to in part of the conditions of poverty and the lack of regulatory laws in the country. The industry is generating $\$ 2-3$ billion annually. This news report puts forward the need for a legal framework that is "stringent" (Perappadan, 2014). The emphasis is on a need for strict legal framework that addresses all crucial issues around exploitation of women and the nationality of the child. In October 2014, the discussion around banning foreign nationals from surrogacy arrangements is addressed again (Ramachandran, 2014). This time, however, the recommendations are not to ban surrogacy for single parents or foreign nationals, but to provide legal restrictions without discriminating against same-sex or single parents through the ART (Regulation) Bill 2014. 


\subsubsection{Conclusion and Future Developments}

The discourse in India is on the need for a legal framework that prevents exploitation of women, protects the rights and health of the children, and prevents violations of ethical and medical guidelines. There were legal, medical and ethical concerns. Legal issues are around the citizenship of the children and the rights of the children, as well as the rights of the surrogate women. Many reports showed the exploitation of surrogates by the medical practitioners and especially the surrogacy agencies. Overall, a connection was made between commercialization and exploitation; however, the solution is not a complete ban or a proposal to reduce the extent of the industry. Rather, the solution is better and more effective regulations. The government wants to make sure that consultations have been made with stakeholders and all issues are addressed in the revised ART (Regulations) draft.

It will be up to the ICRM to draft a bill that both permits the industry to continue flourishing, while at the same time making appropriate legal restrictions to avoid exploitation of poor women and protection of the children. It will be interesting to see how the new draft of the bill will manage to balance the interests of the industry with the interest of other stakeholders, such as the government, women's groups and NGOs, who advocate for legal protections of the more vulnerable parties. The commercial interests will have to be balanced with the well being of the surrogates and the children. Throughout the study of surrogacy industry in India, I have observed that the ethical issues are a direct result of the commercialization of surrogacy. Government regulators hope that the new draft ART (Regulation) Bill in India will lead to an effective legal 
framework that permits commercial surrogacy and simultaneously attempts to limit its exploitative practices. This is harm reduction strategy. In an anti-commodification framework, the protection of the individuals and the protection of for-profit interests are in contradiction. This form of anti-commercialization and anti-commodification framework was observed in the Canadian biogovernance of ART, which has led to the ban of commercial surrogacy arrangements in Canada. Indian lawmakers are not even considering this option. The government relies of the ICMR to draft an appropriate bill. The ICMR is "the apex body in India for the formulation, coordination and promotion of biomedical research" (Indian Council of Medical Research, n.d.). Given the role of scientists and doctors in drafting the bill, it is understandable why a complete ban on commercial surrogacy is not even considered as an option, as the ICMR has a stake in protecting the advancement of biomedical research and practice. Even the Indian government shows no interest in a ban on surrogacy. Most of the stakeholders are not advocating for complete control of the surrogacy industry by the government, but merely to introduce norms and strict guidelines to avoid harm to women and children. The ART (Regulation) draft 2010 that is posted on the ICMR website shows that the infertility is framed as a medical problem which contains a lot of social stigma in Indian society. ART including surrogacy and egg donation is considered a form of medical treatment for childlessness. Thus, surrogacy is framed as a treatment and not a commercial service. In the $2010 \mathrm{draft}$, a big emphasis is placed on regulating the functioning of the clinics and ensuring that the legitimate rights of all parties are protected though legislation (The Assisted Reproductive Technologies [Regulation] Bill, 2010). The draft introduces a National Advisory Board, state boards and registration and accreditation of clinics, as 
well as the duties of all parties involved in ART. Third-party assisted reproduction in Indian law will not be an issue over the existence of a for-profit industry. It is only a matter of good medical ethics and medical practices. No attempt is made to reduce the extent of the industry. Is it possible for an ART industry to thrive with many legal restrictions? The effect of such a law will have to be evaluated in the future, if indeed these regulations are introduced. The introduction of medical surrogacy visa requirements has lead to same-sex couples to seek out surrogates in different country, as a direct result of not being able to come to India (Cooper, May \& Christiansen, 2014). In May 2014, a news report reveals a federal investigation into a surrogacy case of an American same-sex couple that was scammed for over $\$ 20,000$. The following is written about the agency known as Planet Hospital:

Since 2006, the California-based medical tourism company had helped Americans with surrogacy and other medical practices in India. But when the country enacted regulations in recent years that restricted gay couples, single parents and those married for less than two years from pursuing surrogacy there, Planet Hospital turned its focus to Mexico, specifically Tabasco, the single Mexican state that doesn't regulate against surrogacy. As long as the baby is born here, just a day's trip from Cancun, all surrogacy contracts are enforceable, and the intended parents - regardless of their sexual orientation - are recognized as the rightful parents. (Cooper et al., 2014, para. 4).

This paragraph confirms that the visa restrictions in India had a direct impact on a certain portion of its clientele. As a result, international fertility agencies decided to offer 
their services in more favourable locations. Mexico seems to be the go-to destination for same-sex couples. It can be suspected that other surrogacy hubs might spring up as a result of new regulations in the upcoming legislations. The result of India's ART (Regulation) Bill will lead to a legalization of commercial surrogacy with the attempt to regulate more tightly the brokers, the fertility agencies and the clinics.

\subsection{The Moral Opposition to Surrogacy in Russia}

\subsubsection{Moral Discourse}

Russia is less known as a surrogacy destination country than India, but it has a similar legal framework. Surrogacy in Russia is regulated by the Family Code, which permits commercial surrogacy for all types of clients (Svitnev, 2011). It is legal for foreign nationals and single parents of all genders to pay for surrogacy. Only the consent of the surrogate is required to hand over the parental rights to the intended parents. My previous chapter identified that both South Asia and Eastern Europe are important destinations areas in cross-border reproductive tourism. Out of all the former Soviet states, Russia is practicing the most permissive laws with respect to ART and is a very favourable destination for reproductive tourism for foreigners, including for citizens of the neighboring C.I.S. countries (Svitnev, 2011). Even though surrogacy is allowed in Russia, there is strong opposition coming from some public figures. The focus of this analysis is on the type of arguments that have been made against surrogacy in the Russian media and to compare the development of discourse around surrogacy in Russia with the discourse on surrogacy in India. The cultural differences between the two countries and differences in the local ART industry may have a role in contributing to a different 
response to third-party assisted reproduction. To offer better context on the surrogacy industry in Russia, a couple of news articles on the international adoption ban and a couple of online sources will be included in the analysis.

In October 2013, Dmitry Smirnov, the head of the Patriarchy Commission for Family Motherhood and Childhood, expressed his opposition to surrogacy with the following statement: "This is mutiny against God, this is very happy fascism with a contract, the money and the confiscation of a child" (as cited in Lisitsyn, 2013, para. 3). He provided this response to a question from media about a popular Russian singer who became a mother through surrogacy. The church representative announced that the Russian Orthodox Church does not support surrogacy arrangements and called for a complete ban of surrogacy. Within the same news article, Lisitsyn, (2013) reports that a politician of the St. Petersburg City legislature, Vitaly Milonov, made a similar moral anti-surrogacy statement. The MP opposed surrogacy on the grounds that it is paying for a child and a woman to be used as an incubator. Milonov also calls into question the morality of such a practice given that their country has "tens of thousands of orphans waiting to be adopted" (Lisitsyn, 2013, para. 8), while these parents are buying children like new models of Ferraris. Both of these positions rely on a moral and an anticommodification argument. Calling the technology unnatural and immoral shows a position that is based on morality. However, this morality is not purely religious because there are many anti-commodification themes that can be captured in the statements made by the church representative and the MP. For example, they reference children being confiscated, women used as incubators, and children being bought and sold like objects. 
Thus, surrogacy is framed as immoral due to the fact that children are turned into objects, while Russian orphaned children are still waiting to be adopted.

The following month, the head of State Duma committee for family and children, MP Elena Mizulina expressed a similar opposition to surrogacy (Alpatkin, 2013). Lumping abortion and surrogacy together, she made the statement that these types of reproductive technologies will lead to human extinction. Mizulina's position is also based on Orthodox family values. The MP claims that the consequence of these reproductive technologies is an end to the natural form of childbirth and human reproduction. According to Alpatikin (2013), the MP's intentions were to start a discussion on these urgent matters without any intention to propose legal action. It is only in February 2014 that the existence of working draft bill on surrogacy is revealed in the media (Lammey, 2014). The main reason for introducing this bill seems to be to prevent single men from having children through surrogate mothers. If approved by State Duma, the bill would however permit heterosexual couples to use surrogacy services. There is also an interest in including specific criteria for intended parents that is similar to the criteria used to evaluate potential adoptive parents. This news article shows that lawmakers and the public do not necessarily share the moral opposition of the Orthodox Church to surrogacy. According to this report (Lammey, 2014), this new bill does not introduce a complete ban on surrogacy, but only legal restrictions on who can quality as intended parents. More information on the draft law is found in an article published in April 2014 (Zarembo, 2014). This article clarifies that the ban on surrogacy would apply for gay couples and single men and women. Thus, surrogacy is framed as only something that infertile heterosexual couples can access, but a law is needed to ensure that there is 
enough state control over the practice. For the first time since the bill was introduced, there is a hint that commercial surrogacy would also be banned. Zarembo (2014) presents a very different bill from the one that was introduced by Lammey (2014). The new bill would include "a ban on hired surrogate mothers, a mandatory agreement from a special medical commission and a restriction of its use by single people" (Zarembo, 2014, para. 1). If it is indeed the case that the bill will ban the possibility of women being hired for surrogacy, that would only allow a very restrictive, even discriminatory form of surrogacy to take place in Russia. Surrogacy would be limited only to altruistic forms for heterosexual couples as a treatment for infertility in exceptional cases. The draft would introduce "state control" (Zarembo, 2014, para. 2) and make exceptions for surrogacy use only when approved by special boards that evaluate each case. Through the introduction of this bill, the Russian form of governance will be one of state control that places limits on the practice as much as possible, without completely banning it. Even MP Mizulina has toned down her argument against surrogacy. She still refers to commercial surrogacy as "an abhorrent practice" (Tétrault-Farber, 2014, para. 1) that is in opposition to traditional Russian family values. Her argument is now less anti-technology and more focused at looking to other European countries such as Germany, France, Norway, Austria and Sweden that have managed to ban surrogate motherhood. Indeed, none of these European countries are destinations for cross-border reproductive tourism. The Russian discourse on surrogacy did not include any reference to cross-border reproductive tourism or foreigners coming to Russia for surrogacy services. Instead, the discourse was focused on Russians using those services within their own country and whether the payment for such services is moral or not. Tétrault-Farber's (2014) article 
was the first to capture political authorities make reference to surrogacy in other countries.

The greatest concern by Russian lawmakers is for the children born out of surrogacy arrangements. Since same-sex couples do not have the right to legally marry in Russia, it is not surprising that restrictions would be put on gay individuals in raising surrogate-born children. Additionally, there is an interest in limiting as much as possible these services to only the cases that have been assessed as having a legitimate need for it. While it would be discriminatory to gay individuals and others who might not qualify based on the evaluation, it is a way to reduce the impact of surrogacy. Russia does not seek to completely ban it as it still considered a beneficial technology if used altruistically for couples with fertility issues. No connection was made by Russian authorities between the use of foreigners of Russian surrogates and the new draft bill, even though Russia is a very desirable country for third-party assisted reproduction.

\subsubsection{Favourable Genetic Material.}

To get a better idea of Russia as a surrogacy destination, a couple of online sources provide the industry perspective on surrogacy in Russia. Russia is seen as one of the most favourable countries for ART tourism because of its permissive laws that do not restrict foreigners or single people or same-sex couples or gay or lesbian individuals from getting surrogacy services. One website with the header "Surrogacy in Russia and Abroad" (http://surrogacy.ru/eng/) that contains legal information on surrogacy and adoption in Russia states that "foreigners are entitled to the same rights to surrogacy as 
the Russians" (Surrogacy in Russia and Abroad, n.d.). This demonstrates that crossborder ART is practiced with no restrictions towards foreigners in Russia.

A Russian surrogacy agency called Mom Service (http://www.surrogatedonation.com/) provides a list of advantageous for choosing surrogacy in Russia. For example, Russia is inaccurately described as "the most developed country among the Third World countries" (Mom Service Surrogate and Donation, n.d.). The following bullet point from Mom Service provides insight into what makes Russia favourable destination for ART:

On the other hand Russian surrogacy program is more preferable from the genetic material point of view. Before severe restrictions were set for American parents up in adoption, for a long time Russia had been the first country Americans adopted children from. Today surrogacy is the only way for Americans to obtain high-quality genetic material from Russia. (Mom Service Surrogate and Donation, n.d.)

This quote demonstrate that the target audience of this website is foreign, and it could even said that the information is mostly tailored to an American audience. It also shows a relationship between surrogacy and desirable genetic material. Mom Service Surrogate \& Donation offers traditional surrogacy, gestational surrogacy, and surrogacy with egg donation programs. It is clear that the combination of getting Eastern European genetic material and surrogacy services is an advantage that some of the agencies are providing when they tailor their services towards an international audience. 
While Russia has made considerable restrictions to foreign adoptions, the laws on surrogacy are lagging behind. The Russian outrage over the scandals in U.S. adoption cases shows a great concern over the wellbeing and protection of the children. Following the death of 19 children that have been adopted by America parents, the Dima Yakovlev Law, a law that was named after one of the boys who died under the care of his adoptive parents, took effect in January 2013 ("Putin sends 2 intl", 2013). This law is seen as one of the national measures that have been undertaken by Russia to protect children against exploitation and abuse ("Putin sends 2 intl", 2013). With the increase in bans on adoptions by foreigners ("Russian region completely", 2013) and by same-sex couples (Black \& Eshchenko, 2014), Russia is favouring internal adoptions by Russians over foreign adoptions where the children are less protected and more vulnerable to abuse. It is thus surprising that Russia has not also considered that many foreign infertile parents even same-sex couples come to Russia for surrogacy. Judging by their response to these adoption cases, it would be reasonable to assume that future discourse on surrogacy might take on a more cross-border approach, since the children are born from Russian surrogates. If indeed the new draft bill passes and restricts the eligibility of the intended parents, then that restriction could prevent American or other foreigners from engaging in Russian surrogacy. Especially now that Americans are not able to adopt Russian children, surrogacy in combination with egg donation in Russia is seen as a good alternative for potential parents. The new surrogacy draft could be the next step, following the increasing restrictions to international adoptions of Russian orphans, in limiting the risks to Russia-born children by also banning foreigners from third-party assisted reproduction in Russia. If Russia pays attention to the international controversies on surrogacy cases, 
the country is very likely to move to a complete ban on international surrogacy. It remains to be seen whether the draft bill will pass in Russia any time soon and what form it will take. A ban on same-sex couples and single individuals from surrogacy arrangements is expected. Stronger requirement for the intended parents are expected to be introduced.

\subsubsection{Conclusion for the Russian Context}

The opposition to surrogacy in Russia is primarily a moral opposition. However, a big part of this moral opposition is the threat of the commodification of children. The language used reflects the dehumanizing and objectifying aspects of surrogacy for the women and the children. This position is not reflective of the whole of the Russian population or of the Russian government in general. Nevertheless, given that recent change in foreign adoption laws, it would not be surprising if surrogacy were to be restricted to foreigners. Russia contained some of the most extreme anti-surrogacy positions captured in the media in 2013 and 2014. There is a strong emphasis on family values and protecting the children. It is also surprising that surrogacy is discussed in connection to abortion. Embryo reductions are often performed in the surrogacy industry and even abortions can be possible depending on the specific state laws. Only in Russia have the two very different type of reproductive technologies been considered as the same threat in the public discourse. Russian biogovernance of ART is a form of state control, if we were to predict the development of its legal framework based on the recent public discourse. The type of solution that is suggested in this discourse is a strong form of state governance through prohibitions and selective restrictions to who can or cannot 
reproduce through surrogacy. It is an anti-commercialization argument as well. If a new law on surrogacy is passed in Russia, it might take the form of prohibiting commercial surrogacy arrangements but making altruistic surrogacy acceptable, similar to the law in Canada. The conclusion seems to be that there is opposition to particularly the commercial character of the surrogacy industry. There are many similarities between the surrogacy industry in Russia and the industry in India, but the differences from the governments' responses are great. In India, one estimate claims that 25,000 children are born each year to Indian surrogates and that $48 \%$ of the intended parents are foreigners ("Clamour grows", 2014). Russia has an estimate of 1000 children born out of surrogacy arrangement each year (Lammey, 2014; Tétrault-Farber, 2014), but it is unclear how many of them are foreigners. India has a highly pro-natalist and patriarchial culture where infertility and childlessness is blamed on the women (Mukherjee \& Nadimipally, 2006). These cultural circumstances and the rampant poverty among many women contribute to making India a good destination for cross-border reproductive tourism. The cultural perception of childlessness also contributes to the legalization of commercial surrogacy in India. The difference between the responses from the Indian and the Russia government can be attributed to the fact that the surrogacy industry is more established in India and that the Indian ART industry lobbies to protect its interests (Mukherjee \& Nadimipally, 2006). In contrast, Russia's Orthodox Christian values contribute to many policy decisions where the family unit is threatened by unconventional and nontraditional arrangements. While the arguments are usually framed with respect to wellbeing and protection of the child, the traditional family values seem to be threatened by ART. Places like India and Thailand have been shown to have some of the most affordable 
surrogacy services. The same programs costs a little more in Eastern European countries, but according to the Russian fertility agencies, they seem to offer more genetic advantages.

\subsection{Controversial Cases in Thailand}

As a newly industrialized country with a lack of enforceable government regulations, Thailand became an important surrogacy destination for many Western intended parents. Many international surrogacy agencies were sending their clients to Thailand until two controversial surrogacy cases were exposed in 2014 that lead to a fast response from the Thai authorities. There have been two significant cases that received large media attention and exposed a darker side of cross-border reproductive tourism. Both cases involve children born from Thai surrogate mothers and being handed over to Western clients. To understand the context of surrogacy in Thailand and the events in 2014 that lead to a complete ban on surrogacy, news reports on these two cases will be analyzed. The goal is to understand the framing of the surrogacy cases and the arguments that are used against surrogacy to justify a ban.

\subsubsection{Baby Gammy}

When an online campaign was posted to raise money for a Down's syndrome baby that was abandoned by his Australian intended parents, a shocking surrogacy case in Thailand caught the world by surprise. In August 2014, a surrogate mother speaks out against an infertile couple that abandoned one of the twins that she carried for them (Pearlman, 2014). The 21-year old woman claims to have been motivated to become a 
surrogate through an agency in order to pay for debts. According to her accounts, she had been asked by the Australian couple to abort the twin with the critical condition at seven months pregnancy (Kittsilpa, 2014). Her refusal to abort left her with a critically ill baby with a congenital heart condition requiring a series of operations and medical care. The Australian couple responded by claiming that they were unaware of the existence of the unhealthy twin (“Australian couple who", 2014). When it became known that the Australian father had previous convictions of child sex offences in Australia (Pearlman \& Forgan, 2014), the concern for children born from surrogates heightened. Not only are children abandoned, but also those who are taken back to the country might not even be safe. In a later interview, the intended parents admitted they wanted to abort the child due to its disability but also wanted to keep him after birth (Maede, 2014).

A month later, we learn more about of the baby Gammy case. Thailand Surrogacy is the agency that arranged the services for the couple (Hawley, 2014a). The American owner claims that the couple had asked the agency to abort the child or to abandon it at a temple. Former Thailand Surrogacy client claimed however that when they had trouble conceiving, they were asked by the agency if they wanted to take a boy with Down's syndrome. This unique surrogacy case shows how children are byproducts of the international ART industry. Some children will be unwanted because the parents are not satisfied with the outcome. Even the agencies are not sure about what they can do with these surplus children and often they are given to orphanages, if they are not aborted. The commodification of children inadvertently leads to having unwanted or undesirable surplus children that often do not receive the protection they need. The back and forth between the different actors involved (i.e., the agency, the intended parents and the 
surrogate) on who is to blame for this particular outcome reflects a big issue with commercial surrogacy. From the perspective of the commissioning parents, they expect a certain outcome for the price that they paid. For these Australian parents, they allegedly wanted a 'normal' child, but not an 'abnormal' one. The problem with reproduction is the difficulty in controlling the resultant product. If no one claims the child, it is an unfortunate but not unexpected aftermath of commercial surrogacy arrangements. It is not surprising thus that for the wellbeing of the children born from surrogates, the local government reacts in a strict manner to put an end to such a high-risk practice. These children are born in the destination country and end up either with the surrogate mothers, being given to orphanages or worse, aborted or abandoned. This case also exposes that often there are many parties involved in this form of reproduction and it is not clear who has the right over the child. It could be the right of legal parentage, the right to abort or not, the right to keep or give away. In the baby Gammy example, we saw that the surrogate mother claimed her right not to want an abortion and stepped up as the mother of the child. Had she not taken this responsibility, one can wonder whether any other parties would have done anything to protect the wellbeing of the child.

There was increased pressure for the Australian authorities to intervene in this case (Pearlman \& Forgan, 2014). However, the Australian government's intervention and follow-up response turned out to be very limited in the short term. The foreign minister and the Australian embassy in Thailand appealed to the military rulers to allow a moratorium for 150 Australian couples who were already in a surrogacy arrangement (Murdoch, 2014). They had to make sure the Australian couples would be able to bring in their surrogate-born children into Australia with Australian visas. Throughout the news 
articles, there is considerable compassion shown to the surrogate mother and the child. The media were not sympathetic to the claims of the commissioning parents and concerns were raised in general about international surrogacy arrangements. The baby Gammy case exposed the involvement of Western intended parents in these types of unethical and exploitative practices. For instance, commercial surrogacy arrangements are banned in Australia, yet Australian couples are travelling to Thailand for services they cannot get in their home country due to their local laws. These types of reproductive travellers come from other Western countries as well. Similar to the Canadian law on ART, only altruistic form of surrogacy is legal in Australia. There are different state regulations, but at the national level commercial surrogacy is forbidden. Australia has even laws in some states that specifically forbid international arrangements for commercial surrogacy; however, no one has been prosecuted for breaking them (Murdoch, 2014). Australians have been going overseas for surrogacy programs without any interventions by the Australian authorities. Even following this controversial case, Australian government did not respond by enforcing its existing ART laws or starting to prosecute any of its citizens for violating Australian law. In summary, the discourse that followed the baby Gammy case became centered on the surrogacy laws in Thailand, given that it happened in Thailand's jurisdiction and impacted the destination country more than the Western countries where majority of the clientele was coming from.

\subsubsection{Japanese Man Fathers 16 Surrogate Babies}

Within the same month of the baby Gammy case, the media learned about another controversial surrogacy arrangement, this time involving a Japanese man and many Thai 
surrogates and children. The first report I was able to find is a video on a surrogacy raid in Bangkok ("Thai police raid", 2014). Nine babies and about nine women who were caring for the children were discovered in a Bangkok condominium. The children were taken into custody and placed into orphanages. The women claimed that a Japanese man had fathered these children through surrogate mothers. They told the Bangkok police that the man's intentions were to take the children to Japan so that they can take over his business. This news report mentions the crackdown on surrogacy and the intentions of Thai authorities to ban surrogacy arrangements. There was no evidence that the man was trafficking the children or that he had any monetary motives, as he is believed to be the son of a Japanese billionaire (Thongnoi \& Halpin, 2014). Overall, it was confirmed that he had fathered 16 babies through surrogacy through more than 11 different surrogate mothers. He also used surrogates in India and is believed to have taken three of the children to Cambodia (Hawley, 2014b).

The Japanese father instantly became an alleged trafficker in the media discourse and to the Thai authorities (Murdoch, 2014). Because of a lack of existing surrogacy laws, the government decided to enforce the Human Trafficking Laws for commercial surrogacy. The Thai authorities announced that they would treat commercial surrogacy as human trafficking until the new law on surrogacy passes in the parliament. This is an interesting turn of events. International agencies cannot expect anymore that their international clients can be sent to any country where there are no ART-specific laws that forbid commercial surrogacy arrangements. In fact, the unique case in Thailand shows that a government can use other existing laws to shut down fertility clinics in the country and fast track a surrogacy ban. This is a strong message to the international ART agencies 
and their foreign customers. In the future, ART agencies will have to be even more flexible in where they place their operations and have to be on the lookout for any legal developments on ART.

\subsubsection{The Impact on International Surrogacy Industry}

The effect of the crackdown in Thailand had an impact on Australians who seek surrogacy services internationally due to a lack of a market in Australia. International surrogacy agencies are already looking at new destination countries (Browne, 2014). The direct effect of strict regulations over the last couple of years had the Western clients discover new frontiers. Thailand became an option when India introduced medical visa norms. Now that Thailand is not a viable option, potential parents are turning to Mexico, Nepal and even the United States. While Mexico and Nepal are much more affordable options than the United States, all of the three countries are favourable destinations because of a permissive legal framework for surrogacy arrangements. Thailand is not even considered by international agencies an option for an underground or grey market. The crackdown on surrogacy clinics and the fast response by the strict military government are not conductive to running a commercial surrogacy programs. This case shows how a strong response by the government has direct effects on the surrogacy industry in a country.

Online surrogacy agencies are already updating their websites to reflect this change. For example, IVF Sunrise (http://ivf-sunrise.net/) used to advertise surrogacy programs, PGD, IVF, gender selection and gay surrogacy programs in Bangkok, Thailand. They advertised Thailand as a good place to get unique services because 
Thailand was a place where surrogacy was neither allowed nor restricted, according to IVF Sunrise. They also advertised Thailand as a good place for unique services such as sex selection to balance the sexes and for affordable surrogacy packages. A standard package for two surrogates would be 32,100 USD, while a premium package for four surrogates would be 40,600 USD. Since September 2014, the IVF Surrogacy website leads to the same company but now most references to Thailand and the information of program packages has been taken down. Instead, the surrogacy programs are offered in Nepal. The same services are advertised but the cost of programs has been taken down. This example shows how the Thailand's military government's response to the surrogacy scandals impacts international online agencies. The fast reaction from the agencies reflects their ease within which they can close their operations in one country and move to a neighbouring South Asian country. The surrogates are easily replaceable and disposable. The locations are transposable, as long as there are other countries with little government intervention into ART programs. However, not all online agencies have updated their websites. Bangkok Surrogacy (http://www.bangkoksurrogacy.com/) for example is still advertising its services online with no reference to its operations having been shut down.

\subsubsection{The Fast Response of a Strict Military Government}

The case of the Japanese father and the Australian parents who allegedly abandoned baby Gammy contribute to a push to ban surrogacy in Thailand. Global attention was focused on the unregulated industry in Thailand and a draft bill was already

on the table in August (Doksone, 2014). The bill would prohibit commercial surrogacy 
arrangements with punitive provisions for those violating the law, including the recruiters of surrogates, the agencies and the advertisers. Those violating the laws can get up to 10 years in prison. It is clear from this point on that the lenient regulations in Thailand are coming to an end. Thailand's Medical Council has rules against doctors and clinics performing surrogacy for pay, but these regulations had never been enforced. The problem was also the lack of oversight over surrogate agencies and surrogate mothers. It was evident that the new military government had not interest in the country becoming a surrogacy hub. By deciding to act swiftly, they have used their interim authority to outlaw the practice within their own borders with the impact of "essentially ending a lucrative foreign market”. (“Surrogacy Issue: Australian”, 2014, para. 7). An interesting article from the Mass Communication Organization of Thailand (MCOT) reveals the change in perspective on commercial surrogacy ("Thailand urged to legislate", 2014). The theme of the article is that Thailand, in order to avoid becoming the next surrogacy hub, must act quickly to pass the new law. According to one academic quoted in the article, what surrogacy used to be a positive thing, but now it involves human rights infringements. At the end of November 2014, the bill to ban commercial surrogacy in Thailand is finally approved by the parliament ("Thailand's parliament approves", 2014). Putting all the events over the course of the year into perspective, the factors that have pushed this law forward were the military coup in May and the two surrogacy cases that received global media attention. The interim military government was not shy in enforcing the existing laws and in introducing a draft that bans commercial surrogacy and has provisions for criminal punishment for anyone violating the new law. 


\subsubsection{Reflections on Thailand}

Compared to the Indian and the Russian context, the analysis on Thailand revealed some extreme aspects of the surrogacy industry. There is an interesting overlap between human trafficking and commercial surrogacy. Because commercial surrogacy commodifies children, in some cases it can be constructed as a form of human trafficking. When one person is mass producing children through surrogates by paying an agency without meeting the surrogates in person before conception, it paints a very different picture from the usual image of third-party assisted reproduction being a win-win situation for all parties and a useful form of fertility treatment. This form of fertility treatment involves the sale of reproductive labour and gametes and the production of children, some of which will be in surplus. Fertility treatment through third-party assisted reproduction must be seen through this light to completely comprehend how it is manifested in the real world in a global political arena. It is not a form of health care when commercial arrangements are made. Rather, it is a form of corporate medical services that are offered to patient-consumers of higher socioeconomic status and in most cases, reproductive tourism is in the developing countries. When a newly industrialized destination country resists this form of foreign exploitation of their more vulnerable citizens and the risks associated with reproductive tourism that make the country look bad to the rest of the world, biopolitical resistance is formed towards this form of global biopower and commodification. To conclude, the move by the Thai authorities to ban commercial surrogacy was not only for the protection of the children, although it was a big motivation. A big part of the push is to limit international commercial surrogacy 
arrangement, thus limiting the way that foreigner can engage in unethical activities that otherwise they would not be able to do in their home countries.

\subsection{Conclusion and Theoretical Reflections for Case Study Three}

This case study started by looking at how destination countries are responding to the intensification of cross-border reproductive travel and the controversies surrounding global ART. Commercial surrogacy was found to be controversial element in ART for all three destination countries. The Indian government is responding to its booming surrogacy industry by drafting a new bill that attempts to restrict the potential for exploitation of surrogates and to protect the rights of the children born out of surrogacy arrangements. Nevertheless, this type of framework still legalizes commercial surrogacy and does not attempt to reduce its impact. It merely attempts to reduce the risks associated with it, while at the same time letting the industry to continue profiting from this type of business. In contrast, Russian government is approaching the surrogacy issue in its country from a different perspective. The new Russian bill on surrogacy intends to create very restrictive criteria and high requirements to assess on a case-by-case basis which of the intended parents would be allowed to receive surrogacy services. This approach can be described as a form of state control over how ART is practiced. Thus, it is not a matter of introducing regulations within a framework of legalization as we have seen in India. The shift from the current status in Russia where anyone can access surrogacy services to a complete ban on commercial surrogacy will be a drastic change. Lastly, the Thai government has had the strongest and fastest response to the high-risk surrogacy industry in its country. The year 2014 is an important turning point for the 
surrogacy industry in Thailand and might even be significant for the global ART industry as a whole. Thailand used to be one of the most desirable destination hubs for crossborder reproductive travel. In November 2014 with the ban on commercial surrogacy, the military government in Thailand has contributed to changing the pattern of the global ART industry. Now that surrogacy clinics in Thailand are closing down and moving to other countries, Thailand will not be known as a destination country for cross-border reproductive tourism anymore.

This case study proves that the biopolitics of reproduction involve different countries and different governments attempt to handle ART in the best possible manner in order to reduce the risks associated with ART within their own national borders. The main risks that have been highlighted were the lack of protection of the children born out of surrogacy arrangements, the exploitative practices by middlemen brokers and fertility doctors, the existence of surplus children that are being produced through surrogacy arrangements, and the blurring of lines between surrogacy and child trafficking. 


\section{Chapter: Conclusion}

\subsection{Summary of Findings}

The goal of this research project was to discover patterns in cross-border reproductive travel and the complex implications associated with ART. My results support the claim that cross-border reproductive travel is primarily patterned according to national legal and regulatory frameworks of different countries and the bioavailability of egg donors and surrogates in those countries.

To answer my first sub-question on biogovernance and transnational ART practices, I researched the Canadian policy on ART and the impact it had on the ART practices within the country. My first case study on Canada revealed that the cross-border ART networks involving U.S. actors pose challenges to Canadian regulators. It also shows that ART industry can still operate in a grey egg donor market despite legal restrictions. Canadian biogovernance of ART aims to prevent commercialization through a legislation that restricts commercial forms of surrogacy and egg donation. Canada has achieved the goal of not becoming a major destination country for reproductive tourism, yet the existing law cannot prevent all types of reproflows, such as those involving travelling egg donors, frozen egg banks and international networks that extend to other countries. For the second case study, I shifted my focus from the government as an intermediary actor in shaping cross-border ART to the ART industry itself as an intermediary actor in creating global patterns of cross-border reproductive travel. The purpose of my second case study was to discover how an international network group of fertility agencies and clinics handles the complex implications of the services they offer 
and what factors influence where the clinics operate their fertility business. This case study revealed that the ART agencies and clinics offer the services that their customerpatients (i.e., intended parents) desire but the local laws on ART influence which services are offered in which country. Overall, the ART industry aims to offer as many services as possible, but it is limited by local laws and regulations. The ART industry does not have consistent ethical standards. The medical environment is a customer-oriented form of health care where fertility treatment is a service provided to paying clients. A lot of issues were raised in this case study. For example, the egg donors and the surrogates were objectified in terms of their capacity to produce eggs in the former and to carry a healthy pregnancy in the latter. This case study confirms the medicalization/biomedicalization theory of Conrad (2003) and Clarke et al. (2003). Cross-border ART is part of those advanced biomedical technologies that are largely commercialized and that operate within a corporate health care system.

In my last case study, I sought to discover how the governments in different destination countries respond to the intensification of cross-border reproductive tourism in their countries and the risks associated with third-party assisted reproduction. The results from India, Russia and Thailand confirm that there is a common trend to all three countries towards increasing limits on the ART industry; however, each country had a different form of governance with respect to ART. Additionally, this case study revealed many of the risks to women and children born out of cross-border surrogacy arrangements. To conclude, it is clear that the biopolitics of reproduction are in constant flow, as some destination countries are changing their governing rule on ART, while 
other less known destination become new surrogacy or egg donation hubs for foreigners due to their lack of legal restrictions on the ART industry.

\subsection{Implications for Future Research}

My research was based on the commodification and complex biopolitics of thirdparty ART. Thus, I did not evaluate the positive possibilities of IVF technologies and the benefits of other new medical techniques that can help to treat infertility. For instance, there are new promising developments in egg freezing and ovarian tissue preservation technologies. Women who are underdoing chemotherapy treatment have the option of freezing their eggs to preserve them for later use after recovery (Boseley, 2014). Ovarian tissue preservation is also used in cases where egg freezing is not an option (Stoop, Cobo \& Silber, 2014). Some experts are now advocating that these cryopreservation techniques be made more readily available to all women in order to counteract age-related fertility decline (Boseley, 2014; Stoop et al., 2014). Cryopreservation techniques could give women more freedom in managing their own fertility throughout their lives. Therefore, ART permits both infertility treatment and infertility preservation, allowing many women the possibility to become fertile again. Fertility preservation techniques could reduce the overall need for egg donations and gestational surrogacy arrangements. I believe that these techniques if they are made accessible in our health care systems to all women could be a better alternative than a buyer-driven ART industry with its ethical, legal and social implications and its associated risks to women and children. However, the impact of all new reproductive technologies must be carefully and critically assessed. 
To illustrate, 2014 was the year that saw the first successful birth resulting from a womb transplant ("Womb transplant results", 2014). A womb transplant involves the donation of one woman's womb to be transplanted into another women, allowing her the capacity to carry pregnancies. However, these procedures are a bit more problematic than the cryopreservation of eggs and ovarian tissues. While it has been shown to be feasible, doctors warn that the success rates are low and the risks of complications during the long surgery are high ("Womb transplant results", 2014). This represents another example of extreme medicalization where doctors are experimenting on women's bodies. One could also question why women are going to such great lengths by risking their health and lives to be able to conceive. Furthermore, the womb transplant technologies present similar issues as the organ trade with the risk of increasing organs trafficking and contributing to the global exploitation of vulnerable people (Scheper-Hughes, 2003)

My research does not include practical recommendations for the governance of ART. An alternative to having a market driven ART industry would be to have a fully state-funded altruistic type of egg donation program and gestational surrogacy arrangement. Is it possible to have only altruistic third-party assisted reproduction in a country, like some Western governments advocate? Issues around funding and resources must also be evaluated. It could drive up the cost of state-funded heath care, which would be an enormous deterrent for many countries with already high health care costs. Without the financial incentive, there would be a reduced number of women who are willing to donate their eggs or volunteer as surrogates. This lack of supply would make third-party assisted reproduction not a viable option for many infertile people. 
Future research could also evaluate the impact of the new Indian ART

(Regulation) Bill on the surrogacy industry. It would be interesting to assess whether a legalized system of commercial surrogacy is able to effectively prevent exploitative practices and other associated risks to the children. It remains to be proven if the exploitation and commodification of children is an inherent outcome of commercialization of ART or if it is indeed possible to have an ethical low-risk commercial ART industry. 


\section{Bibliography}

Agamben, G. (1998). Homo sacer: Sovereign power and bare life. Stanford, Calif: Stanford University Press.

Ahmad, N. (2011). An international view of surgically assisted conception and surrogacy tourism. The Medico-Legal Journal, 79(4), 135-145. doi: 10.1258/mlj.2011.011029

Alpatkin, A. (2013, November 11). Abortions, surrogacy lead to human extinction senior MP. Russia Today. Retrieved from http://rt.com/

Appadurai, A. (1996). Modernity at Large: Cultural Dimensions of Globalization. Minneapolis: University of Minnesota Press.

Appadurai, A. (2001). Globalization. Durham, NC: Duke University Press.

Armstrong, A., \& Plowden, T. C. (2012). Ethnicity and assisted reproductive technologies. Clinical Practice, 9(6), 651-658. doi:10.2217/cpr.12.65

Assisted Human Reproduction (Section 8 Consent) Regulations. (2007). Retrieved from the Government of Canada's Justice Laws website: http://laws-lois.justice.gc.ca/eng/regulations/SOR-2007-137/page-1.html

Australian couple who 'abandoned' surrogate twin with Down's syndrome 'were unaware of his existence'. (2014, August 4). Independent.ie. Retrieved form http://www.independent.ie/

Bergh, T., Ericson, A., Hillensjö, T., Nygren, K., \& Wennerholm, U. (1999). Deliveries and children born after in-vitro fertilisation in Sweden 1982-95: A retrospective cohort study. The Lancet, 354(9190), 1579-1585. doi:10.1016/S01406736(99)04345-7 
Bill C-6: Assisted Human Reproduction Act. (2004). Retrieved from the Government of Canada's Justice Laws website: http://laws-lois.justice.gc.ca/eng/acts/A-13.4/

Black, P. \& Eshchenko, A. (2014, February 14). Russia enacts anti-gay adoption ban. CNN. Retrieved from http://www.cnn.com/WORLD/

Blackwell, T. (2013, December 15). Canadian fertility consultant received $\$ 31 \mathrm{~K}$ for unwittingly referring parents to U.S. 'baby-selling' ring. National Post. Retrieved from http://www.nationalpost.com/index.html

Boseley, S. (2014, October 3). Egg-freezing should be available to all UK women, experts urge. The Guardian. Retrieved from http://www.theguardian.com/uk

Browne, R. (2014, August 7). Australian parents turn to Mexico as Thailand tightens surrogacy laws. The Sydney Morning Herald. Retrieved from http://www.smh.com.au/

Buying eggs [Video file]. (2012, April 23). CBC News. Retrieved from http://www.cbc.ca/player/News/Technology\%20and\%20Science/ID/2225876221/

Callon, M. (1986). Some elements of a sociology of translation: Domestication of the scallops and the fishermen of St. Brieuc Bay. The Sociological Review Monograph, 32, 196-233.

Canadian women flout laws to donate eggs. (2012, March 27). CTV News. Retrieved from http://www.ctvnews.ca/

Canadians pay egg donors on the grey market. (2014, March 26). CBC News. Retrieved from http://www.cbc.ca/news 
Clarke, A. E. (2008). Introduction: Gender and reproductive technologies in East Asia. East Asian Science, Technology and Society: An International Journal, 2(3), 303326. doi:10.1007/s 12280-008-9063-4

Clarke, A., Shim, J., Mamo, L., Fosket, J., \& Fishman, J. (2003). Biomedicalization: Technoscientific transformations of health, illness, and US biomedicine. American Sociological Review, 68(2), 161-194. Retrieved from http://web.b.ebscohost.com.proxy.library.carleton.ca/ehost/pdfviewer/pdfviewer?s $\mathrm{id}=\mathrm{fd} 737060-2 \mathrm{~b} 7 \mathrm{a}-4 \mathrm{c} 7 \mathrm{~b}-8 \mathrm{c} 01-\mathrm{ef} 27 \mathrm{ff} 40 \mathrm{e} 5 \mathrm{e} 0 \% 40$ sessionmgr115\&vid=1\&hid=101

Cohen, L. (2005). Operability, bioavailability and exception. In A. Ong \& S. J. Collier (Eds.), Global Assemblages: Technology, Politics and Ethics as Anthropological Problems (pp. 79-90). Malden, MA: Blackwell Publishing.

Conrad, P. (2005). The shifting engines of medicalization. Journal of Health and Social Behavior, 46(1), 3-14. doi:10.1177/002214650504600102

Cooper, C., May, A., \& Christiansen, A. (2014, May 15). Desperate for a baby: scammed in global surrogacy's newest frontier. Aljazeera America. Retrieved from http://america.aljazeera.com/

Dhar, A. (2013, July 27). Surrogacy law will wait for experts to address critical issues. The Hindu. Retrieved from http://www.thehindu.com/

Dhawan, H. (2013, July 18). Unregulated surrogacy industry worth over \$2bn thrives without legal framework. The Hindu. Retrieved from http://www.thehindu.com/ Doksone, T. (2014, August 7). Thailand wants to ban commercial surrogacy in wake of controversial cases. CTV News. Retrieved from http://www.ctvnews.ca/

Fletcher, R. (2006). Reproductive consumption. Feminist Theory, 7(1), 27-47. 
doi: $10.1177 / 1464700106061453$

Flyvbjerg, B. (2001). Making social science matter: Why social inquiry fails and how it can succeed again (S. Sampson, Trans.). Cambridge, UK: Cambridge University Press.

Foucault, M. (1973). The birth of the clinic: An archaeology of medical perception. New York: Pantheon Books.

Foucault, M. (1980). Truth and power. In C. Gordon (Ed.), Power/Knowledge. Selected Interviews and other Writings 1972-1977 (pp. 109-133). Hemel Hempstead: Harvester Wheatsheaf.

Foucault, M.(2003). Society must be defended: Lectures at the collège de france, 197576. M. Bertani \& A. Fontana (Eds.). New York: Picador.

Franklin, S. (1997). Embodied progress: A cultural account of assisted conception. New York; London: Routledge.

Frozen human egg buyers may face prosecution. (2012, April 23). CBC News. Retrieved from http://www.cbc.ca/news

Gerlach, N. (2004). The genetic imaginary: DNA in the Canadian criminal justice system. Toronto, Ont: University of Toronto Press.

Gerlach, N., Hamilton, S.N., Sullivan, R. \& Walton, P.L. (2011) Becoming biosubjects: Bodies, systems, technologies. Toronto: University of Toronto Press.

Ginsburg, F., \& Rapp, R. (1991). The politics of reproduction. Annual Review of Anthropology, 20(1), 311-343. doi:10.1146/annurev.an.20.100191.001523

Global In Vitro Fertilization Market to Reach \$21.6 Billion by 2010 - Allied Market Research. (2014, January 29). Retrieved November 4, 2014, from 
http://www.alliedmarketresearch.com/in-vitro-fertilization-market

Govt proposes to bring Bill to regulate surrogacy: Azad. (2013, March 19). The Hindu. Retrieved from http://www.thehindu.com/

Gupta, J. A. (2006). Towards transnational feminisms : Some reflections and concerns in relation to the globalization of reproductive technologies. European Journal of Women's Studies, 13(1), 23-38. doi:10.1177/1350506806060004

Hardt, M., \& Negri, A. (2000). Empire. Cambridge, Mass: Harvard University Press. Hawley, S. (2014a, September 17). Baby Gammy story takes startling turn as extreme options revealed. $A B C$ News. Retrieved from http://www.abc.net.au/news/

Hawley. S. (2014b, September 10). Japanese man fathers $16^{\text {th }}$ baby via surrogate in Thailand. $A B C$ News. Retrieved from http://www.abc.net.au/news/

Hawthorne, S. (2008). Somatic piracy and biophallacies: Separation, violence and biotech fundamentalism. Women's Studies International Forum, 31(4), 308-318. doi: 10.1016/j.wsif.2008.05.007

Health Canada (2013a). Prohibitions related to Purchasing Reproductive Material and Purchasing or Selling In Vitro Embryos. Retrieved November 30, 2014, from http://www.hc-sc.gc.ca/dhp-mps/brgtherap/legislation/reprod/purchasing-achateng.php

Health Canada (2013b). Prohibitions related to Surrogacy. Retrieved November 30, 2014, from http://www.hc-sc.gc.ca/dhp-mps/brgtherap/legislation/reprod/surrogacysubstitution-eng.php 
Health Canada (2014). Assisted Human Reproduction. Retrieved November 30, 2014, from http://www.hc-sc.gc.ca/dhp-mps/brgtherap/legislation/reprod/index-eng.php Indian Council of Medical Research. (n.d.) About us. Retrieved December 4, 2014, from http://icmr.nic.in/About_Us/About_ICMR.html

Indian women carrying babies for well-off buyers. (2007, December 31). CBC News. Retrieved from http://www.cbc.ca/news

Inhorn, M. C. (2010). Assisted' Motherhood in Global Dubai: Reproductive Tourists and Their Helpers. In W. Chavkin \& J. M. Maher (Eds.), The Globalization of Motherhood: Deconstructions and Reconstructions of Biology and Care (pp.180202). New York: Routledge.

Inhorn, M. C. (2011). Diasporic dreaming: Return reproductive tourism to the middle east. Reproductive BioMedicine Online, 23(5), 582-591. doi:10.1016/j.rbmo.2011.08.006

Inhorn, M. C., \& Birenbaum-Carmeli, D. (2008). Assisted reproductive technologies and culture change. Annual Review of Anthropology, 37, 177-196. doi:

10.1146/annurev.anthro.37.081407.085230

Inhorn, M. C., \& Gürtin, Z. B. (2011). Cross-border reproductive care: A future research agenda. Reproductive BioMedicine Online, 23(5), 665-676.

doi:10.1016/j.rbmo.2011.08.002

Inhorn, M. C., \& Patrizio, P. (2009). Rethinking reproductive "tourism" as reproductive “exile”. Fertility and Sterility, 92(3), 904-906.

doi:10.1016/j.fertnstert.2009.01.055 
Ivankiva, M. (2012, September 26). Russian surrogate moms attract foreigners. The Moscow Times. Retrieved from http://www.themoscowtimes.com/

Jones, M., \& Salter, B. (2010). Proceeding carefully: Assisted human reproduction policy in Canada. Public Understanding of Science (Bristol, England), 19(4), 420-434. doi: $10.1177 / 0963662509104722$

Kamath, V. (2014, April 28). No foreign babies for surrogate moms from six months. Bangalore Mirror. Retrieved from www.bangaloremirror.com

Kittsilpa, J. (2014, August 3). Thai surrogate says unaware twin had Downs until late in pregnancy. Reuters. Retrieved from http://www.reuters.com

Klein, R. (2008). From test-tube women to bodies without women. Women's Studies International Forum, 31(3), 157-175. doi: 10.1016/j.wsif.2008.04.006

Kroløkke, C. H. (2014). West is best: Affective assemblages and Spanish oöcytes. European Journal of Women's Studies, 21(1), 57-71. doi:10.1177/1350506813510422

Kroløkke, C., Foss, K. A., \& Pant, S. (2012). Fertility travel: The commodification of human reproduction. Cultural Politics, 8(2), 273-282.

Lahl, J. (2014, May 7). Paid for her silence: the exploitation of Kylee Gilman. The Center for Bioethics and Culture Network. Retrieved November 4, 2014, from http://www.cbc-network.org/2014/05/paid-for-her-silence-the-exploitation-ofkylee-gilman/?utm_source=CBC\%20Newsletter\&utm_campaign=4d5af634c42014_05_07_Paid_4Silence\&utm_medium=email\&utm_term =0_56f2fc828e4d5af634c4-78827989\&mc_cid=4d5af634c4\&mc_eid=b15be 
Lammey, M. (2014, February 5). Draft bill proposes ban on surrogate children for single men. The Moscow Times. Retrieved from http:/www.themoscowtimes.com/

Law needed to regulate surrogacy, says panel report. (2014, July 12). The Hindu.

Retrieved from http://www.thehindu.com/

Lisitsyn, P. (2013, October 6). Orthodox church slams surrogacy as 'mutiny against

God', seeks legal ban. Russia Today. Retrieved from http://rt.com/

Maede, A. (2014, August 10). Gammy: Australian parents wanted a refund and would have aborted him. The Guardian. Retrieved from http://www.theguardian.com/uk

Magnusson, J. (2005). Information and communications technology: Plugging Ontario higher education into the knowledge society. Encounters on Education, 6(6), 119135. Retrieved from http://search.proquest.com.proxy.library .carleton.ca/docview/1367979556?pq-origsite=summon

Menning, B. (1981). In Defense of In Vitro Fertilization. In H.B. Holmes, B.B. Hoskins \& M. Gross (Eds.), The Custom-Made Child? Women-Centered Perspectives. (pp. 263-267). Clifton, NJ: Humana Press.

Mom Service Surrogate \& Donation. (n.d.). Why Russia? Retrieved November 30, 2014, from http://www.surrogate-donation.com/why_russia.shtml

Moss, K. (1988). New reproductive technologies: Concerns of feminists and researchers. Affilia, 3(4), 38-50. doi: 10.1177/088610998800300404

Motluk, A. (2013, March 28). 'I thought I just had to sleep it off': Egg donor sues Toronto fertility doctor after suffering stroke. National Post. Retrieved from http://www.nationalpost.com/index.html

Mukherjee, M., \& Nadimipally, S. B. (2006). Assisted reproductive technologies in India. Development, 49(4), 128-134. doi:10.1057/palgrave.development.1100303 
Murdoch, L. (2014, August 13). Alleged trafficker fathered 15 babies through 11 surrogate mothers in Thailand. The Sydney Morning Herald. Retrieved from http://www.smh.com.au/

Nath, T. (2013, July 16). Surrogate children in India deprived of mother's milk. The Hindu. Retrieved from http://www.thehindu.com/

Nelson, E. (2013). Global trade and assisted reproductive technologies: Regulatory challenges in international surrogacy. The Journal of Law, Medicine \& Ethics, 41(1), 240-253. doi:10.1111/jlme.12016

Neuman, W. L. (2011). Social research methods: Qualitative and quantitative approaches. Boston: Allyn \& Bacon.

New Life Georgia (2008a). New Life Georgia Sex Selection. Retrieved November 30, 201 from_http://www.newlifegeorgia.com/new-life-georgia-sex-selection.html

New Life Georgia (2008b). Egg Donation. Retrieved November 30, 2014, from http://www.newlifegeorgia.com/new-life-georgia-egg-donation.html

New Life Georgia (2008c). Contact New Life Georgia. Retrieved November 30, 2014, from http://www.newlifegeorgia.com/guranteed-ivf.html

New Life Georgia (2008d). New Life Georgia FAQ. Retrieved November 30, 2014, from http://www.newlifegeorgia.com/faq.html

New Life Global Network (n.d.). New Life Georgia. Retrieved November 30, 2014, from http://newlifeglobalnetwork.com/new-life-georgia/

New Life Global Network. (n.d.). The Thailand Fracas. Retrieved November 30, 2014, from http://newlifeglobalnetwork.com/thailand-fracas/ 
New Life India. (2007a). Legislation. Retrieved November 30, 2014, from http://www.newlifeindia.com/Legislation

New Life India. (2007b). Advantages. Retrieved November 30, 2014, from http://www.newlifeindia.com/Advantages

New Life India (2007c) Egg Donation. Retrieved November 30, 2014, from http://www.newlifeindia.com/Egg_Donation

New Life India. (2007d). Blog. Retrieved November 30, 2014, from http://www.newlifeindia.com/Blog/post/39/Miracle\%20in\%20Australian\%20Fam ily/\#p536_items-container

New Life India. (2008e). Guaranteed Program._Retrieved November 30, 2014, from http://www.newlifeindia.com/Guaranteed_Program

New Life Mexico. (2013). Legislation. Retrieved November 30, 2014, from http://www .newlifemexico.net/Legislation

New Life South Africa. (2012a). Step by Step Guide._Retrieved November 30, 2014, from http://www.newlifesouthafrica.com/Step_By_Step_Guide

New Life South Africa. (2012b). Legislation. Retrieved November 30, 2014, from http://www .newlifesouthafrica.com/Legislation

New Life South Africa. (2012c). Become Egg Donor. Retrieved November 30, 2014, from http://www.newlifesouthafrica.com/Become_Egg_Donor

New Life South Africa. (2012d). About us. Retrieved November 30, 2014, from http://www.newlifesouthafrica.com/About_us

New Life Ukraine (2007). Advantages. Retrieved November 30, 2014, from http://www.newlifeukraine.com/advantages 
Not enough safeguards for surrogate mother, child, says study. (2013, July 17). The Hindu. Retrieved from http://www.thehindu.com/

Olivennes, F. (2000). Avoiding multiple pregnancies in ART. Double trouble: Yes a twin pregnancy is an adverse outcome. Human Reproduction (Oxford, England), 15(8), 1663-1665. doi:10.1093/humrep/15.8.1663

Pal, D. (2013, June 8). Israeli sex offender adopts girl: Why India needs to regulate surrogacy better. Firstpost. Retrieved from www.firstpost.com

Pearlman, J. (2014, August 1). Australian couple abandon surrogate twin with Down's syndrome - but keep his sister. The Telegraph. Retrieved from http://www.telegraph.co.uk/

Pearlman, J. \& Forgan, D. (2014, August 5). Dad of abandoned Gammy 'had child sex conviction'. Independent.ie. Retrieved form http://www.independent.ie/

Perappadan, B.S. (2014, August 25). Clamour grows for stringent regulation of surrogacy. The Hindu. Retrieved from http://www.thehindu.com/

Peterson, M. M. (2005). Assisted reproductive technologies and equity of access issues. Journal of Medical Ethics, 31(5), 280-285. doi:10.1136/jme.2003.007542

Prevent exploitation of surrogate mothers, says Health Ministry. (2013, October 24). The Hindu. Retrieved from http://www.thehindu.com/

Prior, L. (2008). Repositioning documents in social research. Sociology, 42(5), 821-836. doi: $10.1177 / 0038038508094564$

Prior, L., Hughes, D., \& Peckham, S. (2012). The discursive turn in policy analysis and the validation of policy stories. Journal of Social Policy, 41(2), 271-289. doi:10.1017/S0047279411000821 
Probe into alleged visa norms violation by three surrogacy clinics in Mumbai. (2014, April 29). The Hindu. Retrieved from http://www.thehindu.com/

Purdy, L. M. (1996). Reproducing persons: Issues in feminist bioethics. Ithaca, NY: Cornell University Press.

Putin sends 2 intl children's rights bills to Duma for ratification. (2013, April 13). Russia Today. Retrieved from www.rt.com

Rabinow, P. (1996). Artificiality and enlightenment: From sociobiology to biosociality. In Essays on the Anthropology of Reason (pp. 91-111). Princeton: Princeton University Press.

Rabinow, P., \& Rose, N. (2006). Biopower today. Biosocieties, 1(2), 195-217. doi: $10.1017 / \mathrm{S} 1745855206040014$

Ramachandran, S.K. (2014, October 4). Move to deny foreign nationals access to surrogacy draws flak. The Hindu. Retrieved from http://www.thehindu.com/

Raymond, J. G. (1993). Women as wombs: Reproductive technologies and the battle over women's freedom. New York : HarperSanFrancisco.

Rose, N. S. (2007). The politics of life itself: Biomedicine, power, and subjectivity in the twenty-first century. Princeton: Princeton University Press.

Royal Commission on New Reproductive Technologies. (1993). Proceed with Care:

Final Report of the Royal Commission on New Reproductive Technologies.

Retrieved from the Library and Archives Canada website: http://epe.lac-bac.gc.ca/100/200/301/pco-bcp/commissions-ef/baird1993eng/baird1993-eng.htm 
Russian region completely bans foreign adoptions. (2013, September 25). Russia Today. Retrieved from www.rt.com

Sarojini, N., Marwah, V., \& Shenoi, A. (2011). Globalisation of birth markets: A case study of assisted reproductive technologies in India. Globalization and Health, 7(1), 27-27. doi:10.1186/1744-8603-7-27

Scheper-Hughes, (2002). Commodity fetishism in organs trafficking. In N. ScheperHughes \& L. Wacquant (Eds.), Commodifying bodies (pp. 31-62). Thousand Oaks, Calif; London: Sage Publications.

Scheper-Hughes, N. (2003). Rotten trade: Millennial capitalism, human values and global justice in organs trafficking. Journal of Human Rights, 2(2), 197-206. doi: $10.1080 / 1475483032000078189$

Schieve, L., Rasmussen, S., Buck, G., Schendel, D., Reynolds, M., \& Wright, V. (2004). Are children born after assisted reproductive technology at increased risk for adverse health outcomes? Obstetrics and Gynecology, 103(6), 1154-1163. doi:10.1097/01.AOG.0000124571.04890.67

Schindler, A. (2013, July 22). Not over easy: The human cost of unregulated international egg donation. First Coast News. Retrieved from http://www.firstcoastnews.com/

Sills, E. S., \& Palermo, G. D. (2002). Preimplantation genetic diagnosis for elective sex selection, the IVF market economy, and the child--another long day's journey into night? Journal of Assisted Reproduction and Genetics, 19(9), 433-437. doi:10.1023/A:1016819908612

Steinberg, D. (1997). A most selective practice - the eugenic logics of IVF. Womens Studies International Forum, 20(1), 33-48. doi:10.1016/S0277-5395(96)00067-2 
Stoop, D., Cobo, A., \& Silber, S. (2014). Fertility preservation for age-related fertility decline. Lancet, 384(9950), 1311-1319. doi:10.1016/S0140-6736(14)61261-7

Storrow, R. F. (2011). Assisted reproduction on treacherous terrain: The legal hazards of cross-border reproductive travel. Reproductive BioMedicine Online, 23(5), 538545. doi:10.1016/j.rbmo.2011.07.008

Strange, H., \& Chadwick, R. (2010). The ethics of nonmedical sex selection. Health Care Analysis, 18(3), 252-266. doi:10.1007/s10728-009-0135-y

Sullivan, R. (2005). An embryonic nation: Life against health in Canadian biotechnological discourse. Communication Theory, 15(1), 39-58. doi:10.1093/ct/15.1.39

Surrogacy in Russia and Abroad. (n.d.). Retrieved November 30, 2014, from http://surrogacy.ru/eng/

Surrogacy issue: Australian same-sex couple allowed to leave Thailand with newborn twins. (2014, August 16). ABC News. Retrieved from http://www.abc.net.au/news/

Svitnev, K. (2011, July). P-068 Legal regulation of medically assisted reproduction treatment in the C.I.S. (former USSR) countries and cross-border reproductive care. Human Reproduction, 26(1): i149. doi.10.1093/humrep/26.s.176

Tétrault-Farber, G. (2014, April 24). Russian lawmaker proposes ban on commercial surrogate motherhood. The Moscow Times. Retrieved from http://www.themoscowtimes.com/ 
Thai police raid surrogacy business [Video file]. (2014, August 6). Retrieved from http://media.smh.com.au/news/world-news/thai-police-raid-surrogacy-business5656891.html

Thailand military seizes power in coup. (2014, May). BBC News. Retrieved from http://www.bbc.com/news/

Thailand urged to legislate commercial surrogacy controls. (2014, August 20). MCOT. Retrieved from http://www.mcot.net/home/index

Thailand's parliament approves bill banning commercial surrogacy. (2014, November 28). The Guardian. Retrieved from http://www.theguardian.com/uk

The Assisted Reproductive Technologies (Regulation) Bill (2010). Retrieved from the Indian Council of Medical Research website: http://icmr.nic.in/guide/ART\%20REGULATION\%20Draft\%20Bill1.pdf

The Royal Commission on New Reproductive Technologies reports [Video file]. (1993, November 30). Retrieved form http://www.cbc.ca/archives/categories/health/reproductive-issues/fightinginfertility/the-royal-commission-reports.html

Thongnoi, J., \& Halpin, D. (2014, August 17). Japanese mystery father: who is he? Bangkok Post. Retrieved from http://www.bangkokpost.com/

Turner, L. (2007). 'First world health care at third world prices': Globalization, bioethics and medical tourism. BioSocieties, 2(3), 303-325.

doi:10.1017/S1745855207005765 
Urman, B., \& Yakin, K. (2010). New Turkish legislation on assisted reproductive techniques and centres: A step in the right direction? Reproductive BioMedicine Online, 21(6), 729-731. doi:10.1016/j.rbmo.2010.06.030

Weinbaum, A. E. (2004). Wayward reproductions: Genealogies of race and nation in transatlantic modern thought. Durham: Duke University Press. doi: $10.1215 / 9780822385820$

Whittaker, A. \& Speier, A. (2010). 'Cycling Overseas': Care, Commodification, and Stratification in Cross-Border Reproductive Travel. Medical Anthropology, 29(4): 363-383. doi: 10.1080/01459740.2010.501313

Williams, H. (2013, April 11). Are Indian surrogacy program exploiting impoverished women? CBS News. Retrieved from http://www .cbsnews.com/evening-news/

Womb transplant results in birth, a world first, doctor says. (2014, October 3). $C B C$ News. Retrieved from http://www.cbc.ca/news

World Health Organization. (2002). Current practices and controversies in assisted reproduction. E. Vayena, P.J. Rowe \& P.D. Griffin (Eds.). Geneva, Switzerland. Retrieved from http://www.who.int/reproductivehealth/publications/infertility/9241590300/en/

Yaxley, L. (2014, October). International surrogacy is 'new frontline in human trafficking', says judge John Pascoe; Indian case sparks renewed calls for inquiry. ABC News. Retrieved from http://www.abc.net.au/news/

Zarembo, I. (2014, April 24). Draft Russian law restricts surrogacy for single people. Russia Today. Retrieved from http://rt.com/ 
Zegers-Hochschild, F., Adamson, G. D., de Mouzon, J., Ishihara, O., Mansour, R., Nygren, K., . . . International Committee for Monitoring Assisted Reproductive Technology. (2009). The international committee for monitoring assisted reproductive technology (ICMART) and the world health organization (WHO) revised glossary on ART terminology, 2009. Human Reproduction (Oxford, England), 24(11), 2683-2687. doi:10.1093/humrep/dep343

Zola, I.K. (1972). Medicine as an institution of social control. The Sociological Review, 20(4):487-504. doi: 10.1111/j.1467-954X.1972.tb00220.x 